US Army Corps of Engineers ${ }_{\circledast}$ Engineer Research and Development Center

\title{
Constituent Materials Characterization for Virtual Concrete Microstructure Generation
}

Jameson D. Shannon, Cody M. Strack, and Robert D. Moser

May 2019

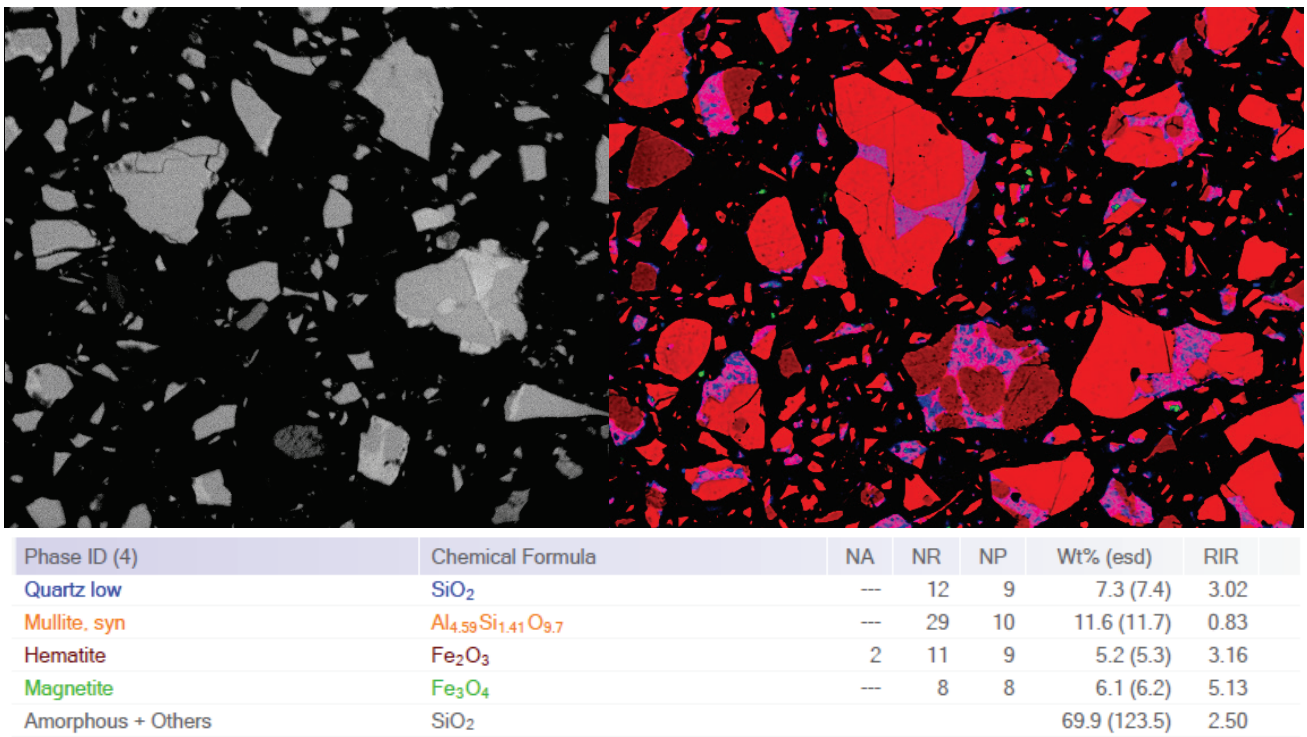

XRF(Wt\%): Fe2O3=11.5\%, SiO2=80.2\%, Al $2 \mathrm{O}=8.5 \%$

Refinement Halted (R/E=1.33), Round=3, Iter=6, $P=37, R=3.76 \%$ ( $E=2.82 \%$, $E P S=0.5)$

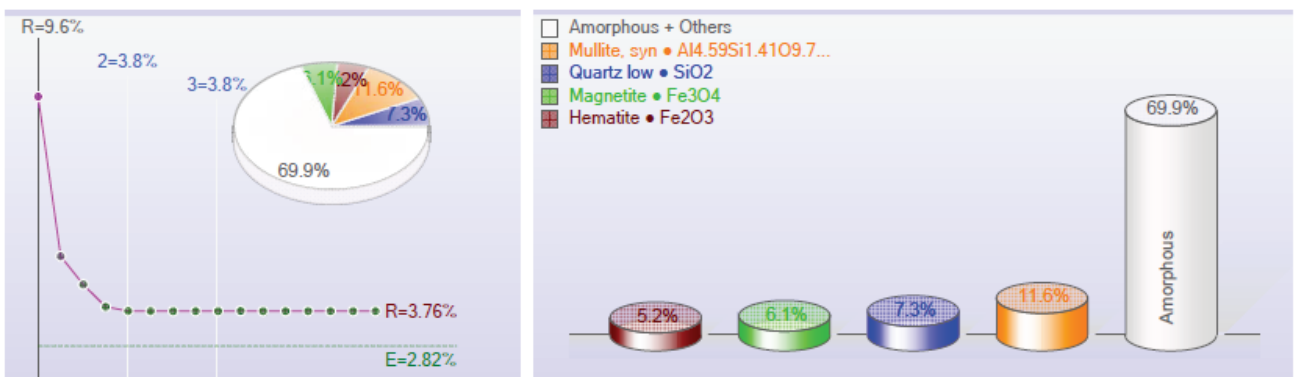


The U.S. Army Engineer Research and Development Center (ERDC) solves the nation's toughest engineering and environmental challenges. ERDC develops innovative solutions in civil and military engineering, geospatial sciences, water resources, and environmental sciences for the Army, the Department of Defense, civilian agencies, and our nation's public good. Find out more at www.erdc.usace.army.mil.

To search for other technical reports published by ERDC, visit the ERDC online library at http://acwc.sdp.sirsi.net/client/default. 


\section{Constituent Materials Characterization for Virtual Concrete Microstructure Generation}

Jameson "Jay" Shannon, Cody M. Strack, and Robert D. Moser

Geotechnical and Structures Laboratory

U.S. Army Engineer Research and Development Center

3909 Halls Ferry Road

Vicksburg, MS 39180-6199

Final report

Approved for public release; distribution is unlimited.

Prepared for U.S. Army Engineer Research and Development Center Under 6.2 Materials Modeling for Force Protection - Work Unit 2 


\section{Abstract}

This effort was undertaken as a part of the Materials Modeling for Force Protection (MMFP) Military Engineering 6.2 applied research program. One of the main philosophies of MMFP is the creation of a materials-bydesign process for predictive properties and material selection capabilities. This report details the capability improvements to facilitate materials-bydesign technologies and the collection and characterization of material data to compile and calibrate an integrated materials-by-design model. The Virtual Cement and Concrete Testing Laboratory (VCCTL) was evaluated for suitability in hydration model generation, and various programs were evaluated for initial virtualization of physical elements. To provide model inputs for particle size analysis, X-ray diffraction (XRD), X-ray fluorescence (XRF), scanning electron microscopy (SEM), and energy-dispersive spectroscopy (EDS) testing were conducted on a wide variety of constituent materials, and characterization data were processed included herein. 


\section{Contents}

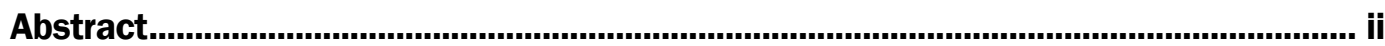

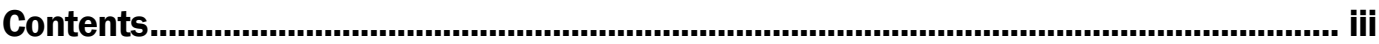

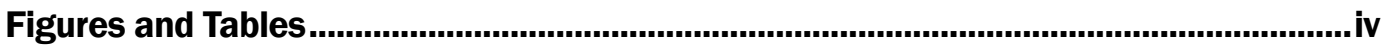

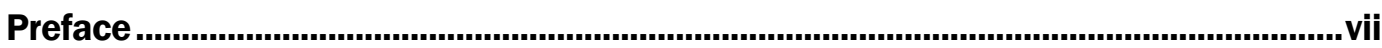

Unit Conversion Factors.........................................................................................viii

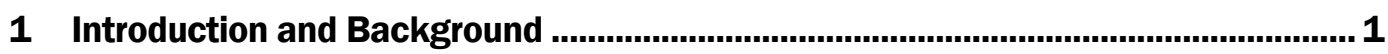

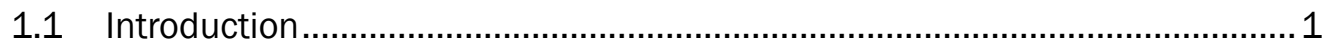

1.2 Materials Modeling for Force Protection (MMFP) Background ......................

1.3 CEMHYD3D and VCCTL background .......................................................

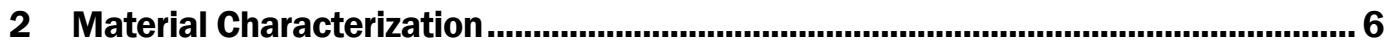

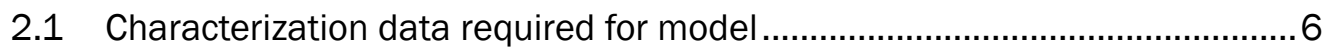

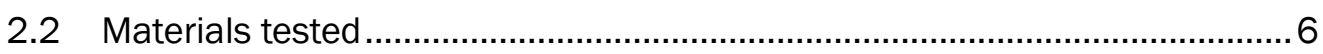

2.3 Advances in characterization capabilities................................................. 7

2.3.1 Scanning electron microscopy and energy dispersive $x$-ray spectroscopy.............. 7

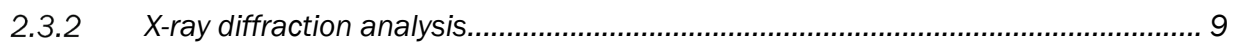

2.3.3 Particle size analysis............................................................................... 9

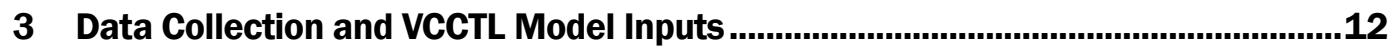

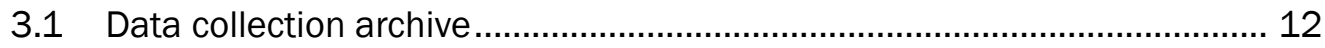

3.2 Image processing and phase identification ................................................ 14

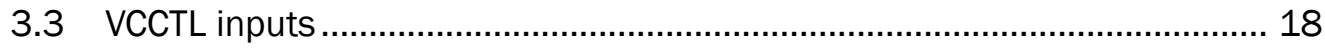

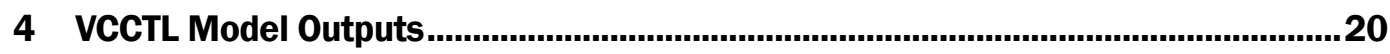

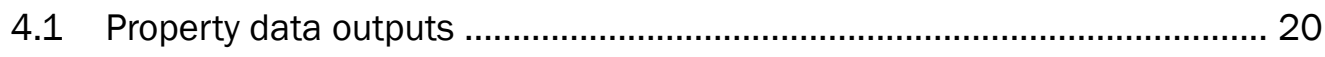

4.2 Data outputs for next level models.......................................................... 26

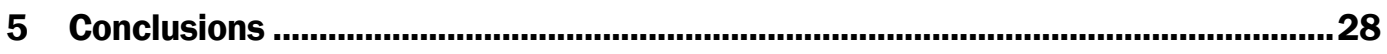

Contact Information ...........................................................................................................29

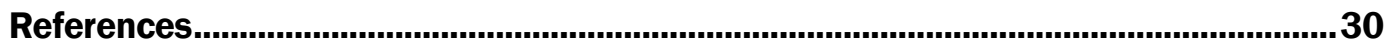

Appendix A: Particle-Size Distribution Results ............................................................. 31

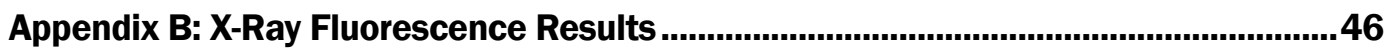

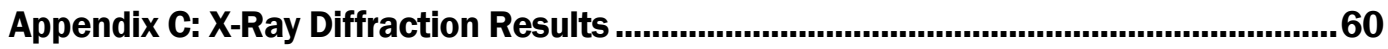




\section{Figures and Tables}

\section{Figures}

Figure 1. Imported 2D image with "false color" (5).......................................................... 4

Figure 2. 3D virtualized microstructure created from 2D image (5)................................. 5

Figure 3. Experimental vs model moduli results (5)...................................................... 6

Figure 4. Mastersizer 3000 with dry powder analyzer. ..................................................... 12

Figure 5. Mastersizer 3000 with dispersed liquid analyzer.............................................. 12

Figure 6. Small volume analyzer module...................................................................... 13

Figure 7. Laser diffraction particle size distribution of silica fume 1500149. .................... 14

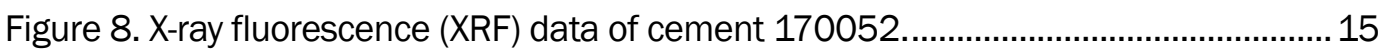

Figure 9. X-ray diffraction (XRD) data of fly ash 100015 ................................................ 15

Figure 10. Scanning electron microscopy (SEM) data of cement 170065........................ 16

Figure 11. Suite of SEM and EDX images using the same location and parameters as Figure 10. ................................................................................ 18

Figure 12. Combined Multispec image of multiple layers of cement 17705 without (a) and with (b) fields labeled.

Figure 13. Calculated false color image with values based on image and labels

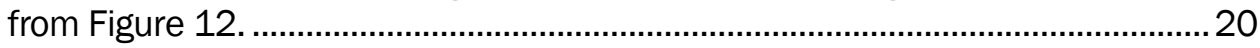

Figure 14. Unhydrated microstructure image of a cement paste for mixture 140-

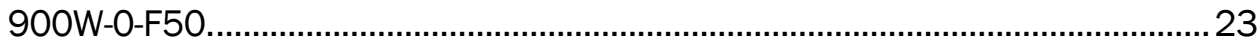

Figure 15. Legend for VCCTL microstructure image phases..............................................23

Figure 16. Hydrated microstructure image of a cement paste for mixture 140900W-0-F50.

Figure 17. Degree of hydration over the first 20 hours for mixture 140-900W-0F50. 25

Figure 18. Porosity over the first 20 hours for mixture 140-900W-0-F50.......................... 26

Figure 19. Gel-space ratio over the first 20 hours for mixture 140-900W-0-F50.............. 26

Figure 20. Heat release over the first 20 hours for mixture 140-900W-0-F50. ................. 27

Figure 21. VCCTL calculated moduli results for mixture 140-900W-0-F50.......................28

Figure 22. Virtual microstructure of aggregate for mixture 140-900W-0-F50................... 28

Figure A1. PSD results of cement (150146)...................................................................... 33

Figure A2. PSD results of cement (150147)..................................................................... 33

Figure A3. PSD results of cement (150148),..................................................................... 34

Figure A4. PSD results of cement (160160)................................................................... 34

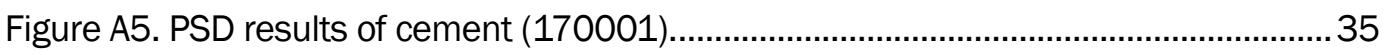

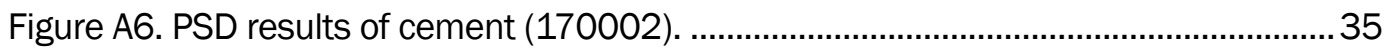

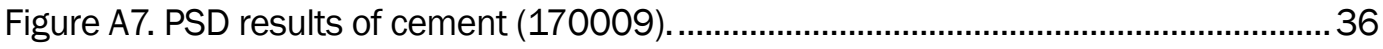

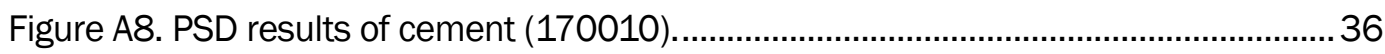

Figure A9. PSD results of cement (170052). .................................................................... 37 


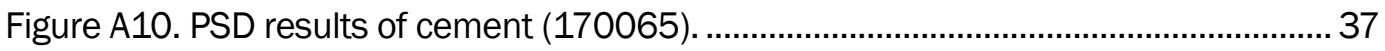

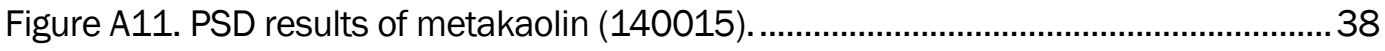

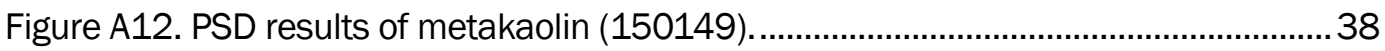

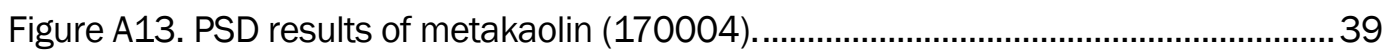

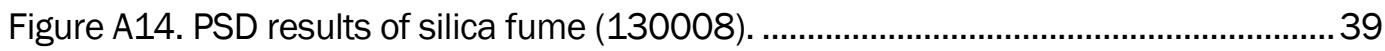

Figure A15. PSD results of silica fume (140092) ........................................................... 40

Figure A16. PSD results of silica fume (130050). ........................................................... 40

Figure A17. PSD results of silica fume (140093)............................................................. 41

Figure A18. PSD results of silica fume (140094). .......................................................... 41

Figure A19. PSD results of silica fume (150048). ............................................................ 42

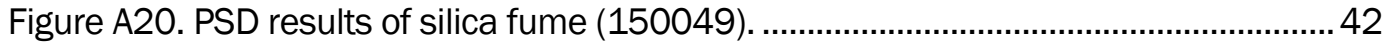

Figure A21. PSD results of silica fume (150050). ....................................................... 43

Figure A22. PSD results of silica fume (150051). ............................................................ 43

Figure A23. PSD results of silica fume (150052) ....................................................... 44

Figure A24. PSD results of silica fume (170003)............................................................ 44

Figure A25. PSD results of silica fume (Guam F10). ...................................................... 45

Figure A26. PSD results of silica fume (Ecotech85)........................................................ 45

Figure A27. PSD results of silica flour (Sil-co-sil).............................................................. 46

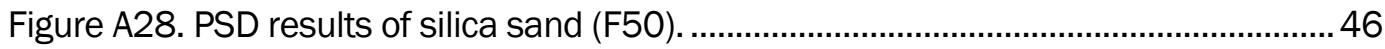

Figure A29. PSD results of slag (170080) .................................................................... 47

Figure B1. XRF results of cement (170052)................................................................... 48

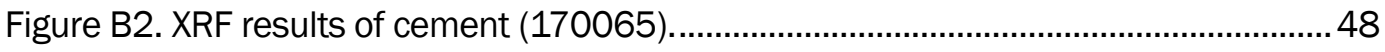

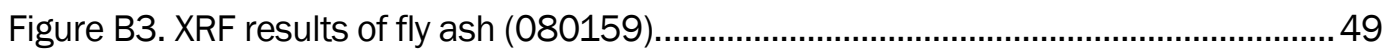

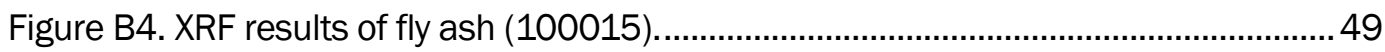

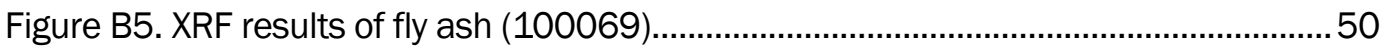

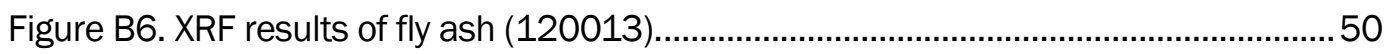

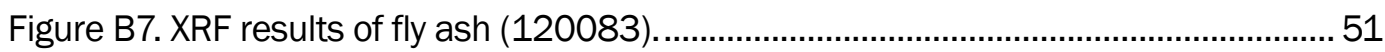

Figure B8. XRF results of fly ash (120104).................................................................. 51

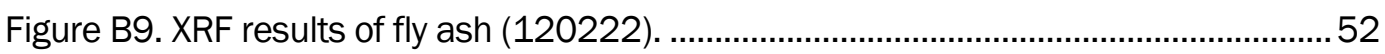

Figure B10. XRF results of fly ash (130032). ................................................................ 52

Figure B11. XRF results of fly ash (140022). ................................................................... 53

Figure B12. XRF results of fly ash (140054)................................................................ 53

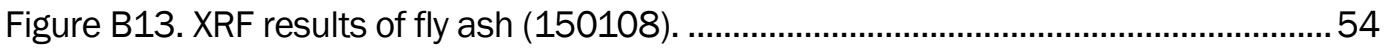

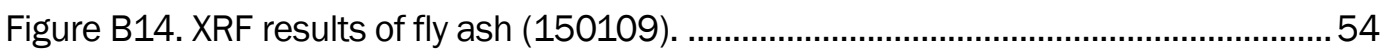

Figure B15. XRF results of silica fume (Guam F10)......................................................... 55

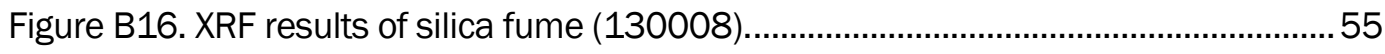

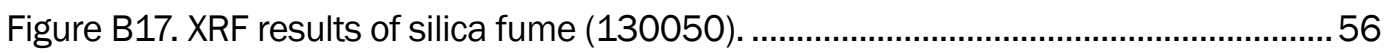

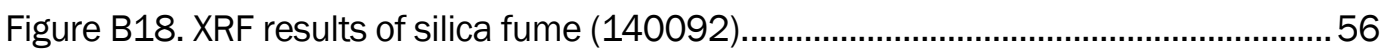

Figure B19. XRF results of silica fume (140093)........................................................... 57 
Figure B20. XRF results of silica fume (140094).......................................................... 57

Figure B21. XRF results of silica fume (150148)......................................................... 58

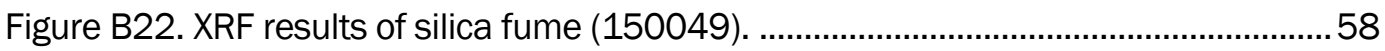

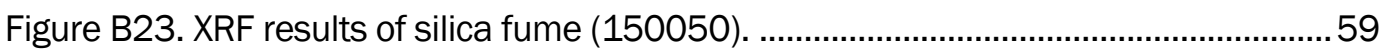

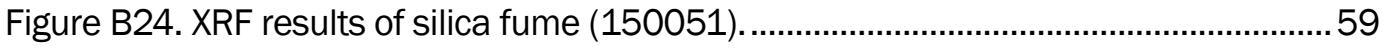

Figure B25. XRF results of silica fume (Ecotech85). ....................................................... 60

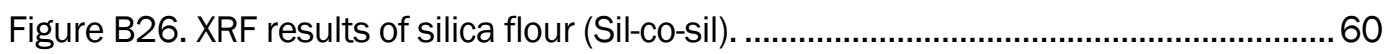

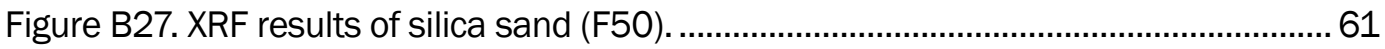

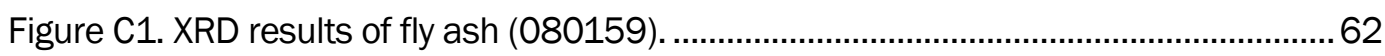

Figure C2. XRD results of fly ash (100015). .................................................................... 63

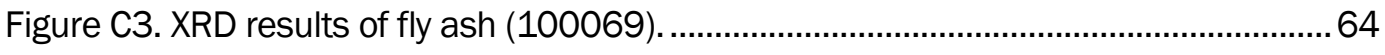

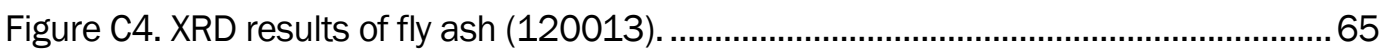

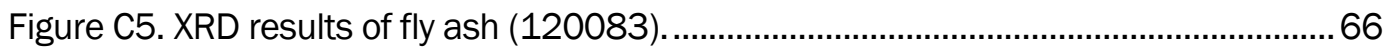

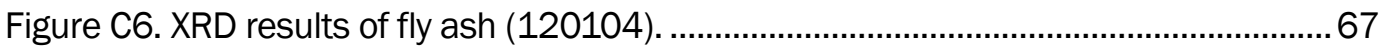

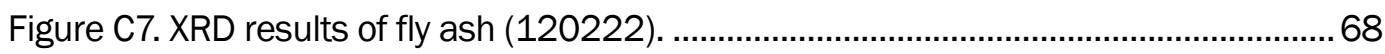

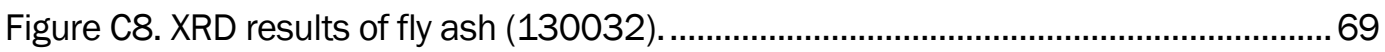

Figure C9. XRD results of fly ash (140022)................................................................... 70

Figure C10. XRD results of fly ash (140054)................................................................... 71

Figure C11. XRD results of fly ash (150108)................................................................ 72

Figure C12. XRD results of fly ash (150109).............................................................. 73

Figure C13. XRD results of fly ash (150110)................................................................ 74

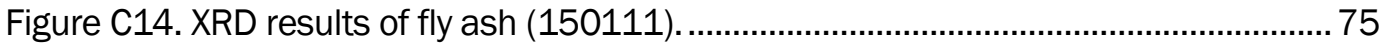

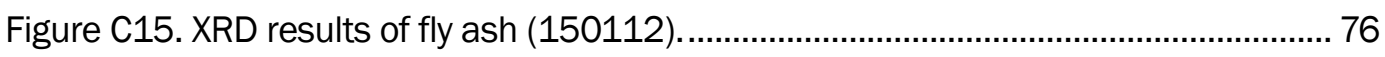

Figure C16. XRD results of fly ash (150113)................................................................... 77

\section{Tables}

Table 1. Material Selection and Status of Data Collection ................................................. 9 


\section{Preface}

This study was conducted for the U.S. Army Engineer Research and

Development Center, Geotechnical and Structures Laboratory (GSL). The technical monitor was Dr. Jameson D. Shannon.

The work was performed by the Concrete and Materials Branch (GMC) of the Engineering Systems and Materials Division (GM), U.S. Army Engineer Research and Development Center, Geotechnical and Structures Laboratory (ERDC-GSL). At the time of publication, Mr. Christopher M. Moore was Chief, CEERD-GMC; Mr. Jeffrey G. Averett was Acting Chief, CEERD-GM; and Ms. Pamela G. Kinnebrew, CEERD-GTZ, was the Technical Director for Military Engineering. The Deputy Director of ERDC-GSL was Mr. Charles W. Ertle II, and the Director was Mr. Bartley P. Durst.

COL Ivan P. Beckman was the Commander of ERDC, and Dr. David W. Pittman was the Director. 


\section{Unit Conversion Factors}

\begin{tabular}{|l|c|l|}
\hline Multiply & By & To Obtain \\
\hline cubic feet & 0.02831685 & cubic meters \\
\hline degrees Fahrenheit & $(\mathrm{F}-32) / 1.8$ & degrees Celsius \\
\hline feet & 0.3048 & meters \\
\hline inches & 0.0254 & meters \\
\hline square feet & 0.09290304 & square meters \\
\hline square inches & 6.4516 E-04 & square meters \\
\hline
\end{tabular}




\section{Introduction and Background}

\subsection{Introduction}

The Army has identified materials-by-design as a key area of research interest in recent years. Materials-by-design describes the complete process of the ability to transition between systems-level performance and analysis, and compositional material design seamlessly. This previously unattained computational capability would allow for virtual material design, fabrication, and optimization without the need for expensive and lengthy physical testing. The computational ability, once achieved, will allow for rapid analysis of system options based on available materials and for further optimization of material components. Using this system may also allow for new and advanced analysis of composites and additional performance increases of currently available products.

One of materials-by-design's key aspects is its integration of both topdown and bottom-up design considerations. However, the additional complications caused by this approach will require a large amount of build-up, and the original implementation will have to be studied and optimized to ensure the technique is viable to a wide range of materials. Overall, materials-by-design has great merit and if successful brings an immensely effective technique to Army engineering capabilities, but creation of a successful materials-by-design computational ability is ambitious and will require many years of research to fully implement.

\subsection{Materials Modeling for Force Protection (MMFP) Background}

This effort was undertaken as a part of the Materials Modeling for Force Protection (MMFP) Military Engineering 6.2 applied research program. Force protection solutions increasingly rely on the use of indigenous construction materials that are able to be obtained and produced intheater. There is no current capability to design and develop highperformance construction materials in a virtual environment. Presently, available raw materials from areas of interest must be imported to U.S. laboratories, and iterative experimentation must be undertaken to create and optimize materials for protective design. To improve efficiency and resiliency, a materials-by-design approach is needed. 
Materials-by-design determines material engineering properties needed to produce a specified structural response, and those material properties are then achieved through targeted formulation and synthesis processes. In the case of cementitious materials, the synthesis process is focused mainly on hydration of materials. Though multi-scale modeling approaches have been developed to predict weapons effects on structural elements, the capability to model the synthesis of the materials is missing. To date, material synthesis has been conducted solely by trial-and-error experimentation and characterization. Furthermore, advanced materials systems and structural elements are needed that provide improved protection with reduced logistics and cost.

A computational synthesis capability for advanced force protection materials does not currently exist. Though some material synthesis models are available, they do not account for the modern worldwide variety of constituent materials and the specialized curing conditions that are advantageous in advanced material formulations. Additionally, there is a current lack of multi-scale model coupling pathways to integrate synthesis, structure-property, and performance models. Because the needed model coupling does not exist, using a materials-by-design approach to develop protective components is not presently possible and represents a barrier to technical success. Finally, structural element optimization using indigenous materials cannot be performed virtually with current capabilities.

During the course of the MMFP research effort, a combination of computational model development and advanced experimentation using domestic and foreign raw materials will be performed to develop and validate an integrated materials-by-design capability. Synthesis models will be developed to predict material microstructures. Model coupling will be achieved by developing both analytical and computational approaches that predict material properties from the predicted microstructures, then predicted properties will feed performance models. Guided by simulations, new protective materials and structural elements will be fabricated, optimized, and validated experimentally.

Testing and validation of the materials-by-design capability will occur in two-ways: 1) structural element optimization based on selected sets of available raw materials (bottom-up), and 2) targeted material synthesis based on protective performance requirements (top-down). Integration with performance modeling efforts being conducted in other U.S. Army Engineer Research and Development Center (ERDC) programs will be 
facilitated through semi-annual technical workshops, led by this work package, with broad participation from material developers, testers, modelers, and users across the ERDC direct and reimbursable programs as well as outside partners.

The remainder of this report discusses the first steps of this process being undertaken at the ERDC Geotechnical and Structures Laboratory. This phase of the effort focuses on improving materials characterization capabilities and increasing the amount of available data. These characterization data are then to be used as inputs in a cementitious material hydration model. Advancements in model coding and usage are necessary to achieve the desired results in a meaningful format that could be used to further feed higher scale models. Additional background on the hydration model and coding is given in Section 1.3. Characterization procedures and model usage, featuring inputs and outputs, are described in Chapters 3,4 , and 5 .

\subsection{CEMHYD3D and VCCTL background}

CEMHYD3D is a package of programs designed by the National Institute of Science and Technology (NIST) to simulate cement hydration. The package functions by simulating a virtual cement in three dimensions and applying multiple hydration codes to form a virtual hydrated microstructure from which certain performance properties can be obtained. A two-dimensional image is first obtained experimentally and loaded into the program, from which a three-dimensional cube be can predicted. The virtual threedimensional cube is formulated to reliably predict particle size distribution and volumes, surface areas, and autocorrelation functions of cementitious phases. Technical details of the interworkings of the CEMHYD3D package of programs are discussed in previous publications by Bentz (1995, 1997a, 1997b) and Bentz et al. (1996).

The Virtual Cement and Concrete Testing Laboratory (VCCTL) was created to improve the usability of the CEMHYD3D by providing a Graphical User Interface (GUI) and expanded control, input, and output options. VCCTL functions in the same way as the CEMHYD3D code it was built upon, beginning first with a 2-D segmented image and building a 3-D virtual mixture. Figures 1 and 2 illustrate examples of the imported 2-D image and virtualized 3-D microstructure. Chemical phases are identified on a pixel-by-pixel basis in the imported image and are transitioned into 3 -D pixels (voxels) in the 3-D microstructure. 
Figure 1. Imported 2-D image with “false color" (from Garboczi et al. 2004).

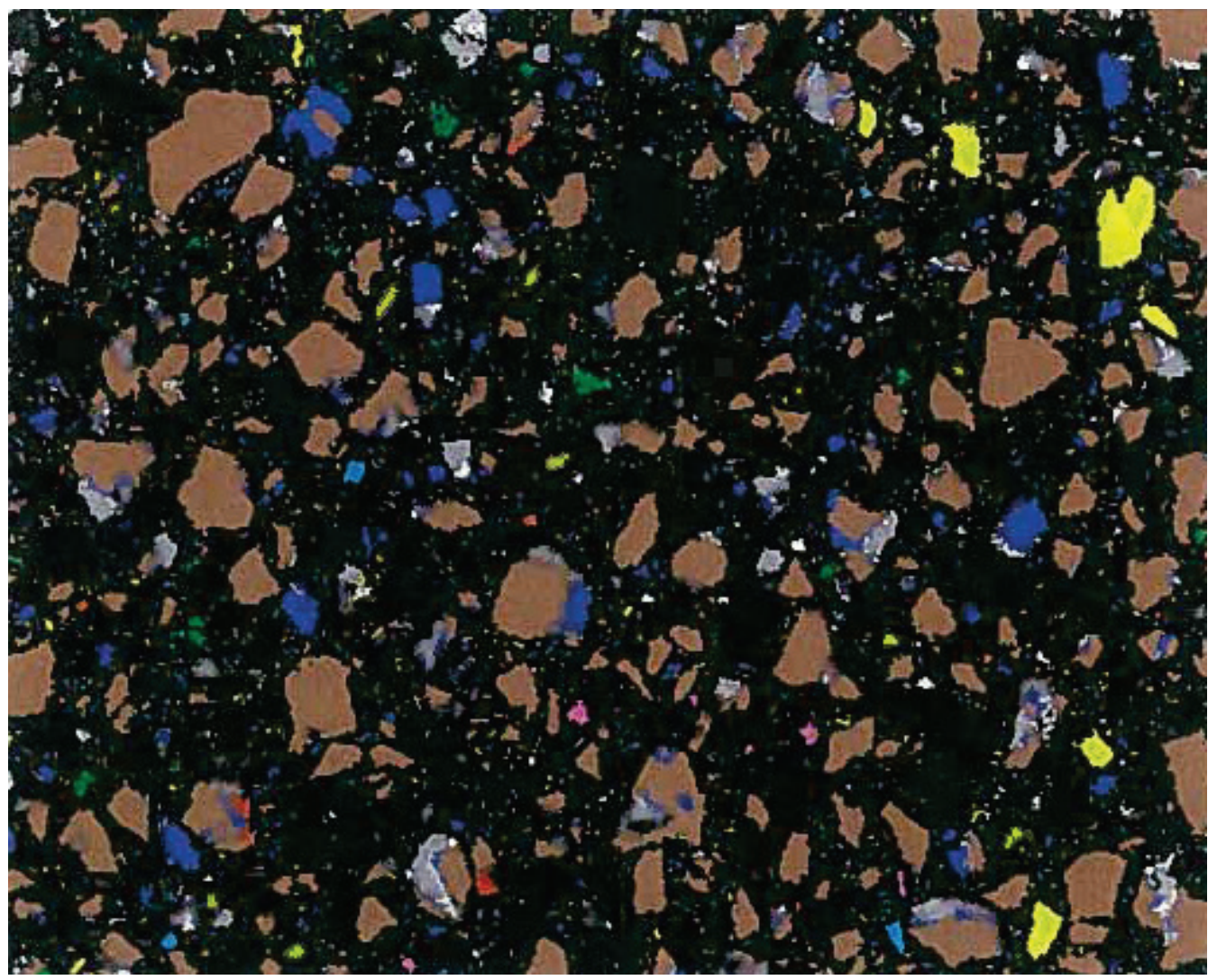

Figure 2. 3-D virtualized microstructure created from 2-D image (from Garboczi et al. 2004).

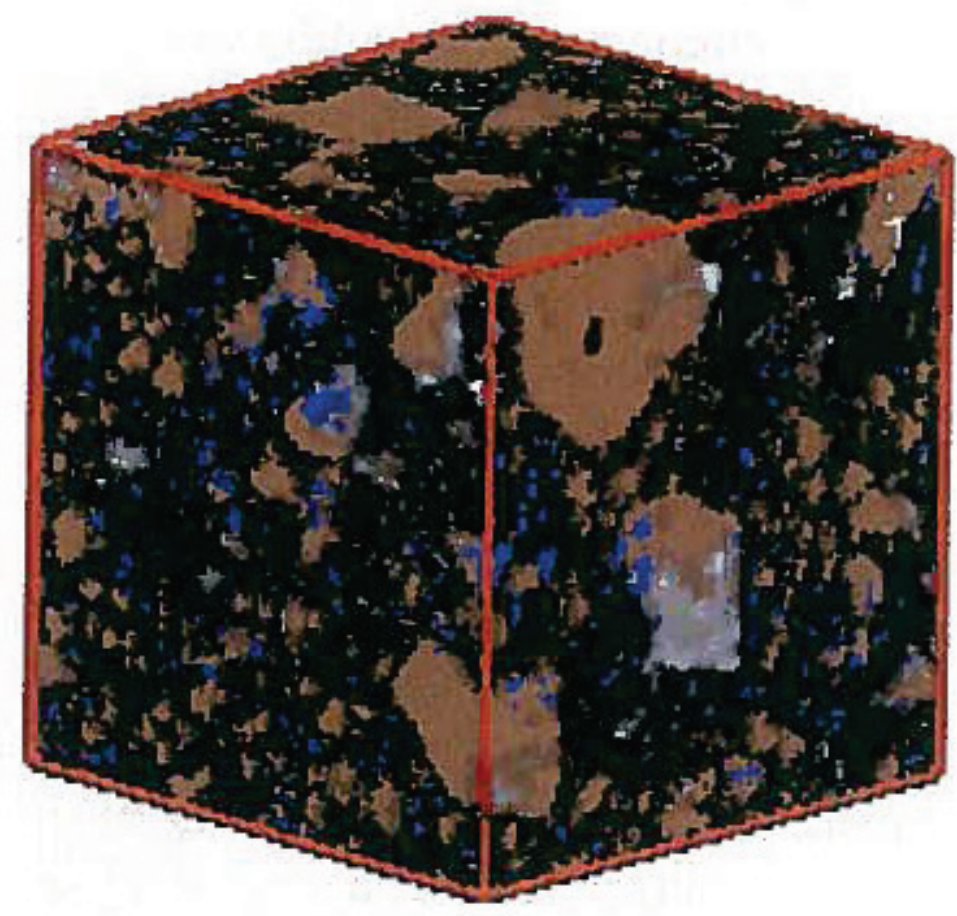


The VCCTL software package includes pre-installed cement, supplementary cementitious materials, and aggregate data to facilitate virtual testing. Materials unique to a certain project must be added to the software before modeling. Due to the large size differences between aggregates and cement paste particles, the two systems are handled separately. The cement paste portion is first calculated and stored, and an aggregate randomization program is used to determine fine and coarse particle locations in a matrix. The paste portion is then added to fill gaps between aggregate particles.

Running the hydration model "dissolves" the individual voxels, allowing them to react with water and produce a 3 -D hydrated microstructure where each voxel becomes a phase of the cement paste. The hydrated image can then be used to calculate properties such as set point, temperature changes, chemical shrinkage, desiccation, and diffusion. Values for mechanical properties, such as elastic moduli, are then calculated by utilizing finite element techniques. A comparison of moduli results showing experimental values (exp) compared to model values (mod) is shown in Figure 3. Other concrete properties, such as compressive strength, may be calculated by using empirical or semi-empirical relations to the model's calculated gelspace ratio or Young's modulus.

Figure 3. Experimental vs model moduli results (from Garboczi et al. 2004).

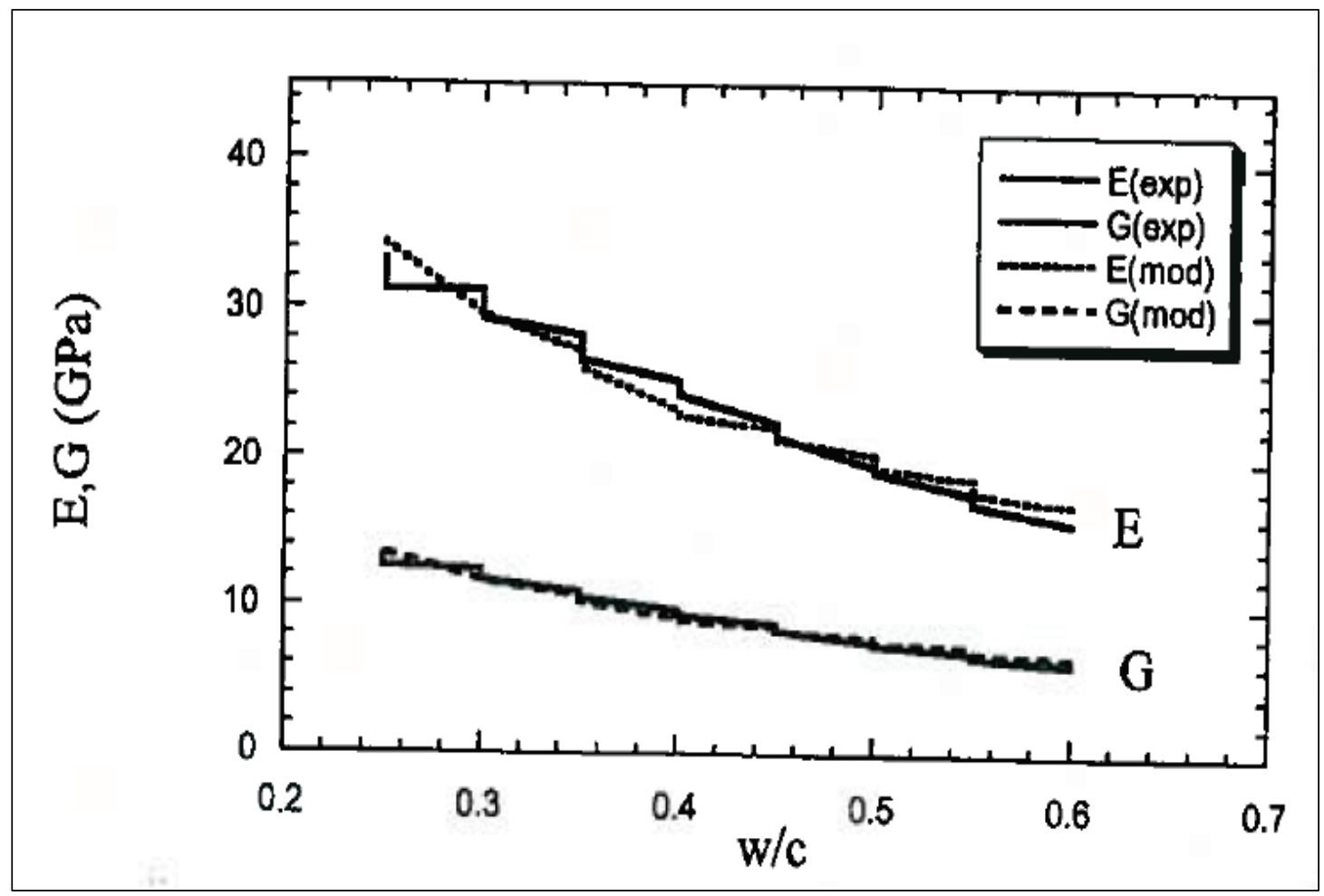




\section{Material Characterization}

\subsection{Characterization data required for model}

In order to accurately produce results with the model, certain characterizations of the materials are necessary. For cement, a segmented indexed image file is required, most likely obtained by scanning electron microscopy (SEM) and adjusted using imaging software. Other necessary inputs include chemical property data, most likely obtained using x-ray diffraction (XRD) techniques, and a physical particle size distribution (PSD), which can be obtained by a variety of methods.

Other cementitious materials, such as silica fume, fly ash, slag, etc., require similar chemical composition and particle-size distribution inputs, but do not require their own segmented indexed image file. Aggregate input requirements include basic particle shape information and particlesize distribution files. However, shape requirements appear to be estimable without negative effects on the model as long as aggregates are roughly normally shaped for their type, e.g., no or a low content of flat or elongated particles.

Although the above requirements represent the minimum inputs required to use the model, additional information may be useful or desired. For example, characterization techniques such as x-ray fluorescence (XRF) can be used to further validate chemical compositions. Other characterization areas, such as particle-size distribution information that can be determined by multiple methods, may need to be optimized to provide the most accurate inputs. Depending on material type, various different methodologies may produce the most relevant particle size distributions, and as is the case with all virtual models, improving input accuracy increases the overall reliability.

\subsection{Materials tested}

At the time of publishing this report, 79 sets of material characterization data have been developed and processed into a digital material properties data storage location. An additional 59 sets of material characterization data have been collected and are awaiting processing into digital data storage. Table 1 lists materials selected for characterization and status of characterization data. Black checkmarks indicate data that have been 
collected and processed. Green checkmarks indicate data that have been collected and awaiting processing. Material ID numbers were assigned at the time the material was received and are used to reference specific materials for the remainder of the report.

\subsection{Advances in characterization capabilities}

The majority of materials' characterization techniques were performed using existing equipment present in the Concrete and Materials Branch (CMB) of the Geotechnical and Structure Laboratory (GSL). XRD and XRF measurements were taken using a PANalytical X'Pert Pro diffractometer and PANalytical Axios spectrometer, respectively. SEM imaging was conducted using a FEI Nova NanoSEM 630 scanning electron microscope with energy dispersive x-ray (EDX) capability. EDX measurements were used to ensure the SEM image phases were identified appropriately.

\subsubsection{Scanning electron microscopy and energy dispersive x-ray spectroscopy}

Cementitious materials characterized with scanning electron microscopy (SEM) and energy-dispersive X-ray spectroscopy (EDX) measurements were observed in an unhydrated state in order to more accurately model pre-hydration microstructure. Samples were mixed with a quick setting epoxy blend and allowed to set overnight in 1-in.-diameter plastic molds. Epoxy-blended specimens were then cross-sectioned and polished up to a 1 micron suspension and sputter coated. SEM examination was focused on the microstructure of the paste. Imaging was performed using an FEI Nova NanoSEM 630 capable of high-resolution imaging on nonconductive materials. Imaging was performed in low-vacuum mode at pressures of 0.1-0.5 mbar and accelerating voltage of $15-30 \mathrm{kV}$. 
Table 1. Material selection and status of data collection.

\begin{tabular}{|c|c|c|c|c|c|c|}
\hline \multirow{2}{*}{ Material Type } & \multirow{2}{*}{ Description } & \multirow{2}{*}{ ID } & \multicolumn{3}{|c|}{ Property Data } & \multirow{2}{*}{$\begin{array}{c}\text { Microstructure } \\
\text { Images }\end{array}$} \\
\hline & & & PSD & XRF & XRD & \\
\hline Cement & Type V (Hanil Plant) & 150146 & $\checkmark$ & $\checkmark$ & $\checkmark$ & \\
\hline Cement & Type I/II (Hanil Plant) & 150147 & $\checkmark$ & $\checkmark$ & $\checkmark$ & \\
\hline Cement & Type III - National (Ragland Kiln) & 160160 & $\checkmark$ & $\checkmark$ & $\checkmark$ & \\
\hline Cement & South Korea & 170001 & $\checkmark$ & $\checkmark$ & $\checkmark$ & \\
\hline Cement & White cement - South Korea & 170002 & $\checkmark$ & $\checkmark$ & $\checkmark$ & \\
\hline Cement & White cement - Lehigh & 170009 & $\checkmark$ & $\checkmark$ & $\checkmark$ & \\
\hline Cement & Type I - National (Ragland Kiln) & 170010 & $\checkmark$ & $\checkmark$ & $\checkmark$ & \\
\hline Cement & Type I/II MMC (St. Gen Kiln) & 170052 & $\checkmark$ & $\checkmark$ & $\checkmark$ & $\checkmark$ \\
\hline Cement & Type $\mathrm{H}$ & 170065 & $\checkmark$ & $\checkmark$ & $\checkmark$ & $\checkmark$ \\
\hline Cement & Type I/II MMC (St. Gen Kiln) & 170096 & & $\checkmark$ & $\checkmark$ & \\
\hline Cement & Type I/II MMC (St. Gen Kiln) & 170098 & & & $\checkmark$ & \\
\hline Cement & PLC & 170099 & & & $\checkmark$ & \\
\hline Slag & Lafarge Chicago & 170080 & $\checkmark$ & & & \\
\hline Slag & South Korea & 150150 & $\checkmark$ & $\checkmark$ & $\checkmark$ & \\
\hline Slag & Guam & --- & & $\checkmark$ & $\checkmark$ & \\
\hline Fly Ash & Trok & 80159 & & $\sqrt{4}$ & 4 & \\
\hline Fly Ash & Meuth & 100015 & & $\checkmark$ & $\checkmark$ & \\
\hline Fly Ash & Gaston & 100069 & & $\checkmark$ & $\checkmark$ & \\
\hline Fly Ash & Nashville & 120013 & & $\checkmark$ & $\checkmark$ & \\
\hline Fly Ash & GHR & 120083 & & $\checkmark$ & $\checkmark$ & \\
\hline Fly Ash & China Lake & 120104 & & $\checkmark$ & $\checkmark$ & \\
\hline Fly Ash & Monroe & 120222 & & $\checkmark$ & $\checkmark$ & \\
\hline Fly Ash & Cumberland & 130032 & & $\checkmark$ & $\checkmark$ & \\
\hline Fly Ash & Cook & 140022 & & $\checkmark$ & $\checkmark$ & \\
\hline \begin{tabular}{|l|l|} 
Fly Ash \\
\end{tabular} & NHS & 140054 & & $\checkmark$ & $\checkmark$ & \\
\hline Fly Ash & Pro Ash Ecotherm & 150108 & & $\checkmark$ & $\checkmark$ & \\
\hline \begin{tabular}{|l|} 
Fly Ash \\
\end{tabular} & Pro Ash Ecotherm & 150109 & & $\checkmark$ & $\checkmark$ & \\
\hline Fly Ash & Activated Carbon Addition & 150110 & & & $\checkmark$ & \\
\hline Fly Ash & Activated Carbon Addition with Re & 150111 & & & $\checkmark$ & \\
\hline Fly Ash & Limestone Addition & 150112 & & & $\checkmark$ & \\
\hline Fly Ash & Trona Addition & 150113 & & & $\checkmark$ & \\
\hline Fly Ash & Guam & & & $\checkmark$ & $\checkmark$ & \\
\hline Fly Ash & NNSS & & & $\checkmark$ & $\checkmark$ & \\
\hline Fly Ash & South Korea (Handuk) & 170003 & $\checkmark$ & $\checkmark$ & $\checkmark$ & \\
\hline Silica Fume & F10k (CMB) & 130008 & $\checkmark$ & $\checkmark$ & $\checkmark$ & \\
\hline Silica Fume & Elkem 970D & 130050 & $\checkmark$ & $\checkmark$ & $\checkmark$ & \\
\hline Silica Fume & Elkem ES 900W & 140092 & $\checkmark$ & $\checkmark$ & $\checkmark$ & \\
\hline Silica Fume & Elkem Sidistar & 140093 & $\checkmark$ & $\checkmark$ & $\checkmark$ & \\
\hline Silica Fume & Elkem 955U & 140094 & $\checkmark$ & $\checkmark$ & $\checkmark$ & \\
\hline Silica Fume & Angelfort - White & 150048 & $\checkmark$ & $\checkmark$ & $\checkmark$ & \\
\hline Silica Fume & Angelfort - Concrete & 150049 & $\checkmark$ & $\checkmark$ & $\checkmark$ & \\
\hline Silica Fume & RED Hydraulic - Original Sample & 150050 & $\checkmark$ & $\checkmark$ & $\checkmark$ & \\
\hline Silica Fume & RED Les Clavaux & 150051 & $\checkmark$ & $\checkmark$ & $\checkmark$ & \\
\hline Silica Fume & RED Laudun & 150052 & $\checkmark$ & $\checkmark$ & $\checkmark$ & \\
\hline Silica Fume & Hanil Plant & 150148 & $\checkmark$ & $\checkmark$ & $\checkmark$ & \\
\hline Silica Fume & South Korea & 170003 & $\checkmark$ & & $\checkmark$ & \\
\hline Silica Fume & Ecotech85 (Guam) & Ecotech & $\checkmark$ & $\checkmark$ & $\checkmark$ & \\
\hline Silica Fume & F10k (Guam) & F10 & $\checkmark$ & $\checkmark$ & $\checkmark$ & \\
\hline Silica Fume & Z3-95 & 170107 & $\checkmark$ & $\checkmark$ & $\checkmark$ & \\
\hline Silica Fume & D-1000 & & $\checkmark$ & $\checkmark$ & $\checkmark$ & \\
\hline Silica Fume & Elkem 971U & & $\checkmark$ & $\checkmark$ & $\checkmark$ & \\
\hline Silica Flour & Sil-co-sil & --- & $\checkmark$ & & $\checkmark$ & \\
\hline & & & & & & \\
\hline Metakaolin & Power Pozz & 140015 & $\checkmark$ & $\checkmark$ & $\checkmark$ & \\
\hline Metakaolin & Hanil Plant & 150149 & $\checkmark$ & $\checkmark$ & $\checkmark$ & \\
\hline Metakaolin & South Korea & 170004 & $\checkmark$ & $\checkmark$ & $\checkmark$ & \\
\hline Sand & Silica Sand - F50 & --- & $\checkmark$ & $\checkmark$ & & \\
\hline
\end{tabular}


All images were acquired using a backscattered electron detector to improve phase contrast. Imaging was performed at random sites and at various levels of magnification to capture the overall microstructure along with specific regions of interest. In conjunction with SEM imaging, chemical microanalysis using energy-dispersive X-ray spectroscopy (EDX) was performed using a Bruker Quantax AXS detector in order to characterize the chemical composition of phases of interest observed, particularly focusing on the composition of the cement paste.

\subsubsection{X-ray diffraction analysis}

X-ray diffraction (XRD) analysis was performed to identify the mineralogy of each component present in the concrete according to ASTM C1365 Standard Test Method for Determination of the Proportion of Phases in Portland Cement and Portland-Cement Clinker Using X-ray Powder Diffraction Analysis (2018). The specimen was prepared into random powder-pack sample holders for XRD measurements. Diffraction patterns to be used for qualitative phase identification were obtained using a Panalytical X'Pert Pro materials research diffractometer equipped with a $\mathrm{Co}-\mathrm{Ka} \mathrm{X}$-ray source operated at $45 \mathrm{kV}$ and $40 \mathrm{~mA}$. Diffraction patterns were obtained over a period of $2 \mathrm{hr}$ from $20^{\circ}$ to $70^{\circ}$ with a step size of $0.02 \varnothing$. Phase identification was performed using MDI Jade 2010 powder diffraction file (PDF) reference databases.

\subsubsection{Particle size analysis}

No capability for particle-size distribution analysis was available in the GSL at the onset of this research effort and, as this was expected to be a long-running effort, it was decided to invest in the capability. A Mastersizer 3000 laser diffraction particle size analyzer was obtained and installed on the premises. The laser diffraction method utilizes a controlled laser that interacts with particles with measurements being calculated based on the deflection of the laser off of the particle surfaces.

The unit is capable of determining particle sizes of materials as a solution in a liquid, as a dry powder, and in quantities less than $3 \mathrm{ml}$. These capabilities ensured that the GSL could produce accurate particle-size distribution data on a wide variety of materials. Figures 4-6 show the Mastersizer 3000 with dry powder analyzer (Figure 4), dispersed liquid analyzer (Figure 5), and small volume analyzer module (Figure 6). 
Figure 4. Mastersizer 3000 with dry powder analyzer.

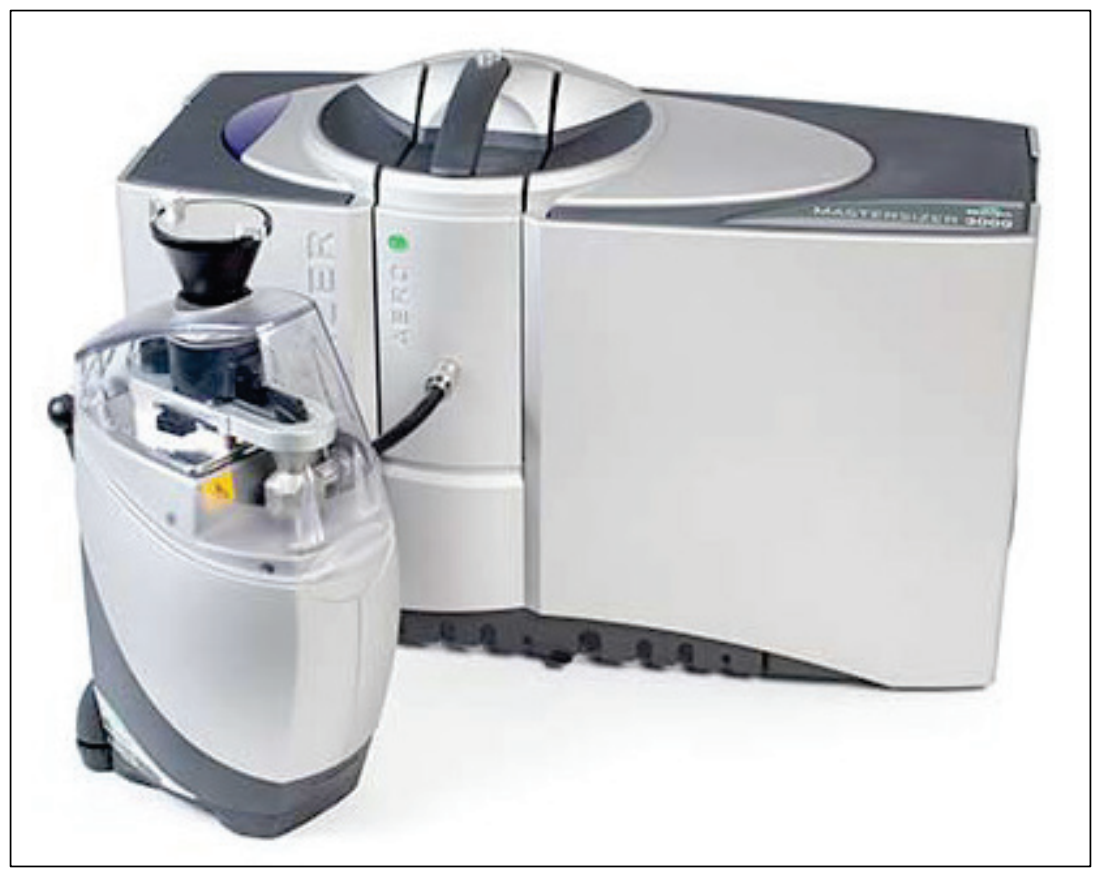

Figure 5. Mastersizer $\mathbf{3 0 0 0}$ with dispersed liquid analyzer.

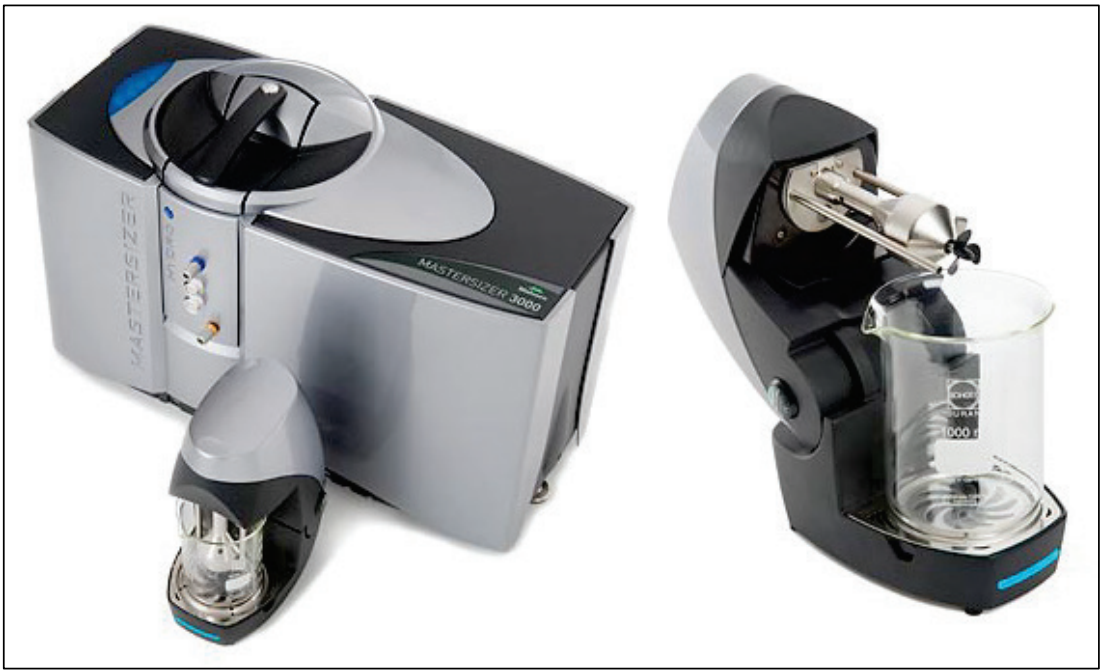


Figure 6. Small volume analyzer module.

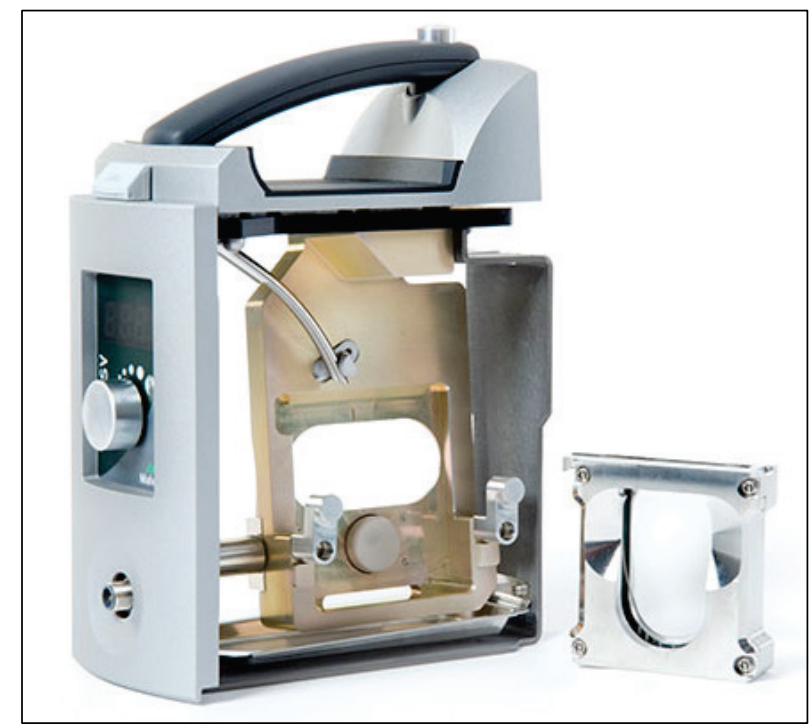




\section{Data Collection and VCCTL Model Inputs}

\subsection{Data collection archive}

Collection of material characterization data on a large scale is a sizable portion of the MMFP research effort. Working with other researchers in the GSL, a priority list was created with materials of key interest. So far, 12 cements, 19 fly ashes, 4 metakaolins, 15 silica fumes, and 1 slag cement have been identified for characterization as well as aggregate materials such as standard sands, gravels, and silica flour. A large archive of material properties for the identified key materials is in the process of being created both for MMFP modeling and for future access needs.

Particle size distribution, XRF, and XRD experiments are being performed and analyzed, and SEM imaging is completed for the identified cements to be used in the model calculations. During the continued collection of the characterization data, virtual model experiments are also being conducted simultaneously so that, when the data collection process has been completed, a majority of the model validation will have already been conducted. Figures 7-10 illustrate some of the different types of data being collected and materials of interest.

Figure 7. Laser diffraction particle -size distribution of silica fume 1500149.

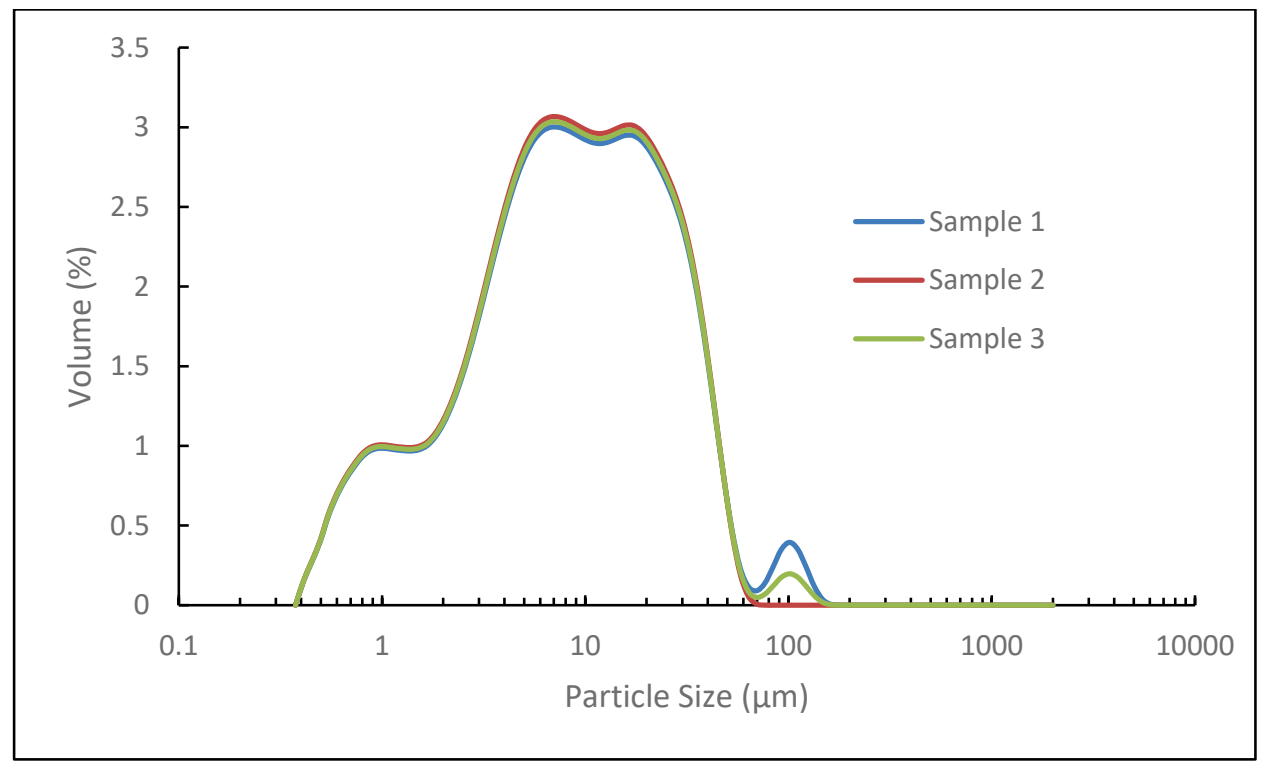


Figure 8. X-ray fluorescence (XRF) data of cement 170052.

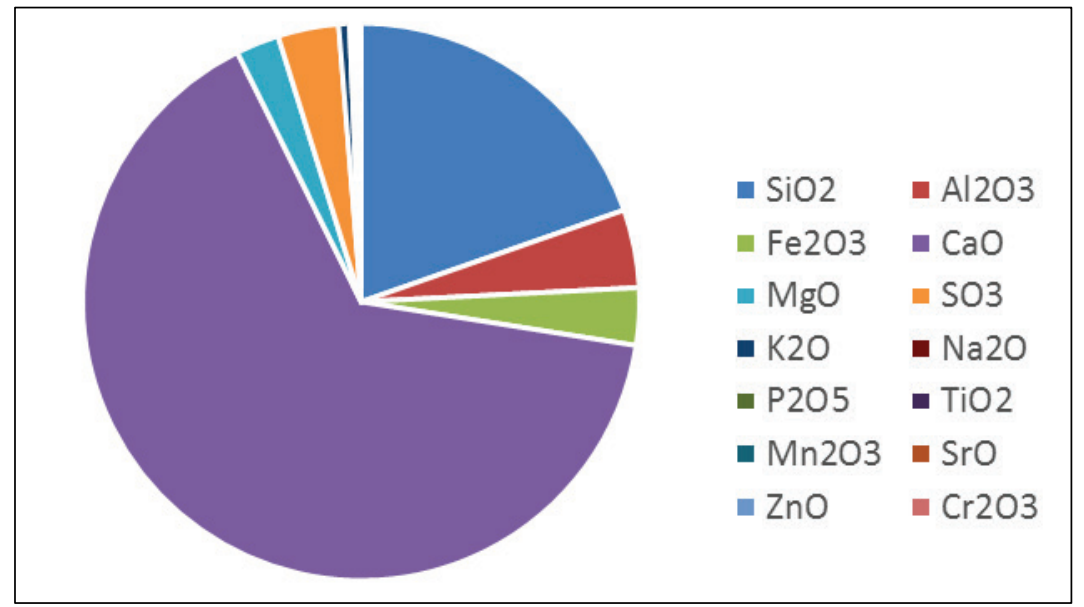

Figure 9. X-ray diffraction (XRD) data of fly ash 100015.

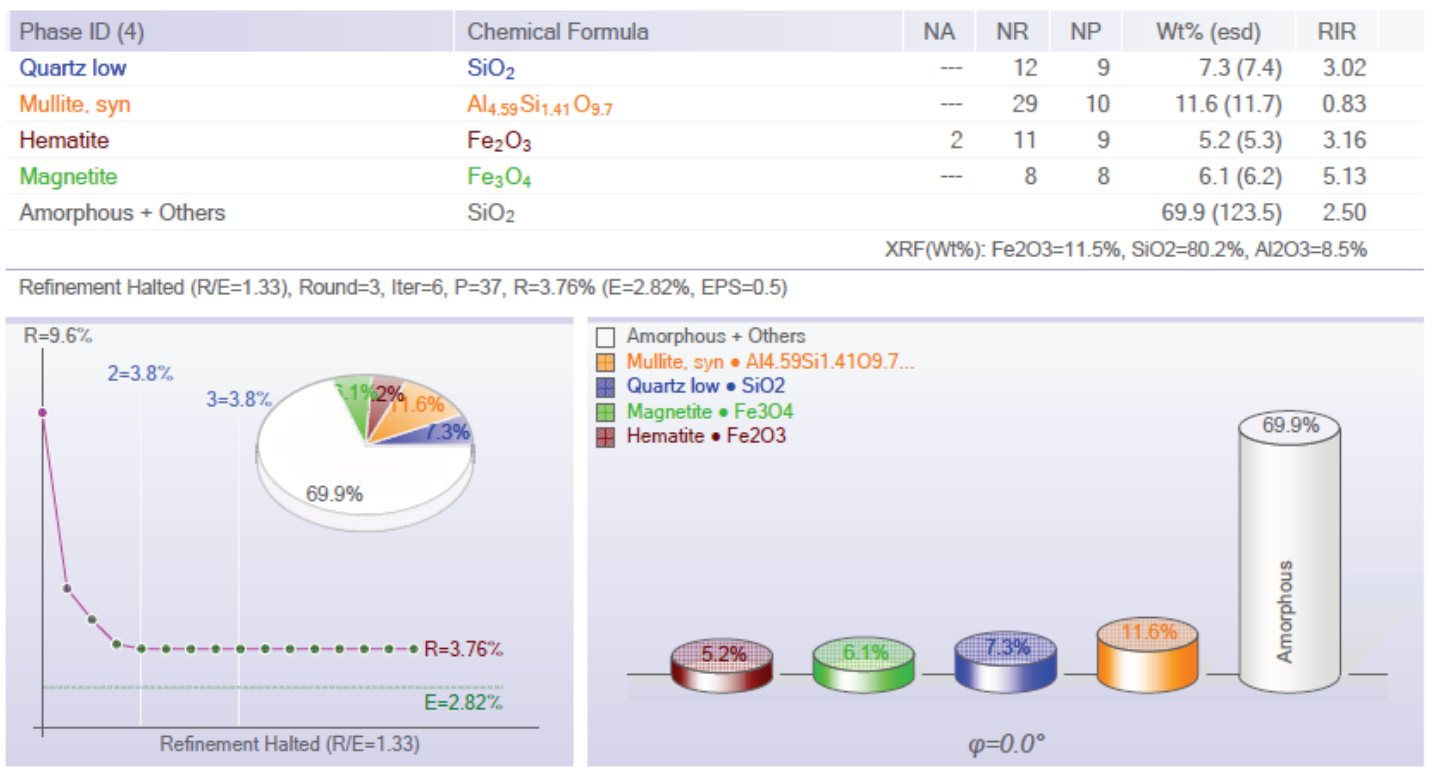


Figure 10. Scanning electron microscopy (SEM) image of type H cement (170065).

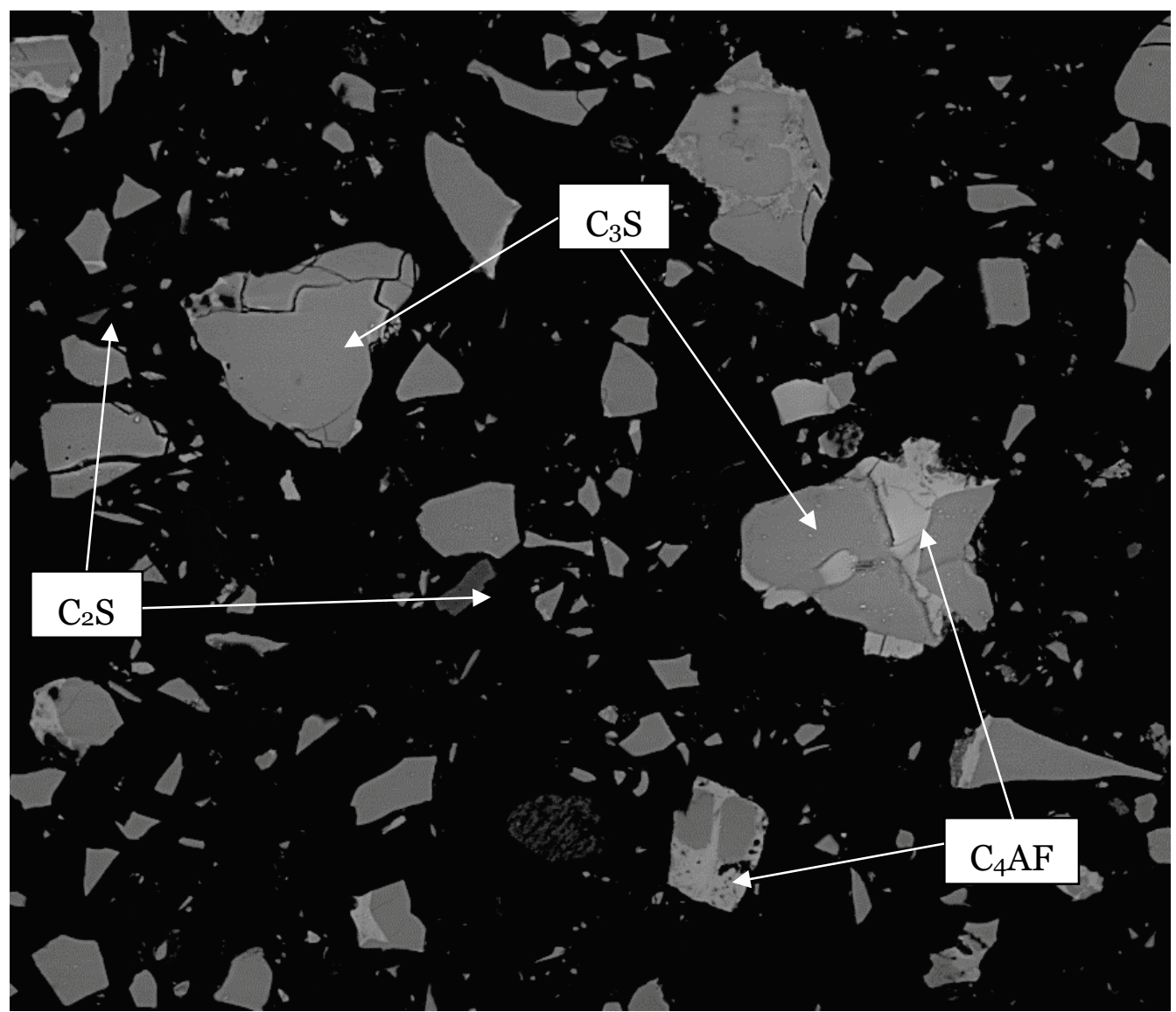

*MAG: 1000x; HV: 15kV; WD: 3.9mm; HFW: 285 mm.

\subsection{Image processing and phase identification}

Multiple images were taken of a single section with each image highlighting a different set of element parameters. An example set of images is shown in Figure 11. The six images represent the backscattered SEM image (a), Silicon highlighted (b), Sulfur highlighted (c), Iron highlighted (d), Aluminum highlighted (e), and Magnesium highlighted (f). The images can then be used to visually identify certain phases in the sample by taking into account which overlapping elements make up each particle

An investigation into digital image processing methodology was conducted using SEM and EDX images and a combination of the programs Imagej and Multispec. Using multiple color patterns and no color layers, it was possible to identify each of the phases present in the sample. For example, setting the base image to red and the aluminum image to blue showed the $\mathrm{C}_{3} \mathrm{~A}$ phase as light red, $\mathrm{C}_{2} \mathrm{~S}$ phase as dark red, and any Ferrite phases as purple. Using this methodology, phases can be processed, identified, and 
labeled using software. An example of this methodology is shown in Figures 12 and 13.

A cement supplied by the Cement and Concrete Reference Laboratory (CCRL), given the designation 17705, was imaged by SEM. Separate images containing the complete gray-scale SEM image and element images of aluminum, magnesium, sulfur, potassium, and sodium were obtained. Images were assigned a color value of either red, blue, green, or none and placed on top of each other to form a single image file, shown in Figure 12a. Using knowledge of cement phases and color values, a label field was assigned to groups or areas of like pixels. This is illustrated in Figure 12b.

The software is then used to determine a calculated set of rules based on the user assigned values. Applying the same value field rules over the entire image produced a false color image of the sample in which each color aligns to a specific cement phase. The calculated false color image for the labeled combined image in Figure 12 is shown in Figure 13. The program also features the ability to calculate the percentages of each phase present in the image. Using the Multispec imaging process as a measure appears to allow for a greater level of certainty in detecting the phase portions of a gray-scale SEM image than visual interpretation. 
Figure 11. Suite of SEM and EDX images using the same location and parameters as Figure 10.

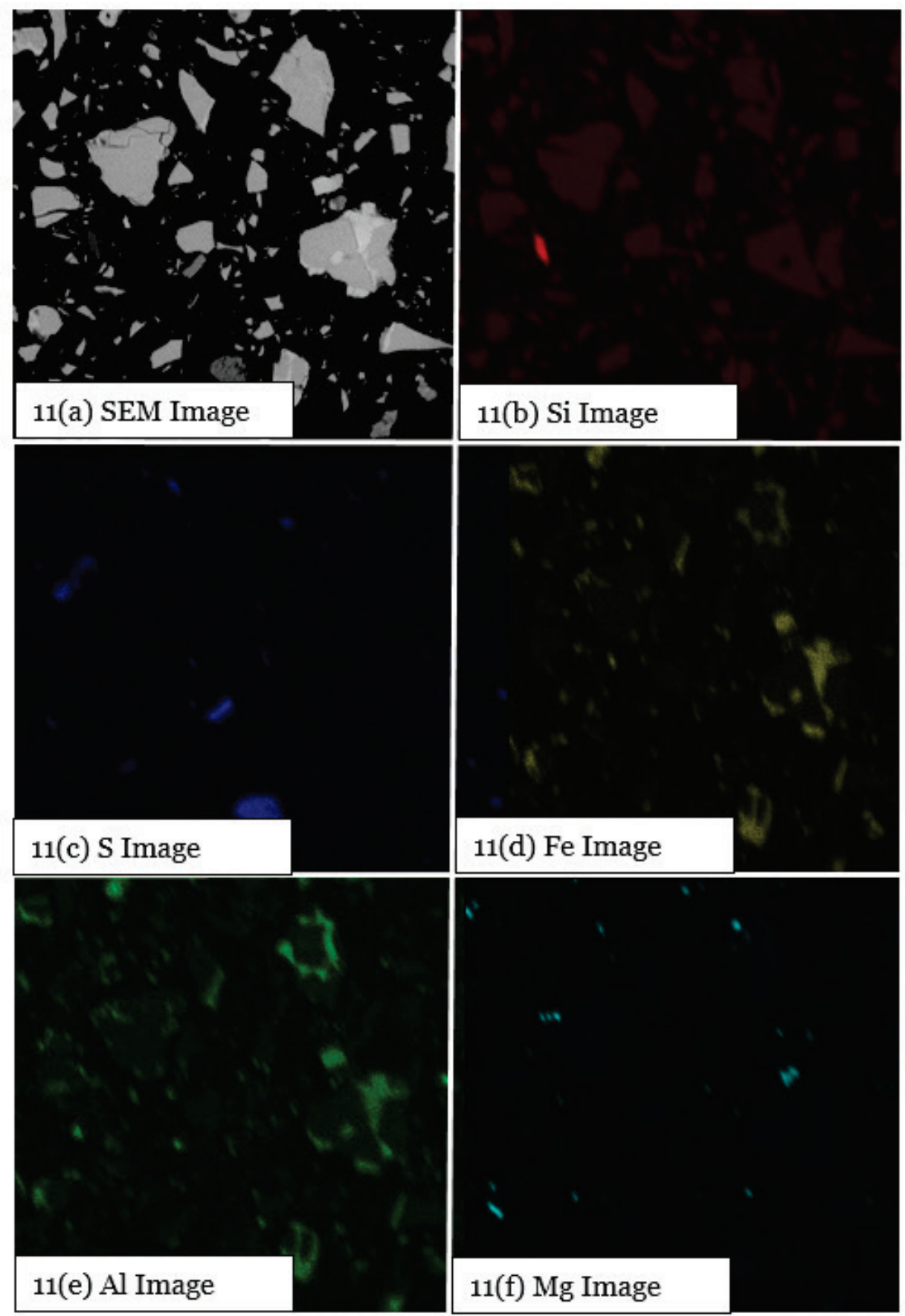

*MAG: 1000x; HV: 15kV; WD: 3.9mm; HFW: 285 mm. 
Figure 12. Combined Multispec image of multiple layers of cement 17705 without (a) and with (b) fields labeled.
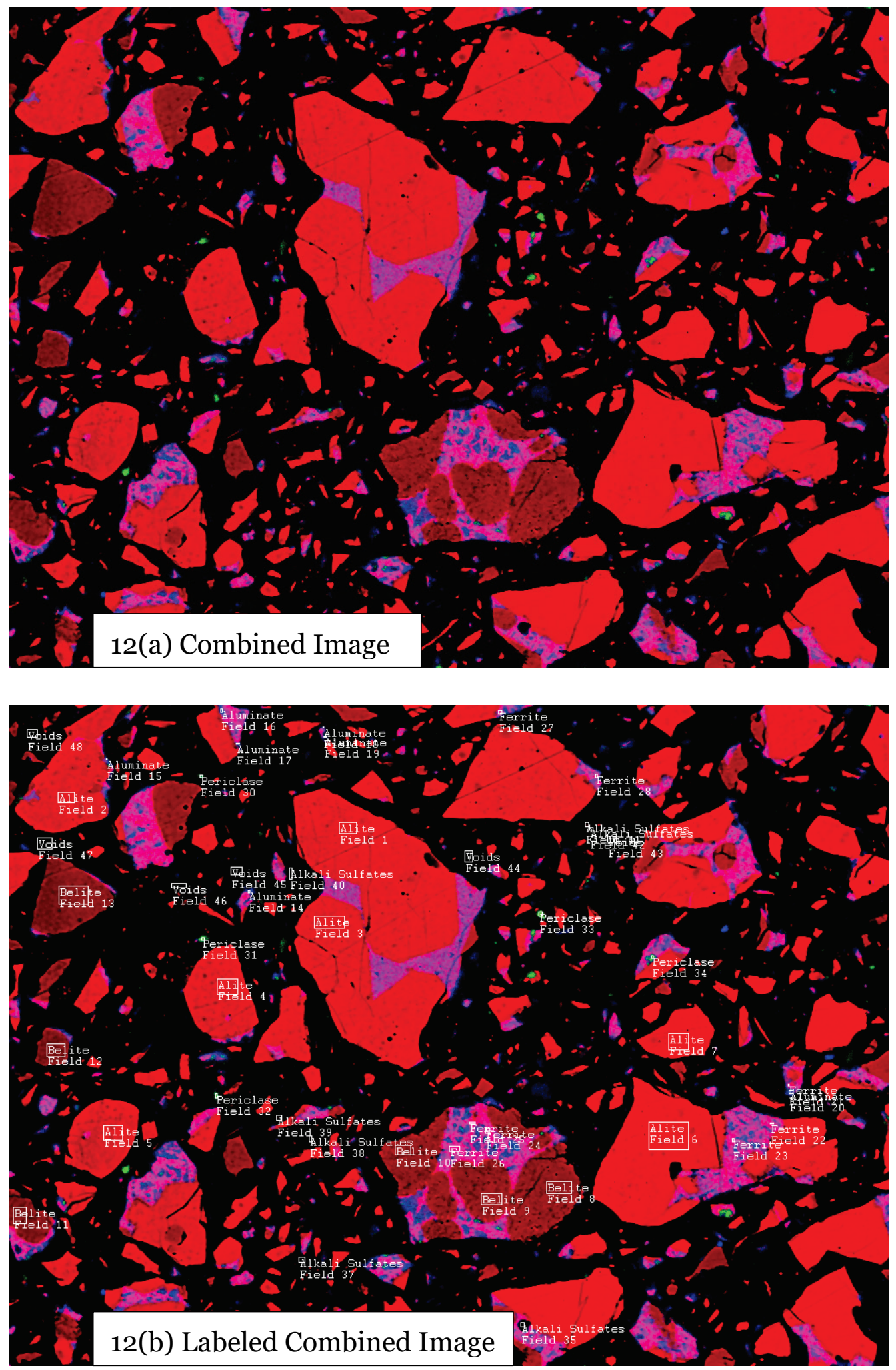
Figure 13. Calculated false color image with values based on image and labels from

Figure 12.

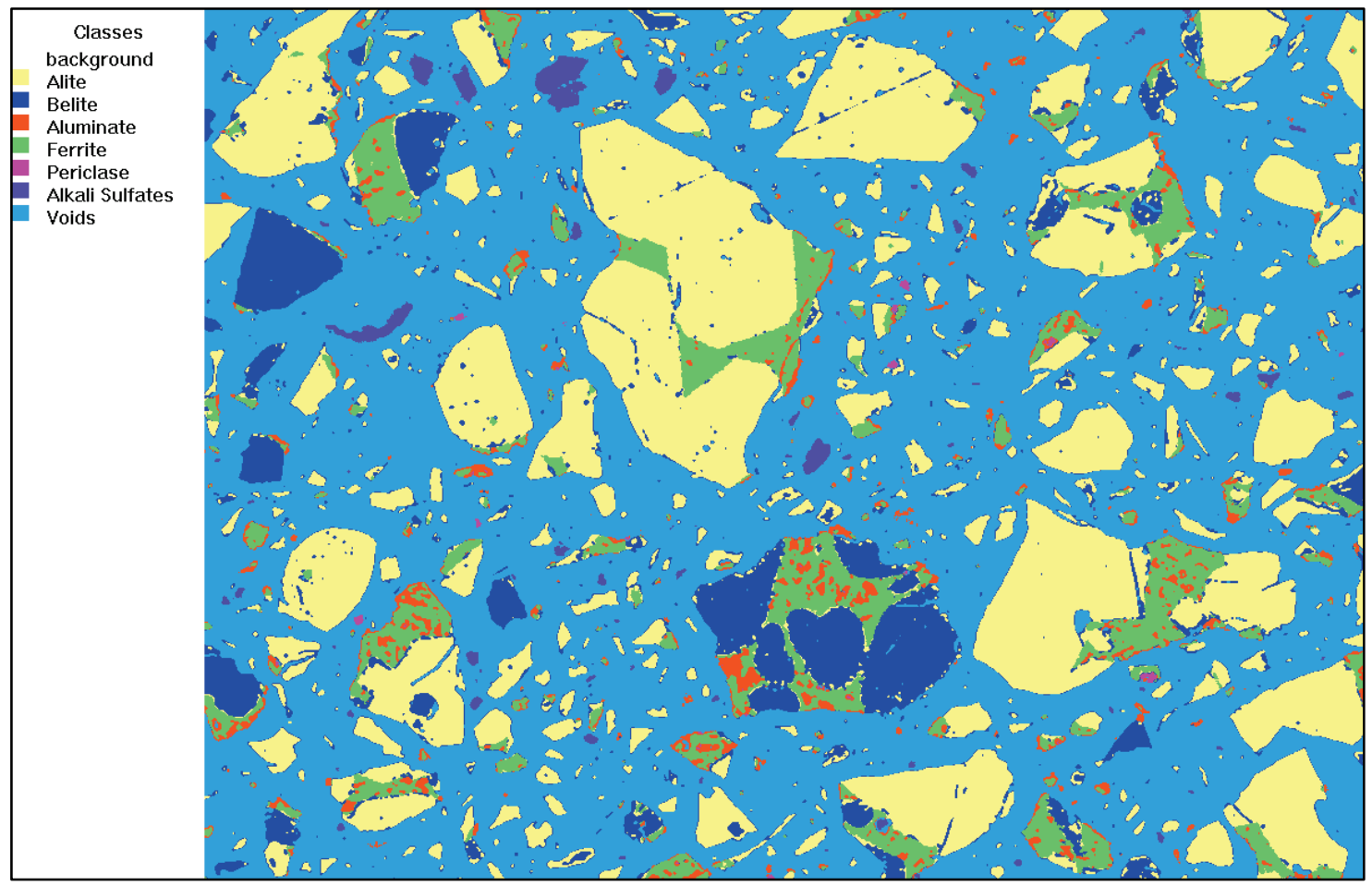

\subsection{VCCTL inputs}

Input requirements into the program are described in Section 2.1. For the remainder of this report, a full example of input requirements and output data is discussed. Materials used in this virtual microstructure include a standard Type I/II cement with $20 \%$ replacement by fly ash, a 0.45 waterto-cementitious material $(\mathrm{w} / \mathrm{cm})$ ratio, 57 stone coarse aggregate, and standard C33 sand fine aggregate.

Selection of materials that are already present in the model database is typically straightforward and can be accomplished using the VCCTL GUI. The GUI allows for selection of a digitized image, particle size distribution file, and chemical composition. The selection can be features of the same material or comprised of multiple material data entries. For example, the user can choose all three files for a single cement or use the chemistry of one cement, the image of a second cement, and the particle size distribution of a third cement. This allows for some experimentation to investigate cement property relationships to performance.

In the case of supplementary cementitious materials, the user only need input particle size distributions and very basic chemistry data, and for 
aggregates only, basic shape information and particle size is required. Due to the simpler inputs, a supplementary cementitious material or aggregate can be entered "on the fly" as the user is selecting the mix proportions. Cement data entries must be made via command line scripts, or uploading property files prior to using the VCCTL GUI.

After all materials are entered, the virtual mixing process begins. The user can specify the desired proportions of each material, the desired w/cm ratio, length of reaction time, and which outputs to be created. The processing time of the program is directly related to length of reaction time and outputs. 


\section{VCCTL Model Outputs}

\subsection{Property data outputs}

Outputs for the program include microstructure image files and mechanical and transport property data files. The mixture is converted into a 100 by 100 by 100 voxel cube, and each voxel is given a color to represent the phase present in that voxel. Microstructure image files are provided as 2-D slices of the 3-D microstructure. One hundred images are created such that each represent one voxel depth of the cube. Figure 14 shows the first voxel depth of a virtually generated unhydrated microstructure.

The mixture design shown includes a standard CCRL type I/II cement, silica fume (ID \#140092), and silica sand. The CCRL cement was already included in the program while the silica fume and silica sand were characterized at the ERDC and added to the program database. The mixture contained $38 \%$ cementitious material by mass ( $80 \%$ cement and $20 \%$ silica fume) at a $0.45 \mathrm{w} / \mathrm{cm}$ ratio. This mixture was given the designation 140-900W-o-F50. The VCCTL legend for relating voxel colors to microstructure phases is shown in Figure 15. The same mixture and virtual microstructure in Figure 14 was hydrated using the program and is shown in Figure 16. 
Figure 14. Unhydrated microstructure image of a cement paste for mixture 140-900W-0-F50.

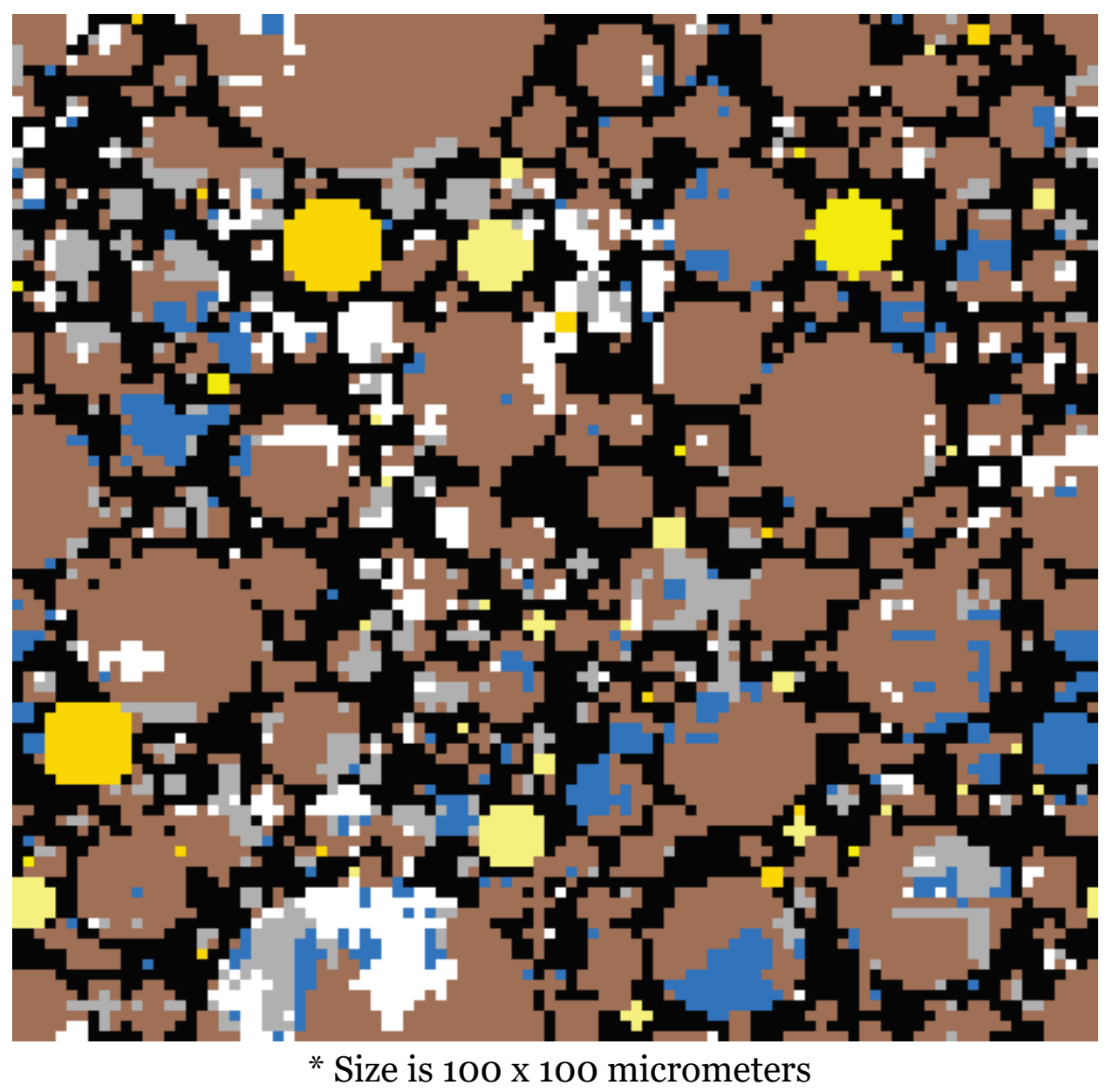

Figure 15. Legend for VCCTL microstructure image phases.

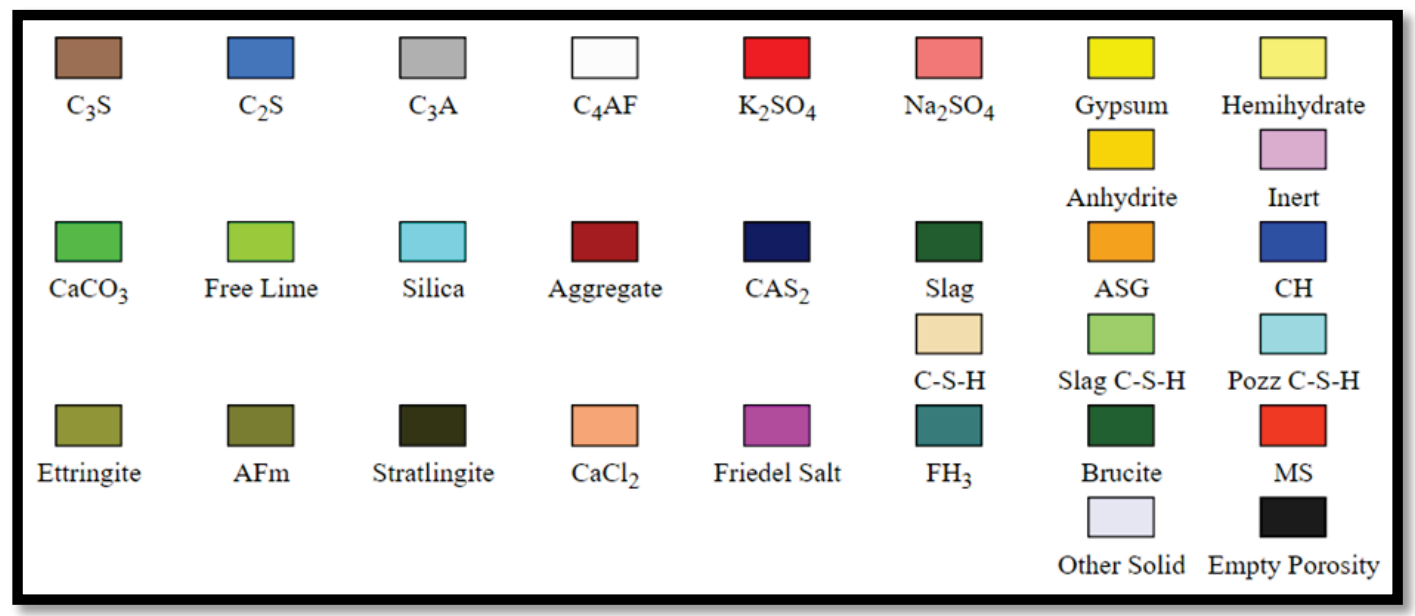


Figure 16. Hydrated microstructure image of a cement paste for mixture 140-900W0-F50.

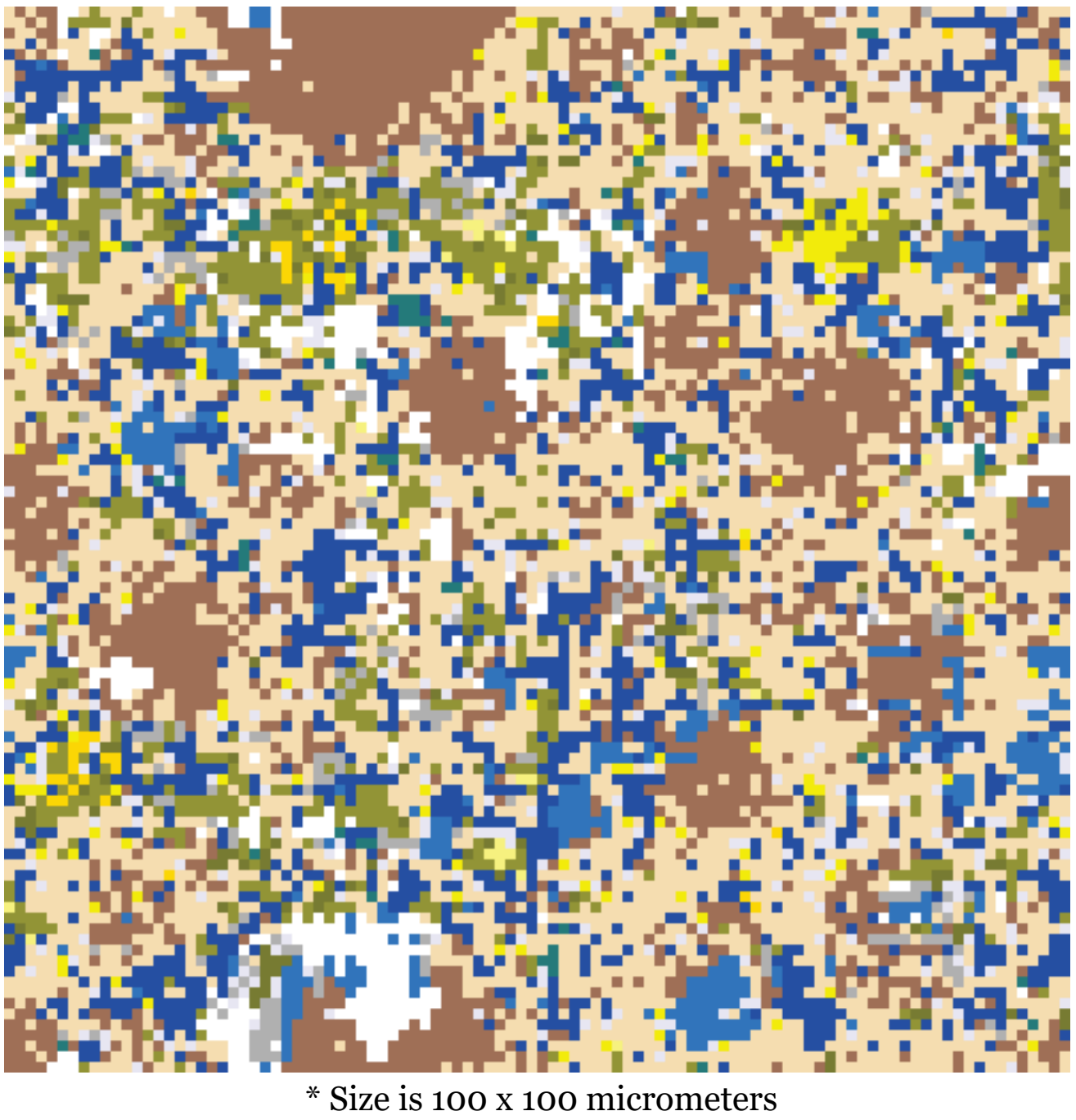

As seen in Figure 17, the CSH portion forms during hydration and encompasses most of the available pore space from the unhydrated image (Figure 14). CSH growth can only occur at the edge of unhydrated, but potentially reactive, materials and must occur one voxel at a time. Essentially, the model investigates constituent material boundaries and performs a numerical check to determine if the materials react and, if a reaction occurs, what phase forms in the voxel along that boundary. If a reaction occurs, checks then continue using the reacted voxel material and its adjacent voxels until no new reactions are predicted.

The hydrated microstructure can also be used to calculate additional outputs such as degree of hydration (Figure 17), porosity (Figure 18), gelspace ratio (Figure 19), and heat release (Figure 20). Overall, 68 property 
measurements can be obtained using the hydration microstruture image. The following four figures illustrate the aforementioned properties over the first $20 \mathrm{hr}$ for the virtual microstructure 140-900W-o-F50.

Figure 17. Degree of hydration over the first $20 \mathrm{hr}$ for mixture 140900W-0-F50.

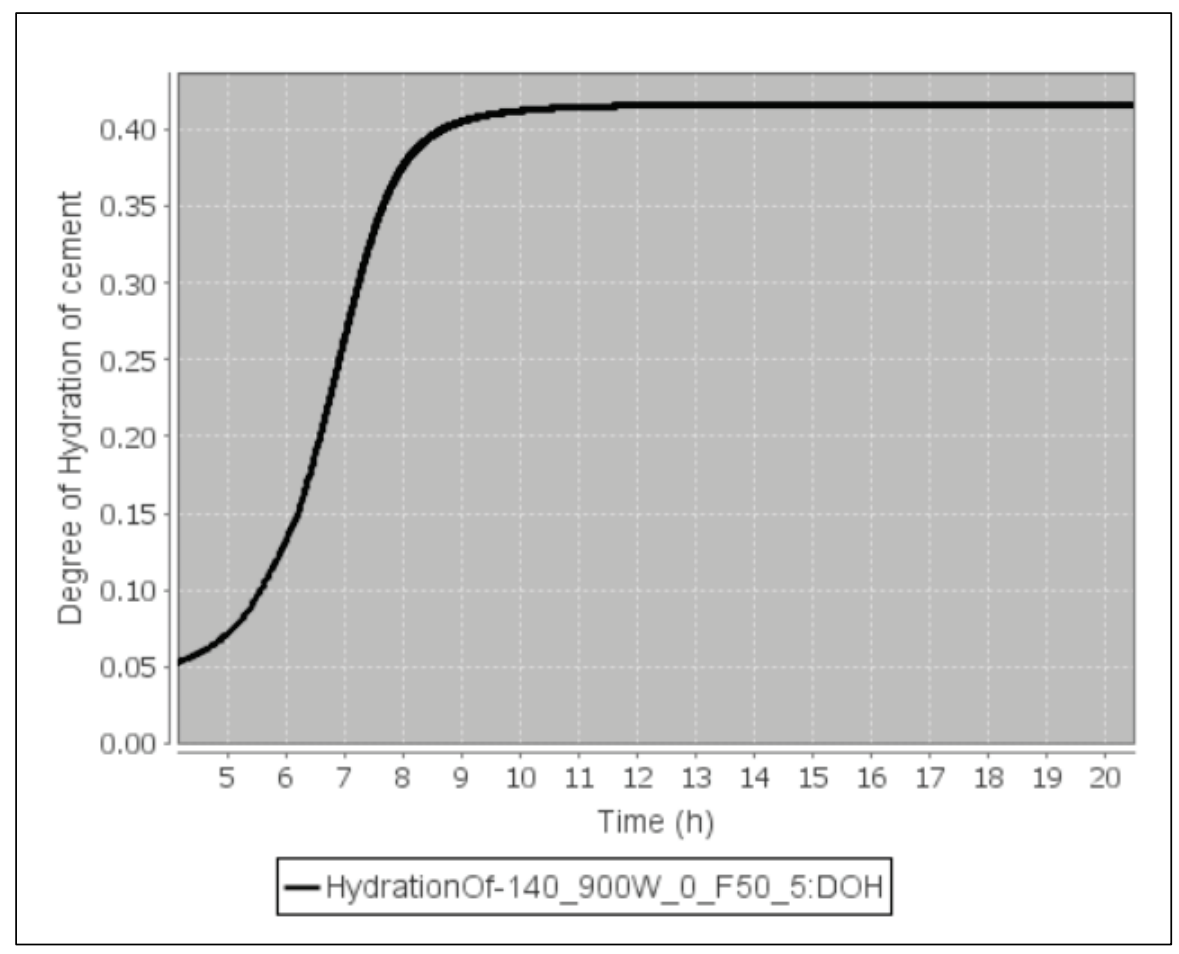


Figure 18. Porosity over the first $20 \mathrm{hr}$ for mixture 140-900W-0-F50.

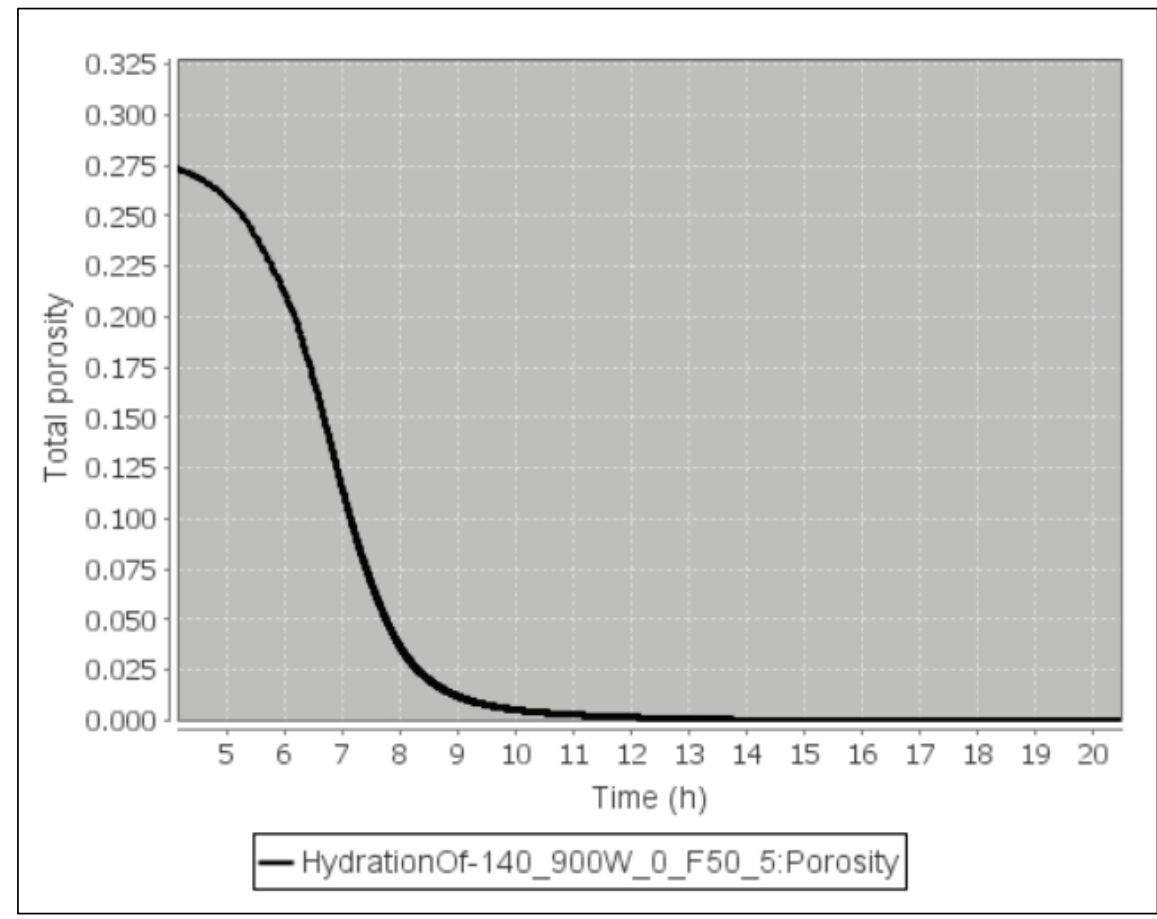

Figure 19. Gel-space ratio over the first $20 \mathrm{hr}$ for mixture 140-900W-0-F50.

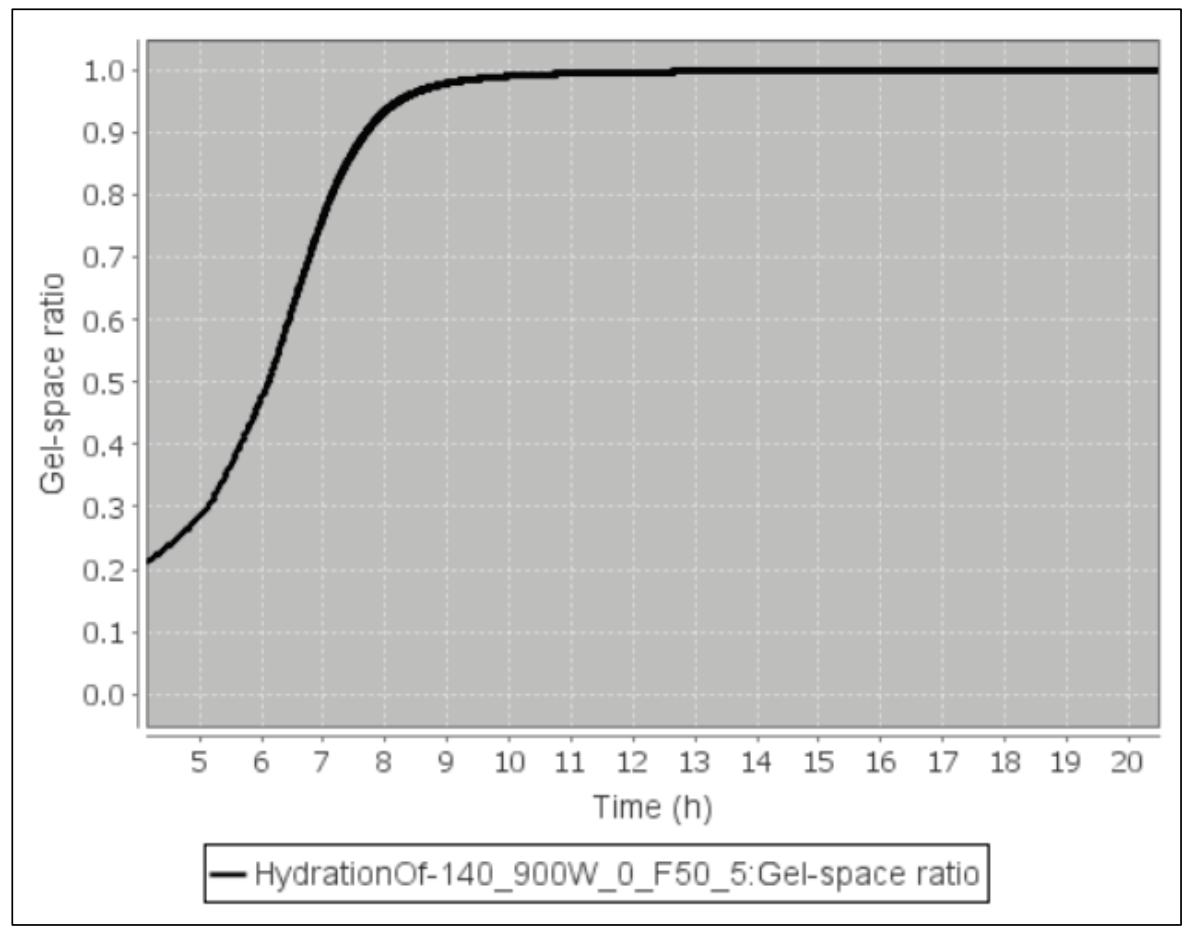


Figure 20. Heat release over the first $20 \mathrm{hr}$ for mixture 140-900W-0-F50.

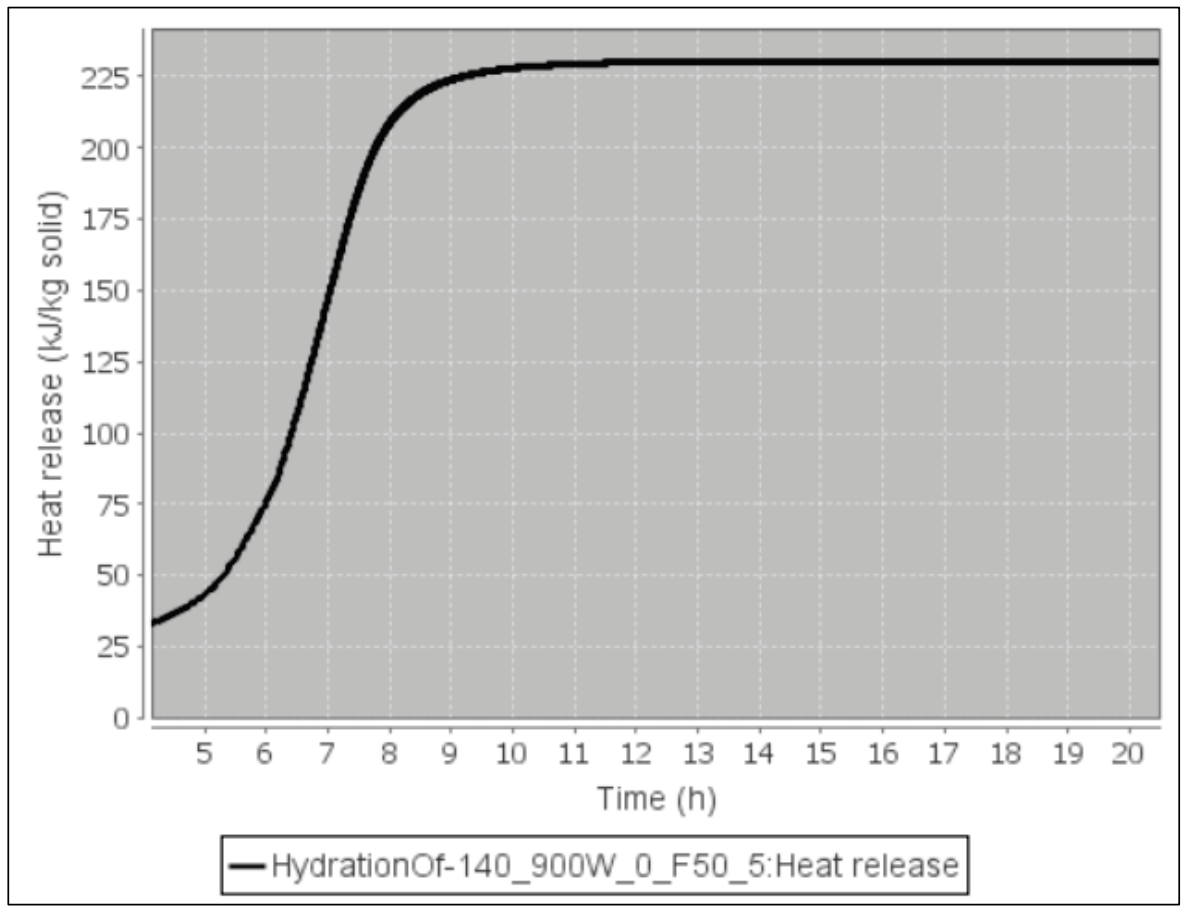

Moduli results are calculated and provided in tabular format. Moduli results from the sample microstructure are shown in Figure 21. Aggregate results are produced separately due to scaling issues. Aggregates are processed using a random number generator and predicted density relationships. The aggregate microstructure image is shown in Figure 22. The image is in the same style as the cement paste in that the image is a 2-D representation of 1 -voxel depth slides of a 3 -D cube. In this image, the large red particles represent coarse aggregates, the small dark red particles represent fine aggregate, and the gray represent a continuum, which is the cement paste.

Figure 21. VCCTL calculated moduli results for mixture 140-900W-0-F50.

\section{CEMENT PASTE ELASTIC MODULI:}

bulk_modulus $32.1 \mathrm{GPa}$ shear_modulus $16.9 \mathrm{GPa}$

Youngs_modulus $43.1 \mathrm{GPa}$

Poissons_ratio 0.27 
Figure 22. Virtual microstructure of aggregate for mixture 140-900W-0-F50.

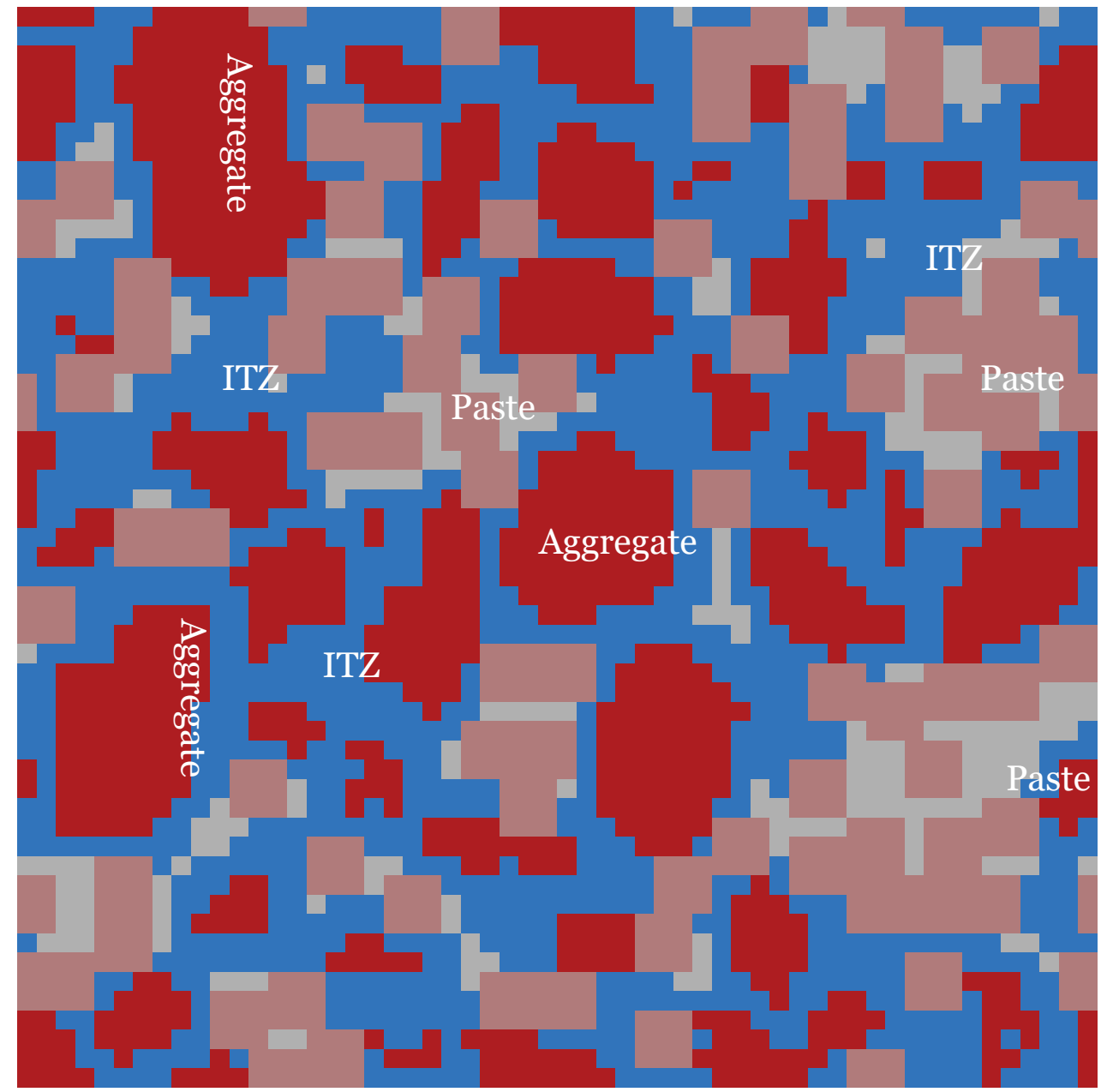

* Size is $2.28 \mathrm{~mm}$ x $2.28 \mathrm{~mm}$; each pixel represents .04 mm

\subsection{Data outputs for next level models}

The overarching goals of the MMFP project include a materials-by-design focus in which it is possible to transition from micro-sized grains to fullscale concrete elements and vice versa with predictable performance properties being measurable throughout the entire process. To achieve this, the results of the VCCTL program must be compatible in higher length scale models. VCCTL features text-based image outputs for both the aggregate and cement paste microstructure files. These outputs contain a list of one million numbers, each representing a voxel in the 100 by 100 by 100 voxel cube. These numbers represent a certain phase of the mixture and are ordered so that the cube could be reconstructed using only the text number file. These files along with the calculated physical properties are thought to be key in transitioning to a higher-level model. 
For example, a text hydrated microstructure file that begins with the numerals 1, 1, o, 0,4 represents consecutive pixels of $\mathrm{C}_{3} \mathrm{~A}, \mathrm{C}_{3} \mathrm{~A}$, porosity, porosity, $\mathrm{C}_{4} \mathrm{AF}$. Reconstructing the entire 1 million number file into a $3-\mathrm{D}$ cube in another scalable program, such as a finite element or lattice discrete particle model, would allow for further research into effects on crack propagation and applied forces. Possible methods to achieve this are currently being studied in the next phase of the MMFP research. 


\section{Conclusions}

Overall, the MMFP program has already increased capabilities in material characterization and the properties being collected may provide substantial benefit and time savings to other programs. VCCTL appears to have the ability to accurately predict hydrated microstructure from raw material properties and fills a much-needed role in the materials-by-design process. Moving on to higher scale models and correctly incorporating hydration model results will be key in progress moving forward.

The appendices provide processed characterization data for XRD, XRF, and particle-size experimentation results. The appendices represent the current data availability at the time of this report, but do not reflect the total amount of data to be collected over the course of the research effort. At the time of this report, the characterization data archive features the processed results for 29 particle size distributions, 27 XRF experiments, and $16 \mathrm{XRD}$ experiments. 


\section{Contact Information}

Permission to publish was granted by the Director, Geotechnical and Structures Laboratory. For questions related to this investigation, contact:

Jameson "Jay" D. Shannon

Geotechnical and Structures Laboratory

U.S. Army Engineer Research and Development Center Office: 601.634.2218 / Email: Jameson.Shannon@usace.army.mil Mail: 3909 Halls Ferry Rd., Attn: CEERD-GMC, Vicksburg, MS 39180

Cody M. Strack

Geotechnical and Structures Laboratory

U.S. Army Engineer Research and Development Center

Office: 601.634.7448 / Email: Cody.M.Strack@erdc.dren.mil

Mail: 3909 Halls Ferry Rd., Attn: CEERD-GMC, Vicksburg, MS 39180

Robert M. Moser

Geotechnical and Structures Laboratory

U.S. Army Engineer Research and Development Center

Office: 601.634.3261 / Email: Robert.D.Moser@usace.army.mil

Mail: 3909 Halls Ferry Rd., Attn: CEERD-GMC, Vicksburg, MS 39180 


\section{References}

American Society of Testing and Materials (ASTM). 2018. Standard test method for determination of the proportion of phases in portland cement and portlandcement clinker using x-ray powder diffraction analysis. Designation C1365-18. West Conshohocken, PA: ASTM International.

Bentz, D. P. 1995. A three-dimensional cement hydration and microstructure program. Hydration rate, heat of hydration, and chemical shrinkage. NISTIR 5756. Washington, DC: U.S. Department of Commerce.

Bentz, D. P. 1997a. Three-dimensional computer simulation of portland cement hydration and microstructure development. Journal of the American Ceramic Society 8o(1):3-21.

Bentz, D. P. 1997b. Guide to using CEMHYD3D: A three dimensional cement hydration and microstructure development modelling package. Gaithersburg, MD: Building and Fire Research Laboratory.

Bentz, D. P., J. R. Clifton, and K. A. Snyder. 1996. A prototype computer-integrated knowledge system: predicting service life of chloride-exposed steel-reinforced concrete. Concrete International 18(12):42-47.

Garboczi, E. J., J. W. Bullard, and D. P. Bentz. 2004. Virtual testing of cement and concrete. Concrete International 39(12)33-37. 


\section{Appendix A: Particle-Size Distribution Results}

Figure A1. PSD Results of Cement (150146).

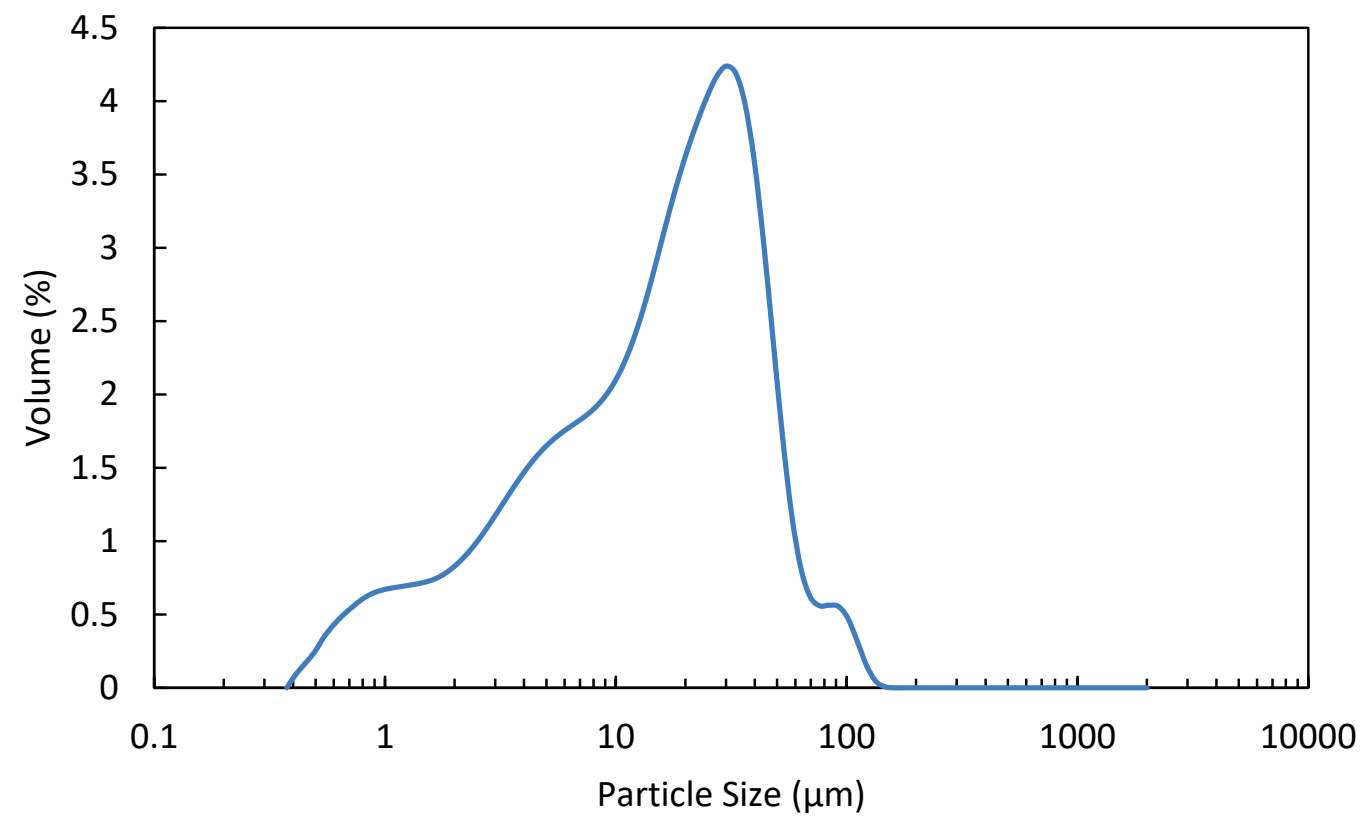

Figure A2. PSD Results of Cement (150147).

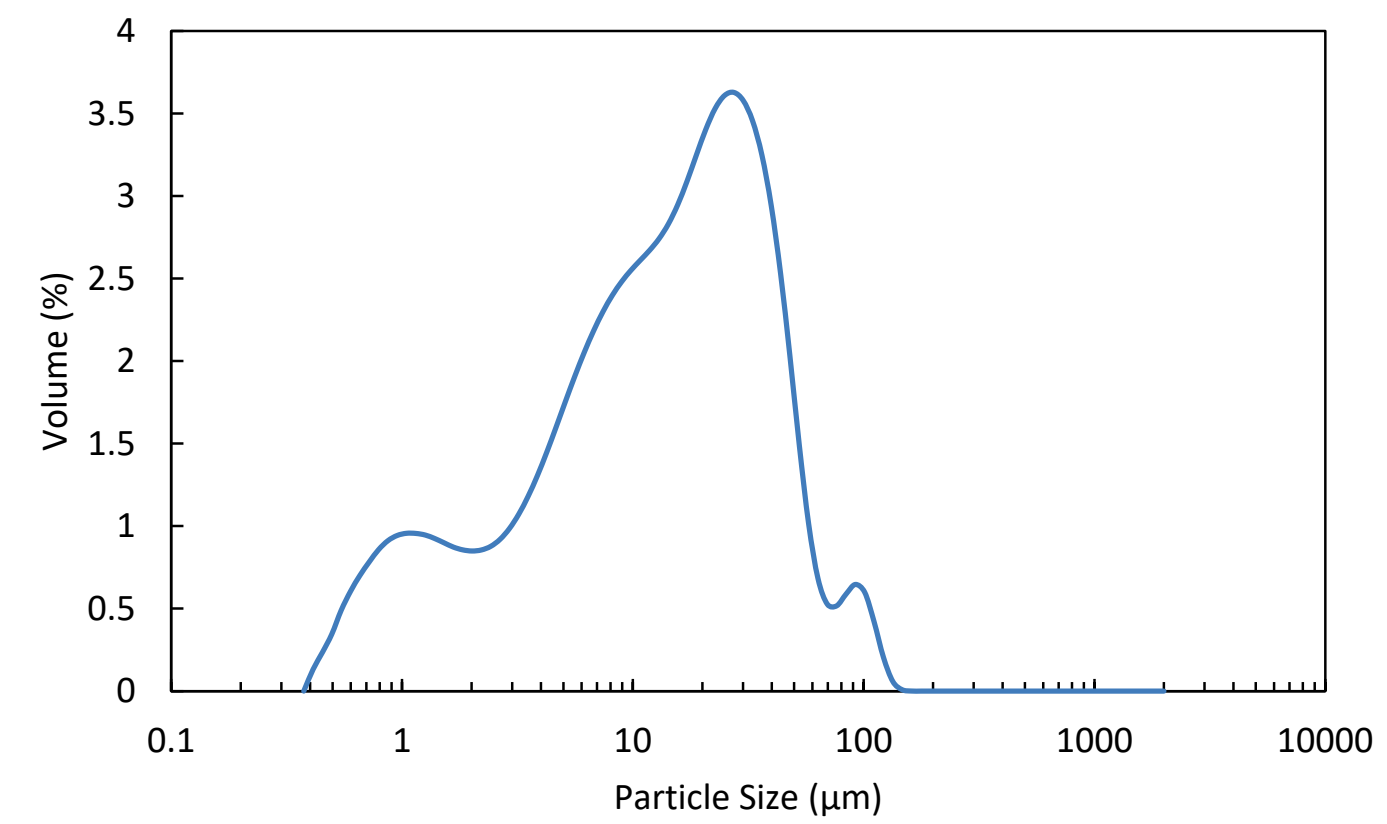


Figure A3. PSD Results of Cement (150148).

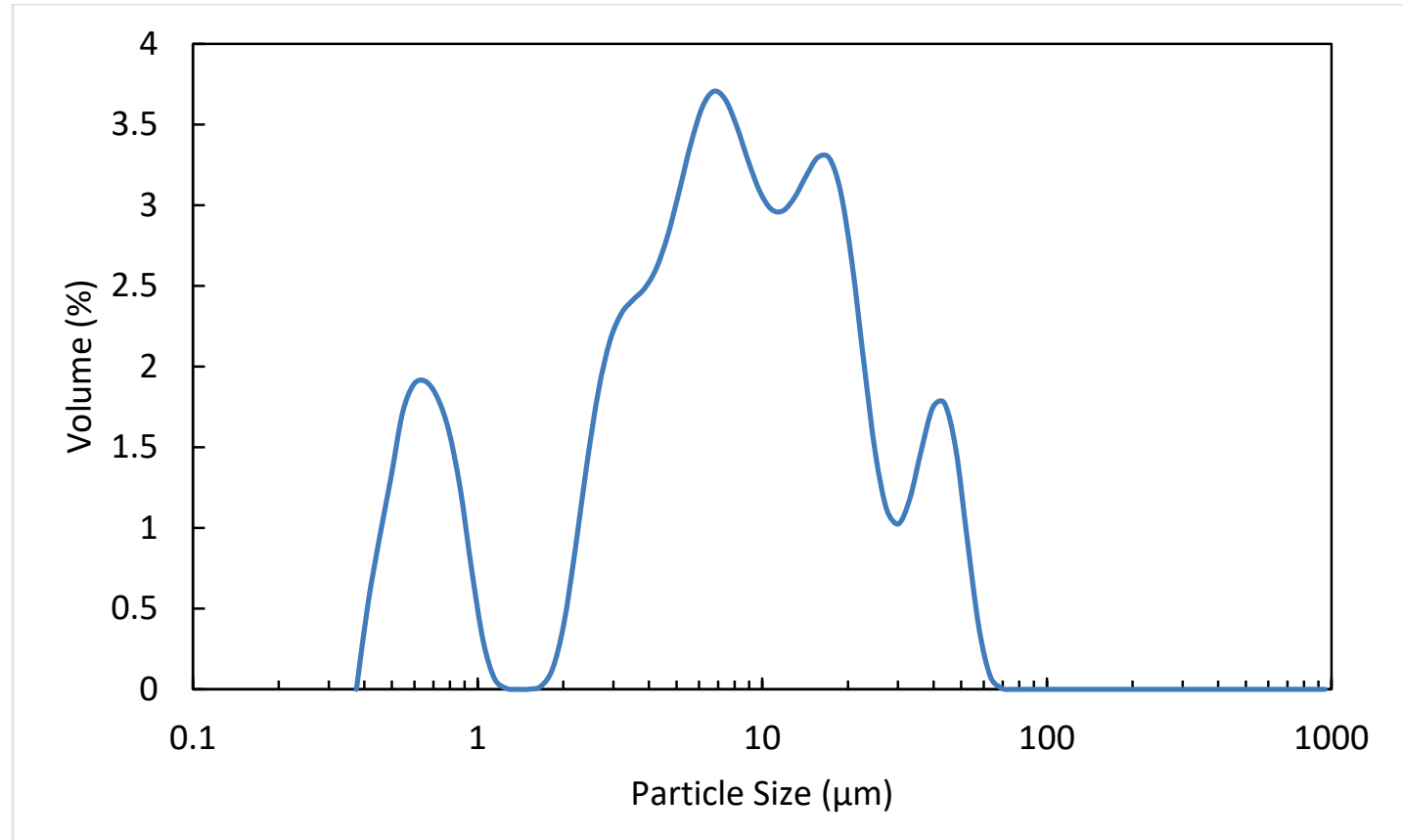

Figure A4. PSD Results of Cement (160160).

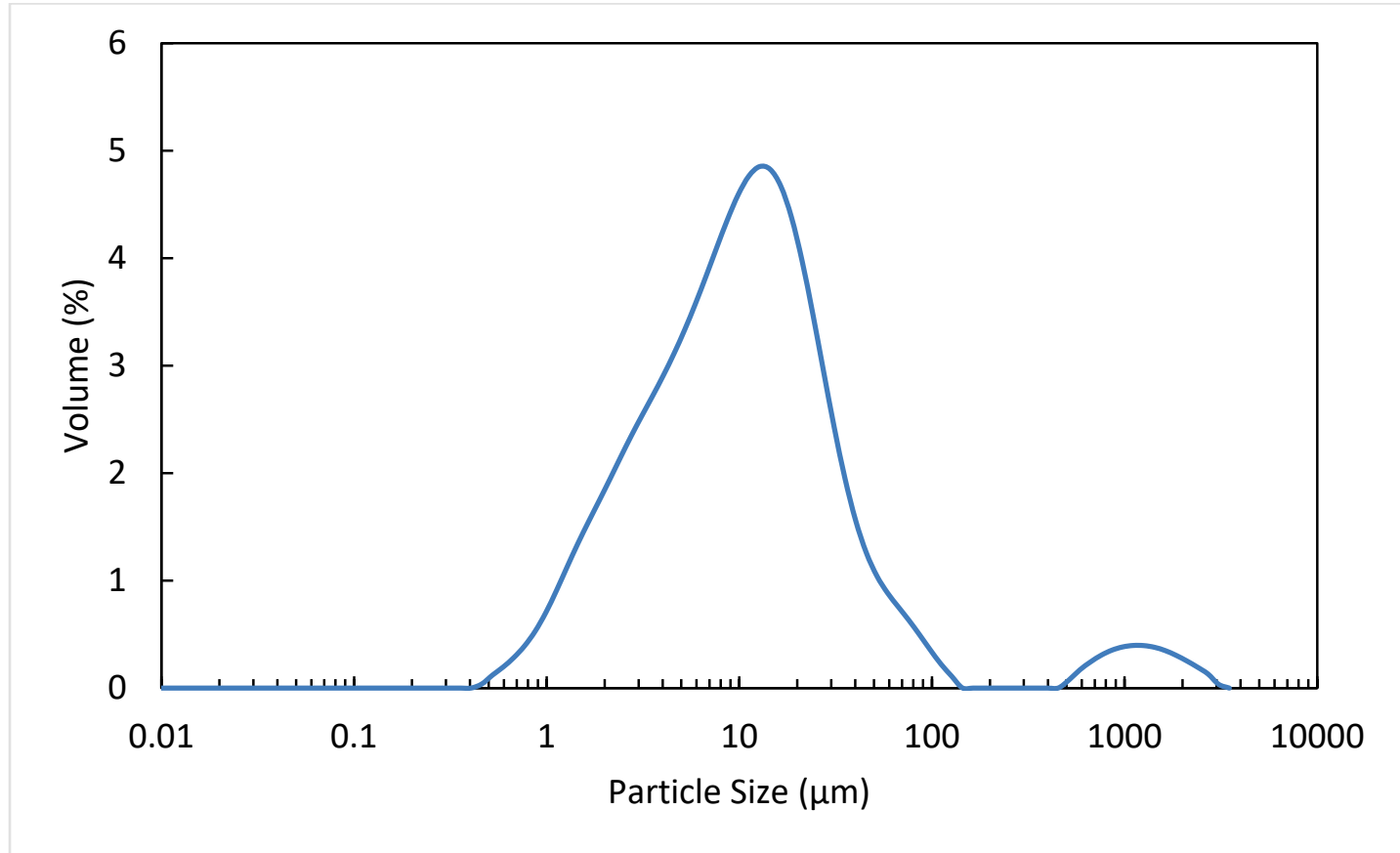


Figure A5. PSD Results of Cement (170001).

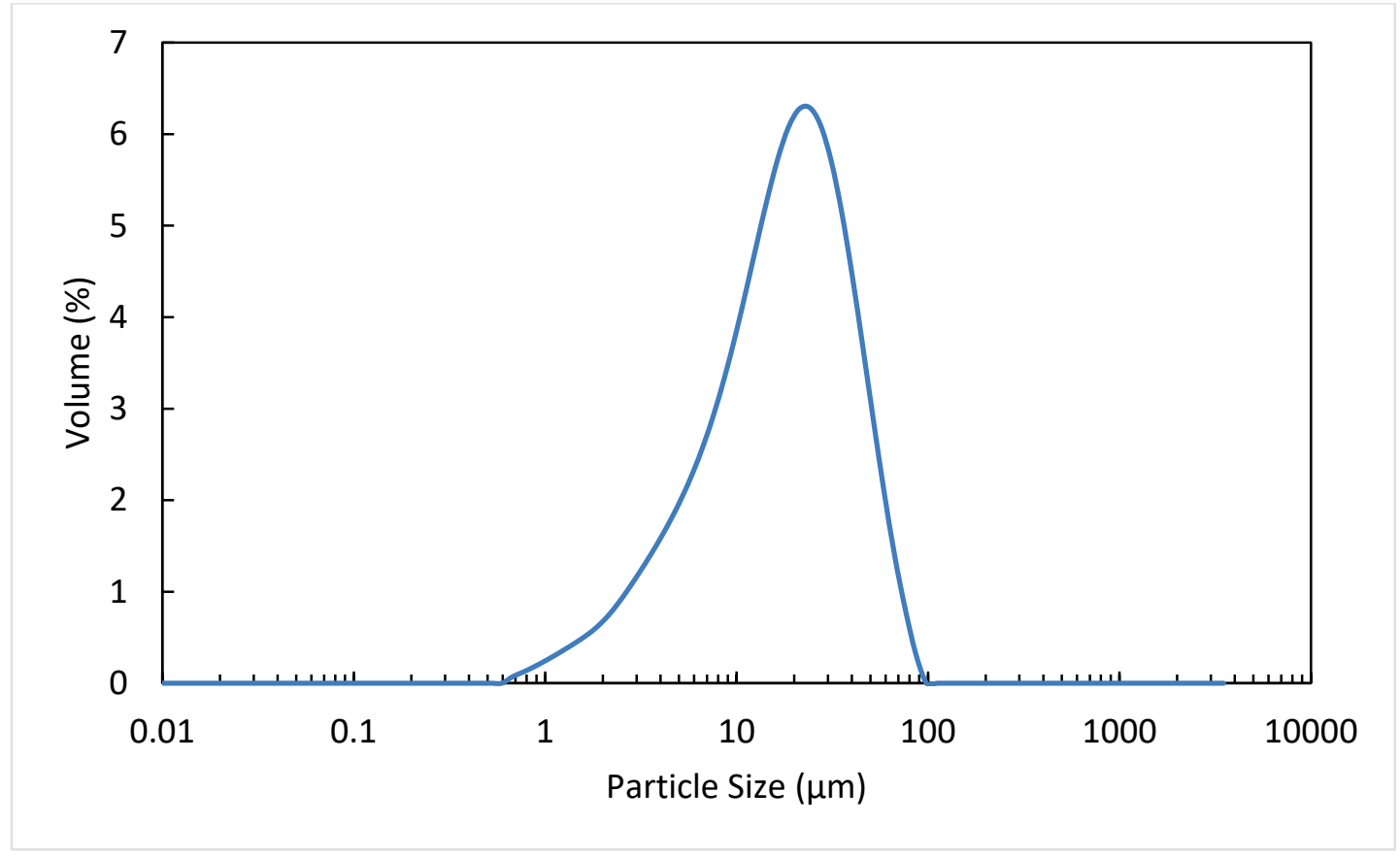

Figure A6. PSD Results of Cement (170002).

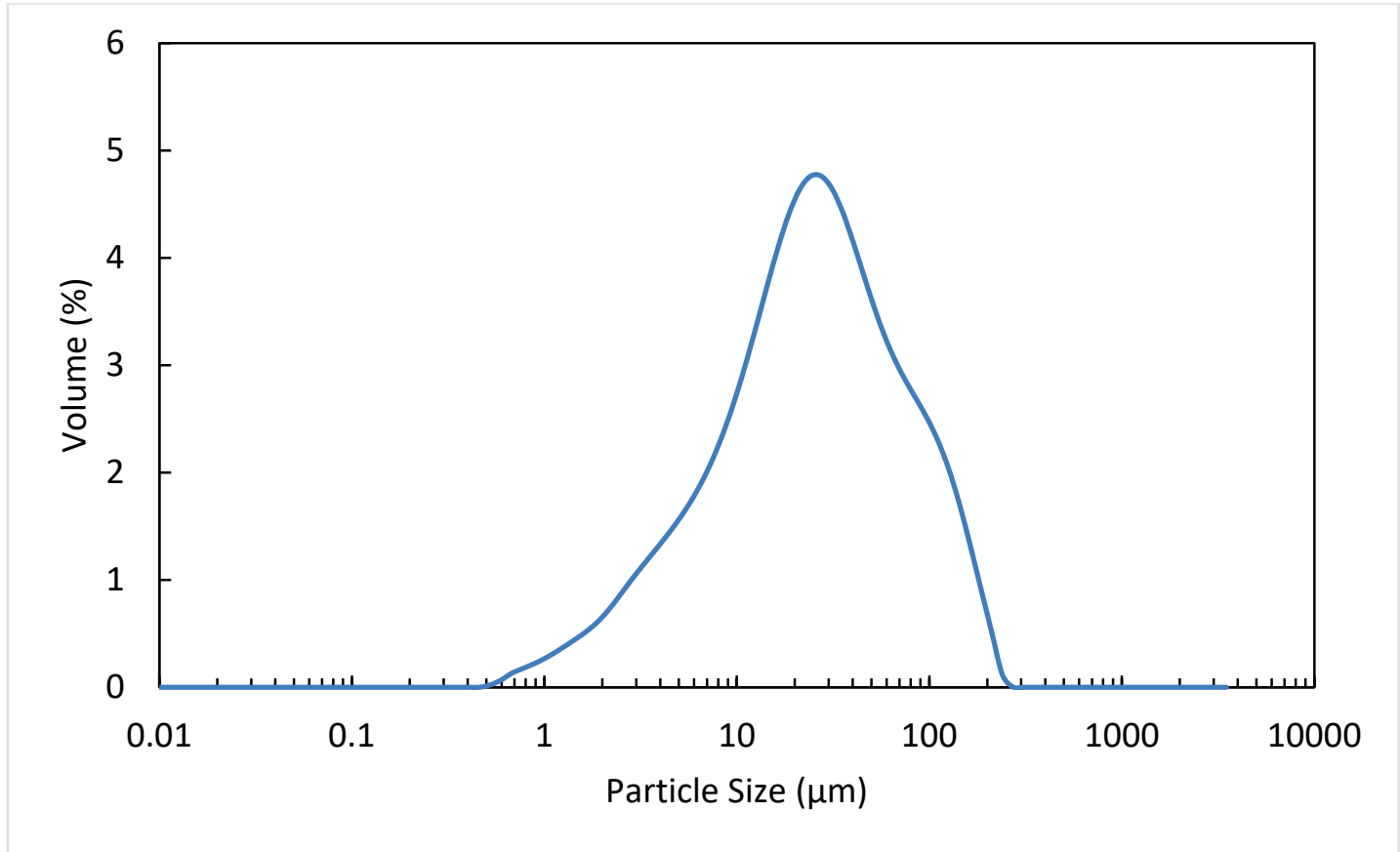


Figure A7. PSD Results of Cement (170009).

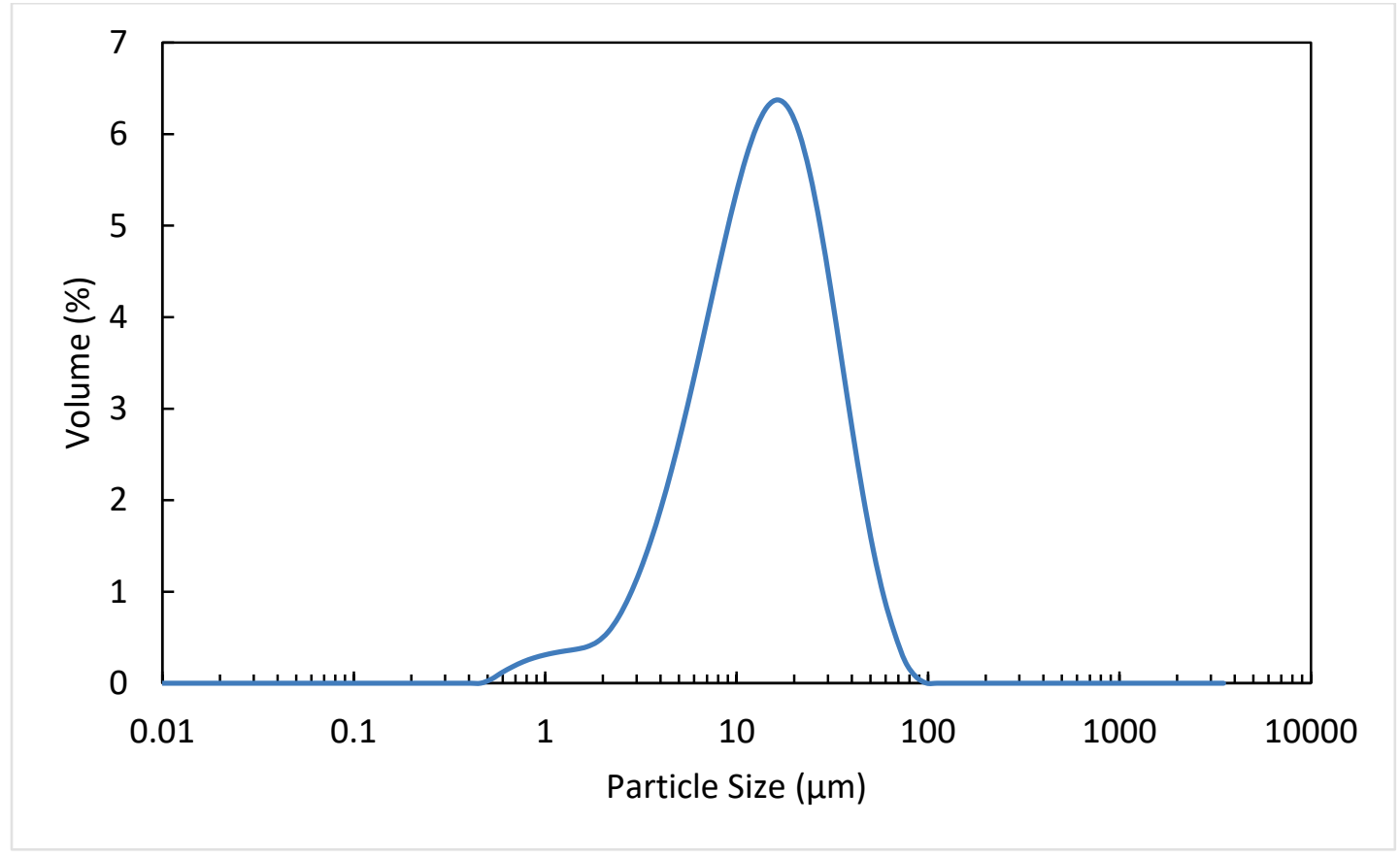

Figure A8. PSD Results of Cement (170010).

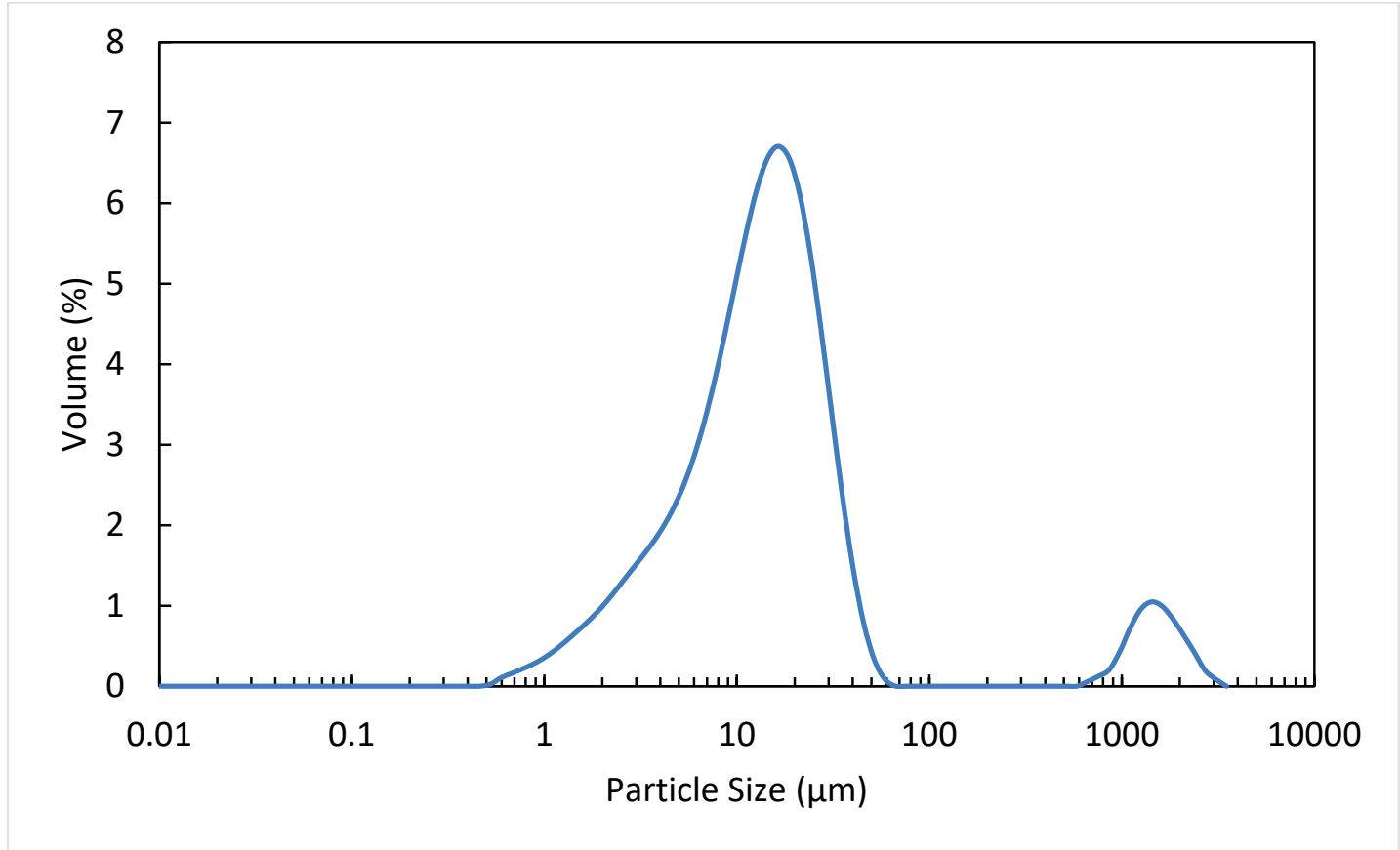


Figure A9. PSD Results of Cement (170052).

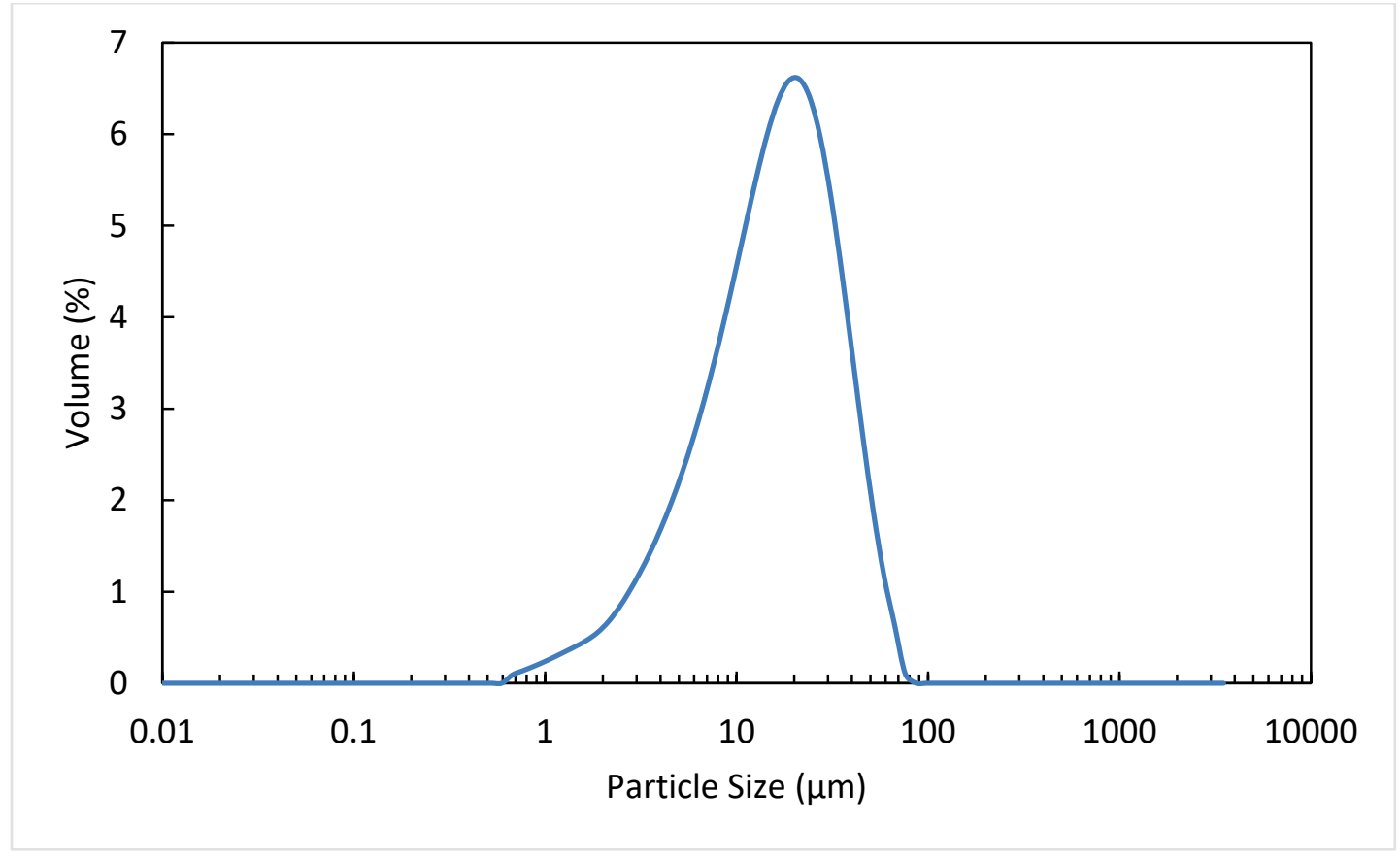

Figure A10. PSD Results of Cement (170065).

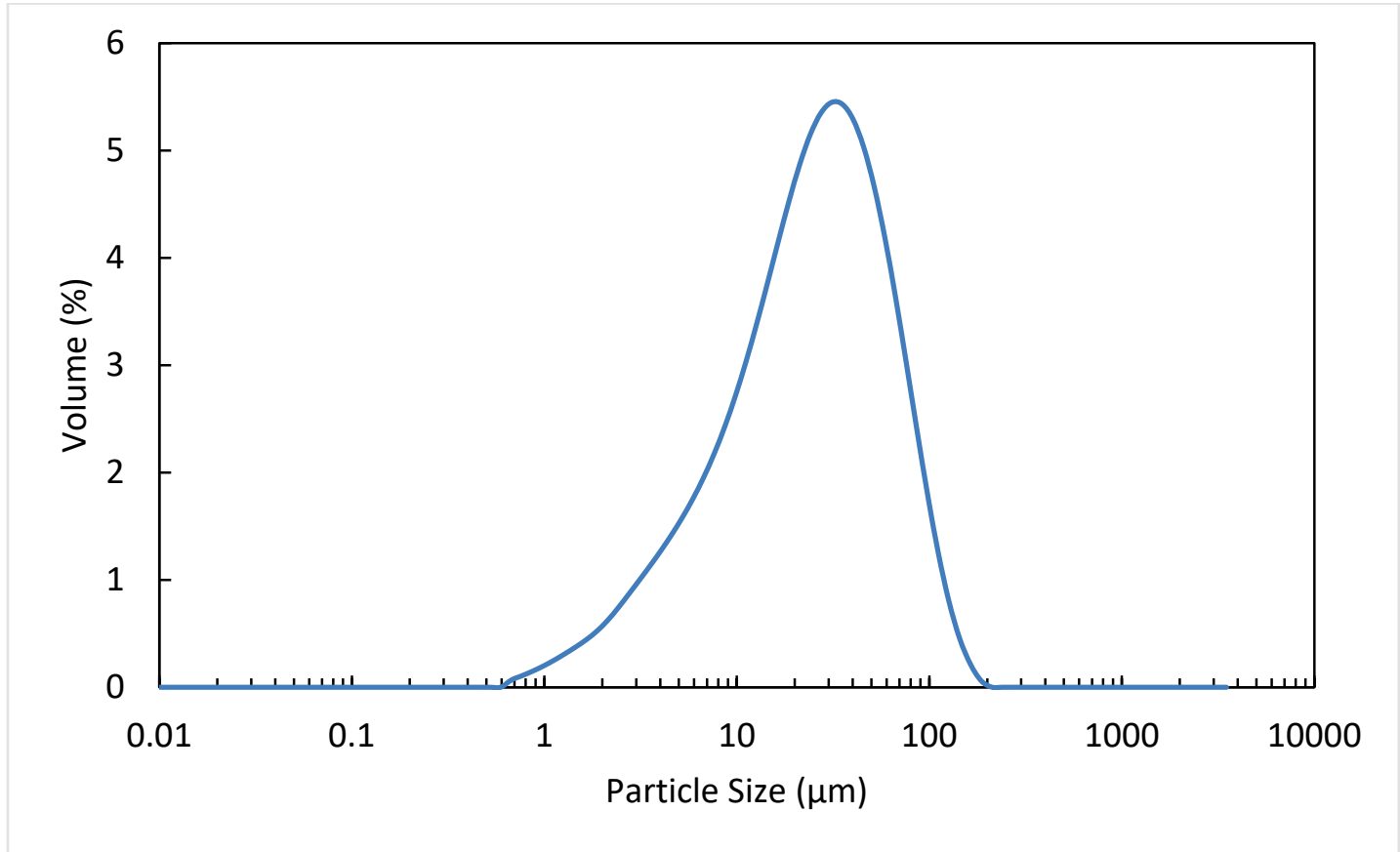


Figure A11. PSD Results of Metakaolin (140015).

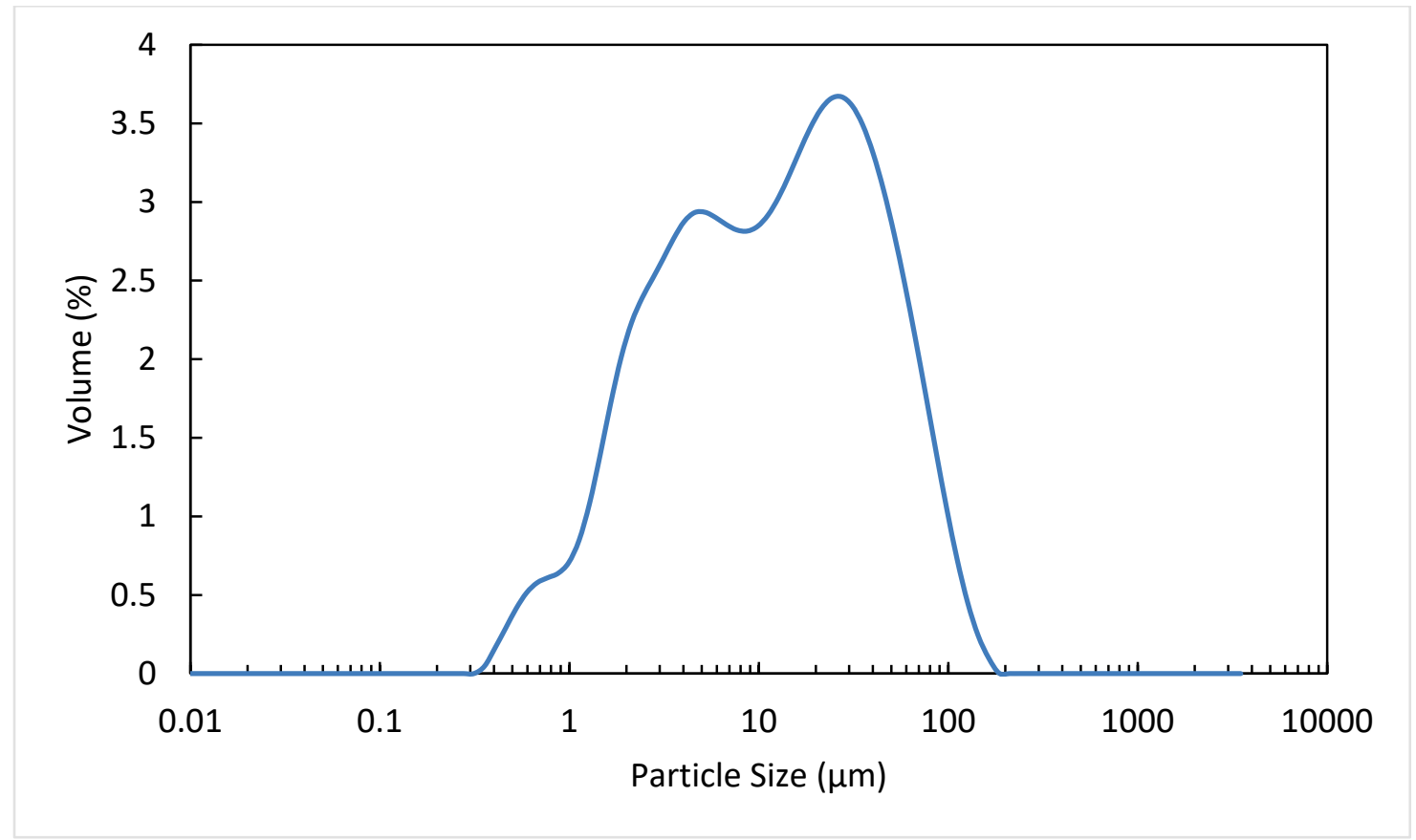

Figure A12. PSD Results of Metakaolin (150149).

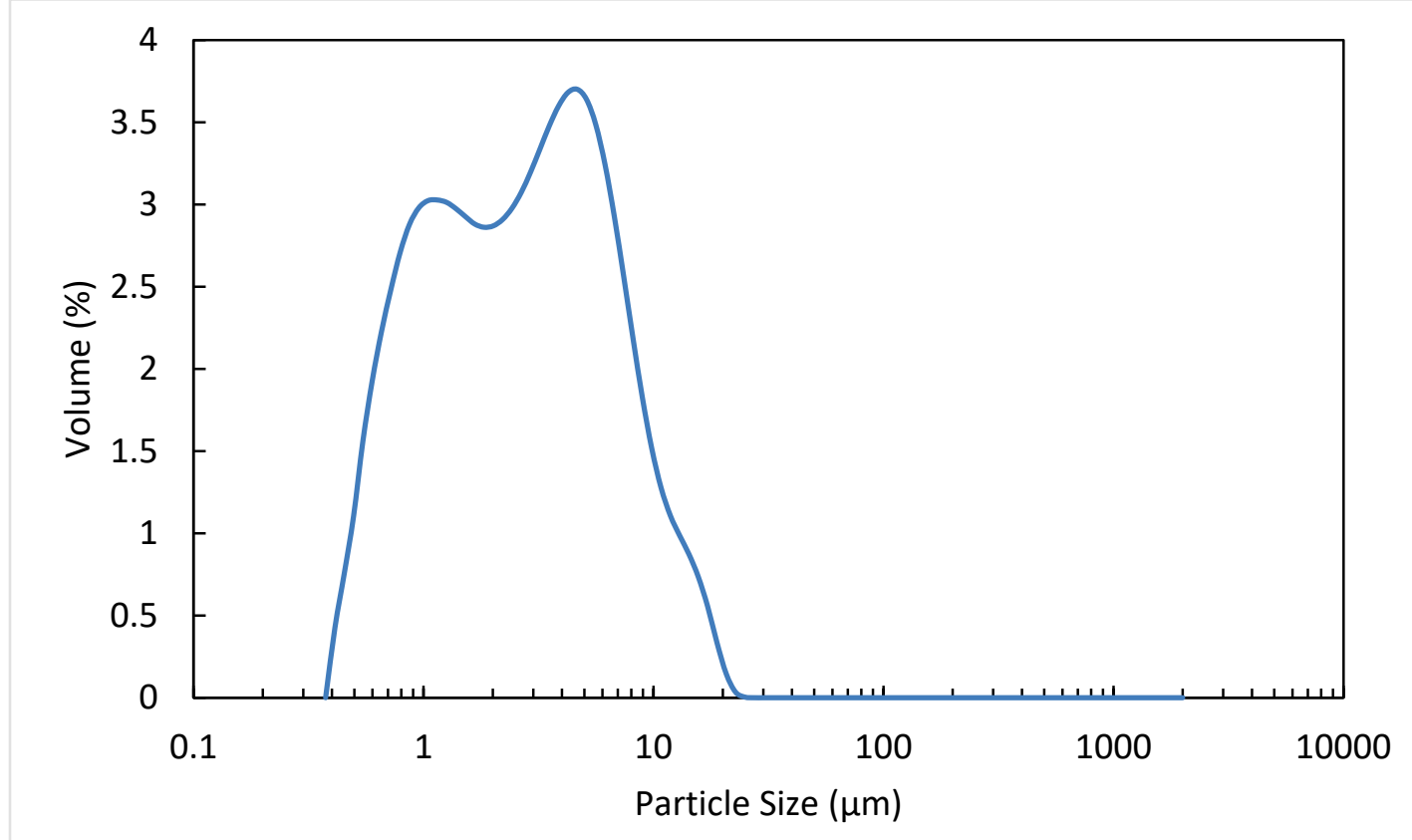


Figure A13. PSD Results of Metakaolin (170004).

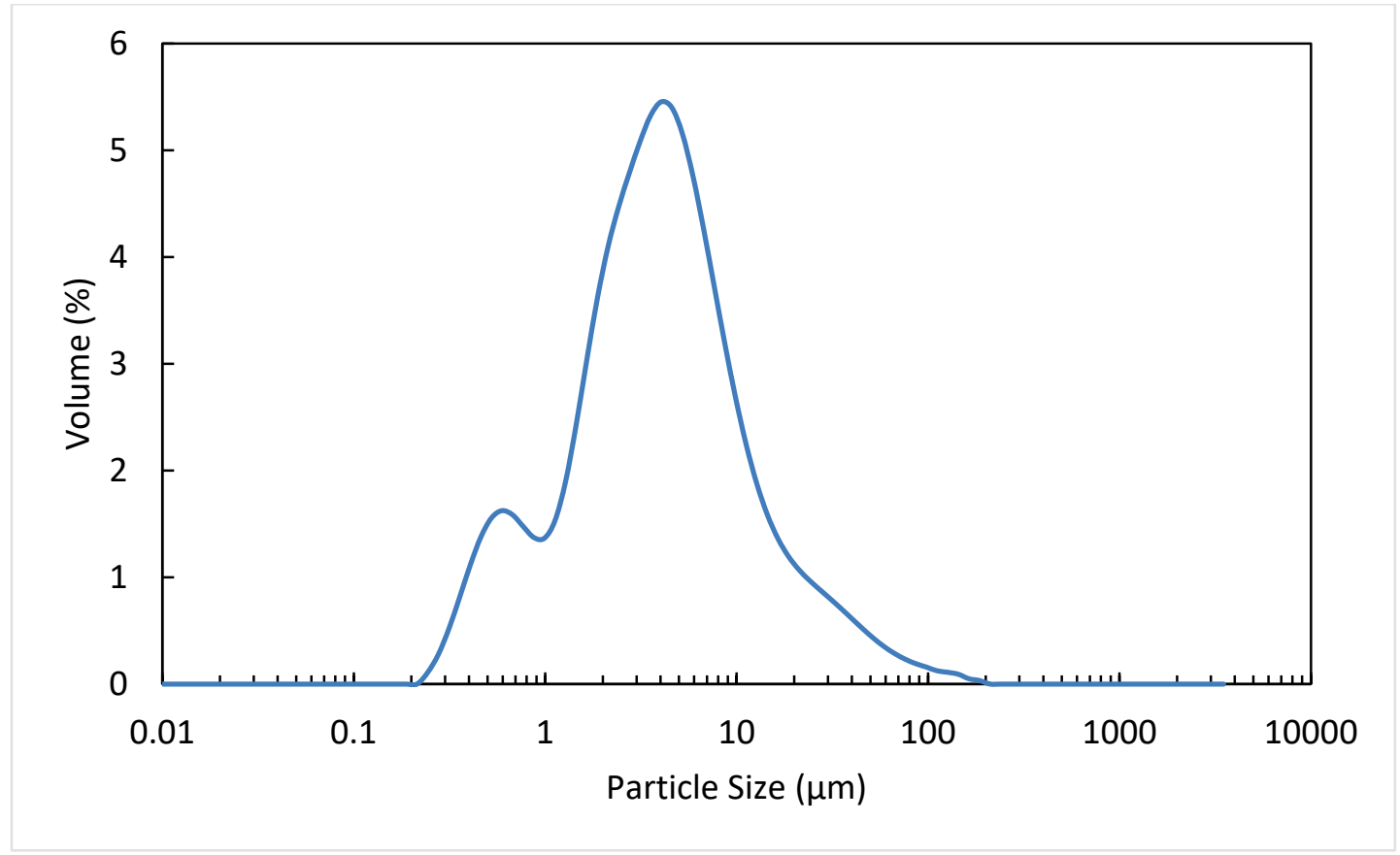

Figure A14. PSD Results of Silica Fume (130008).

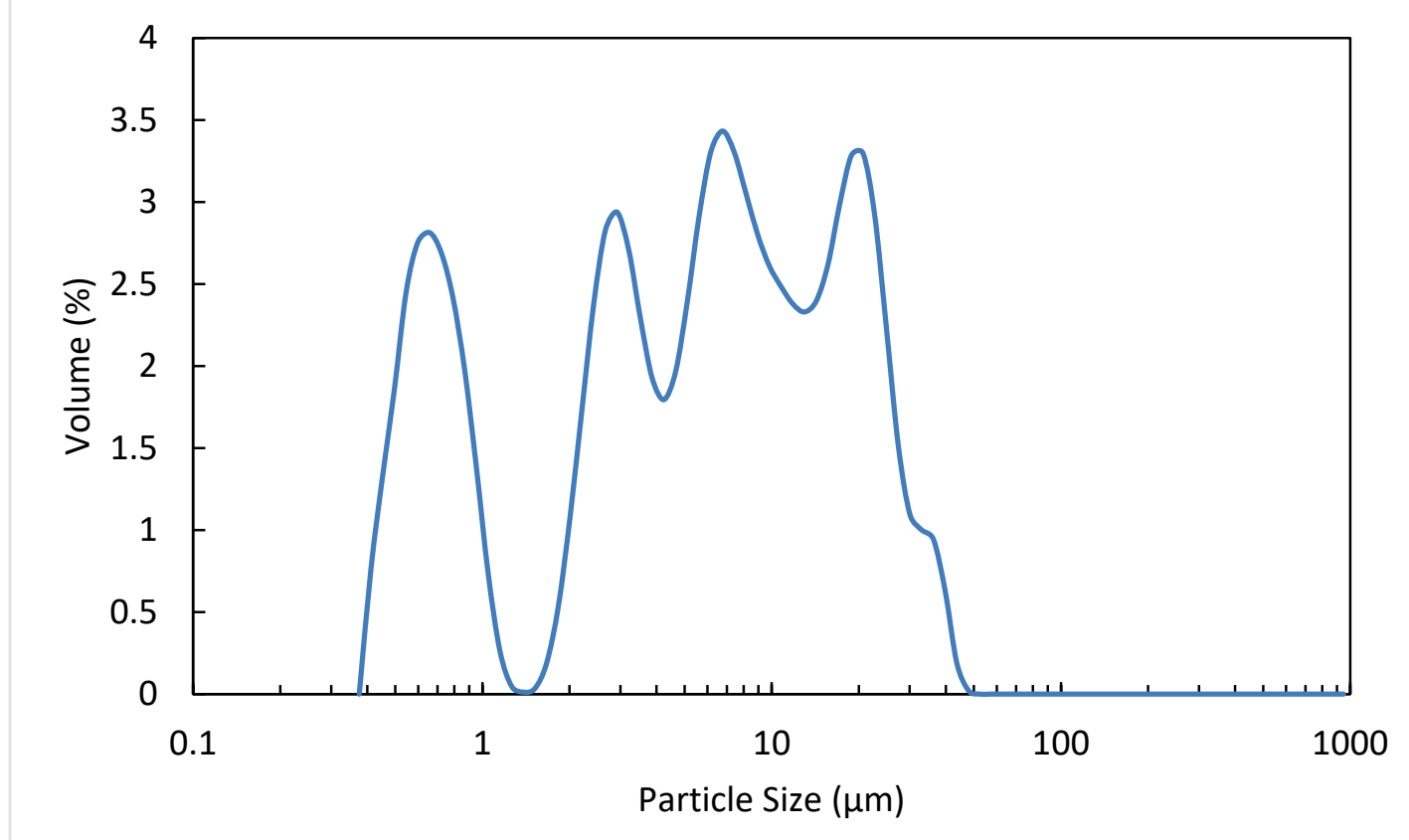


Figure A15. PSD Results of Silica Fume (140092).

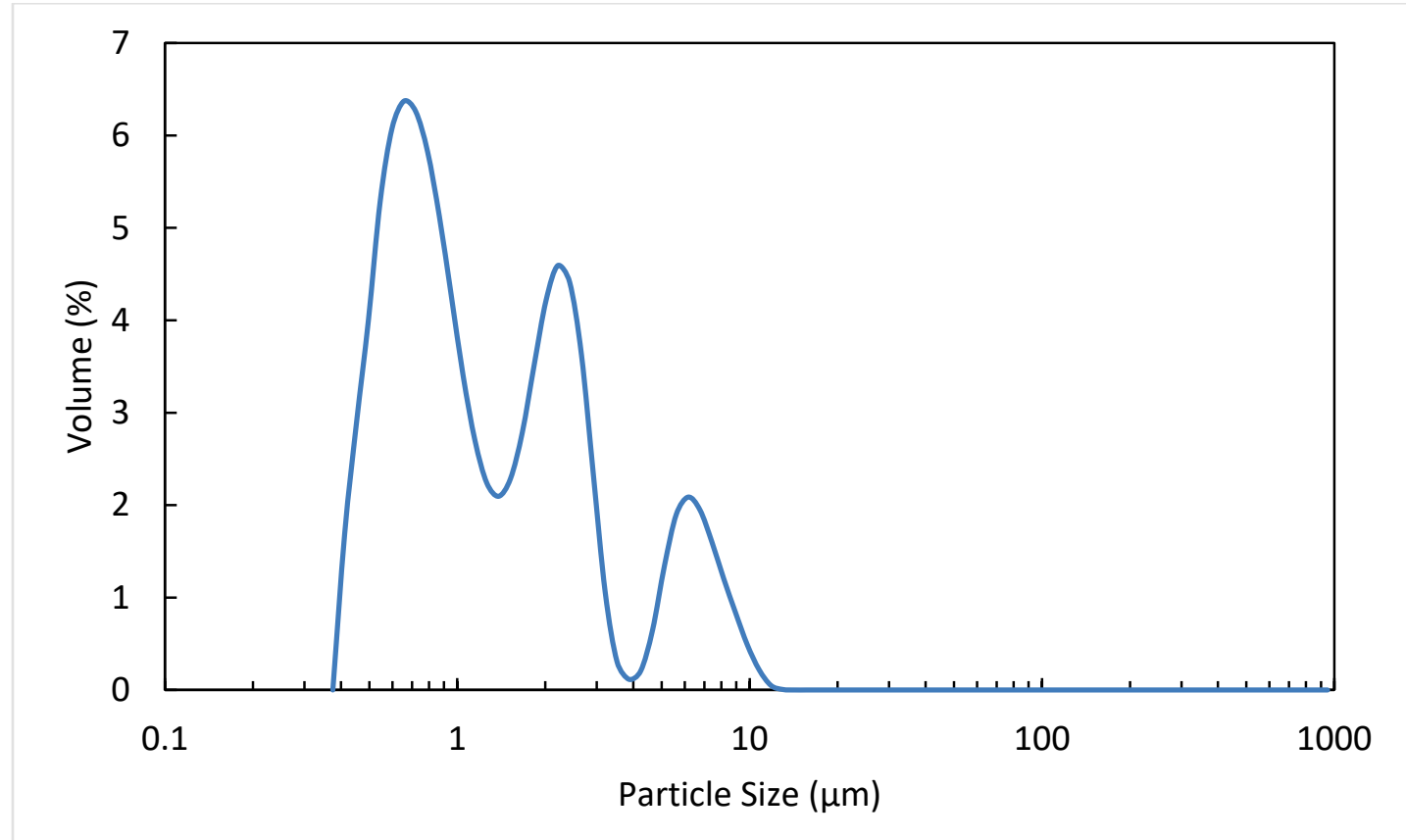

Figure A16. PSD Results of Silica Fume (130050).

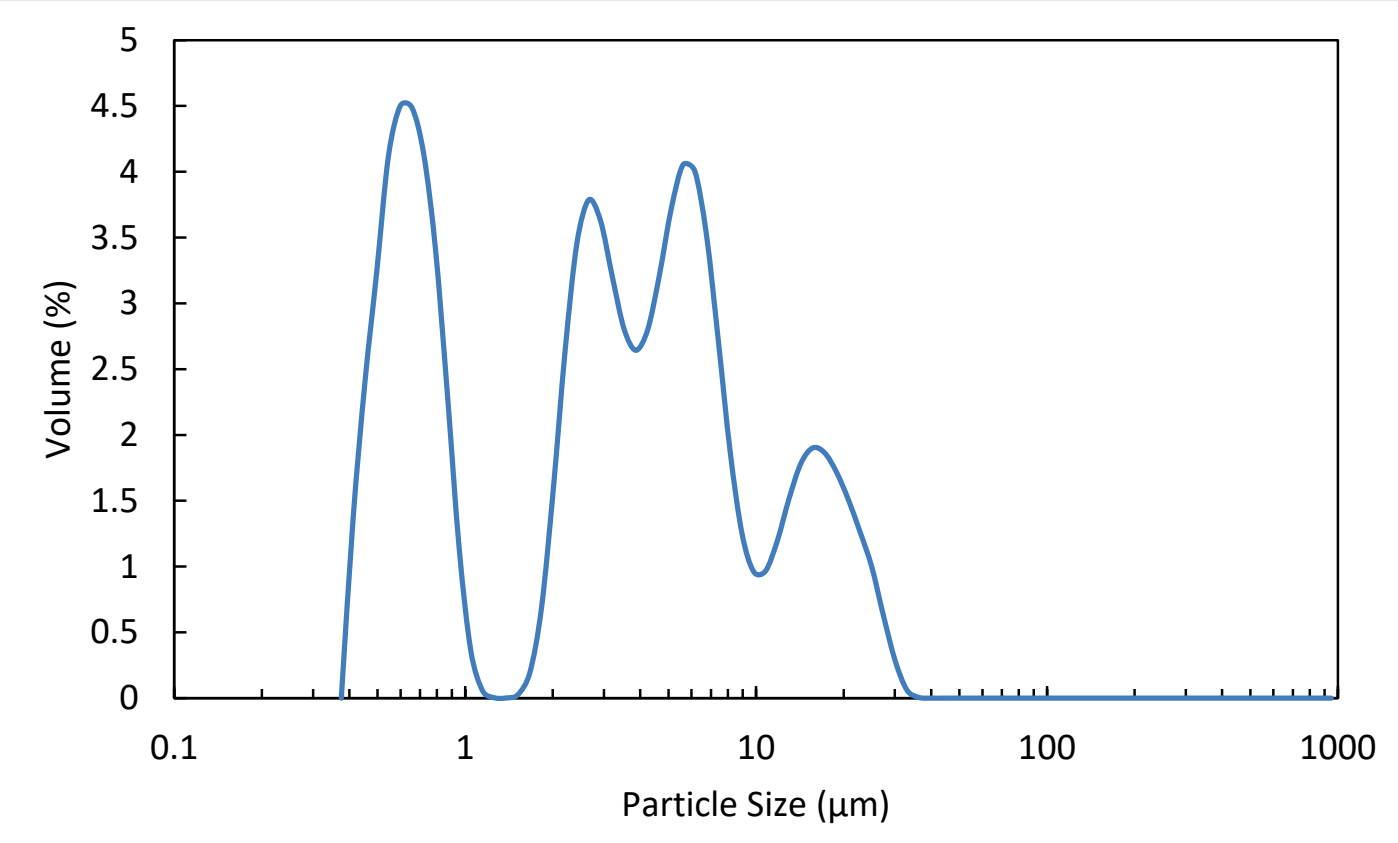


Figure A17. PSD Results of Silica Fume (140093).

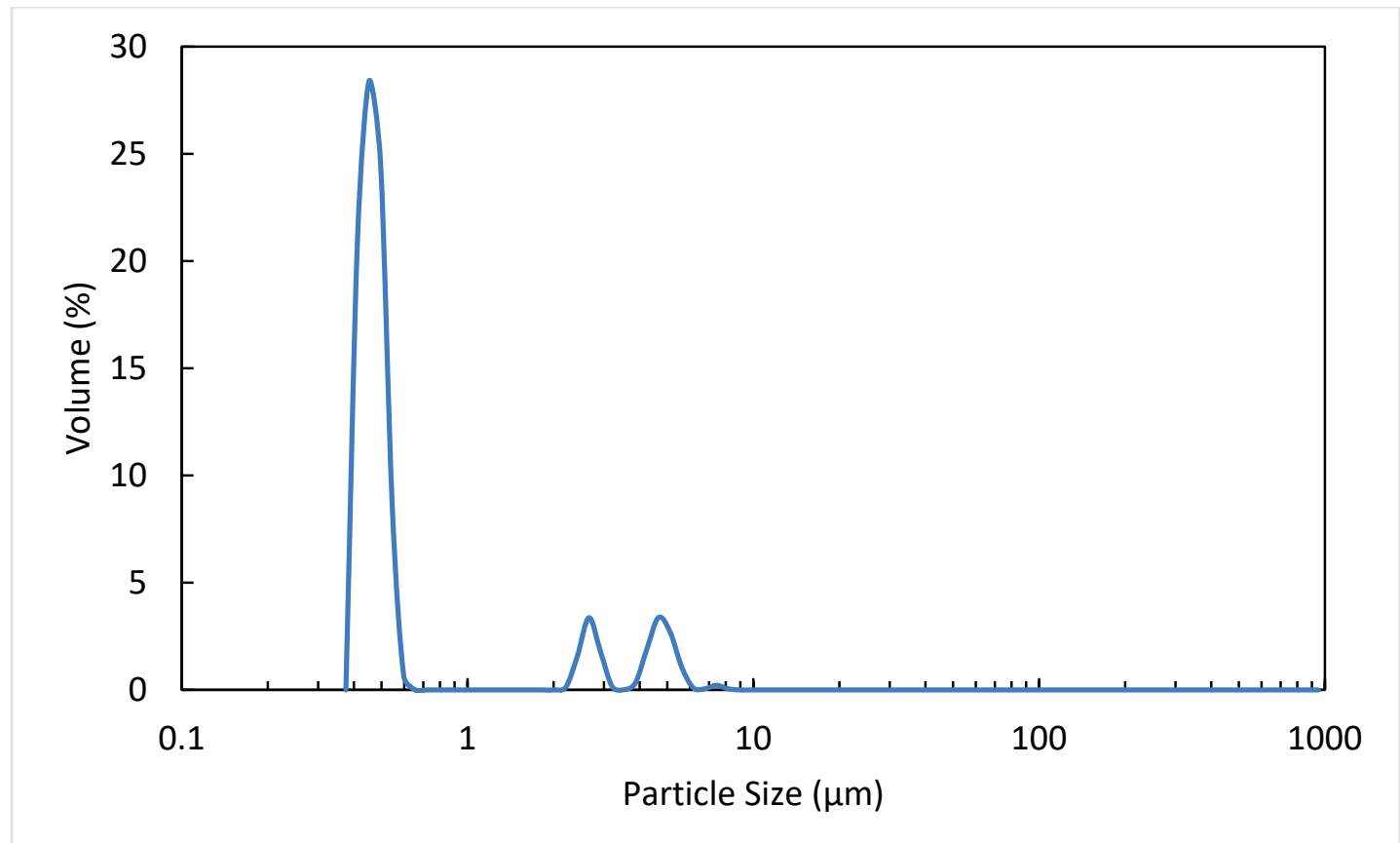

Figure A18. PSD Results of Silica Fume (140094).

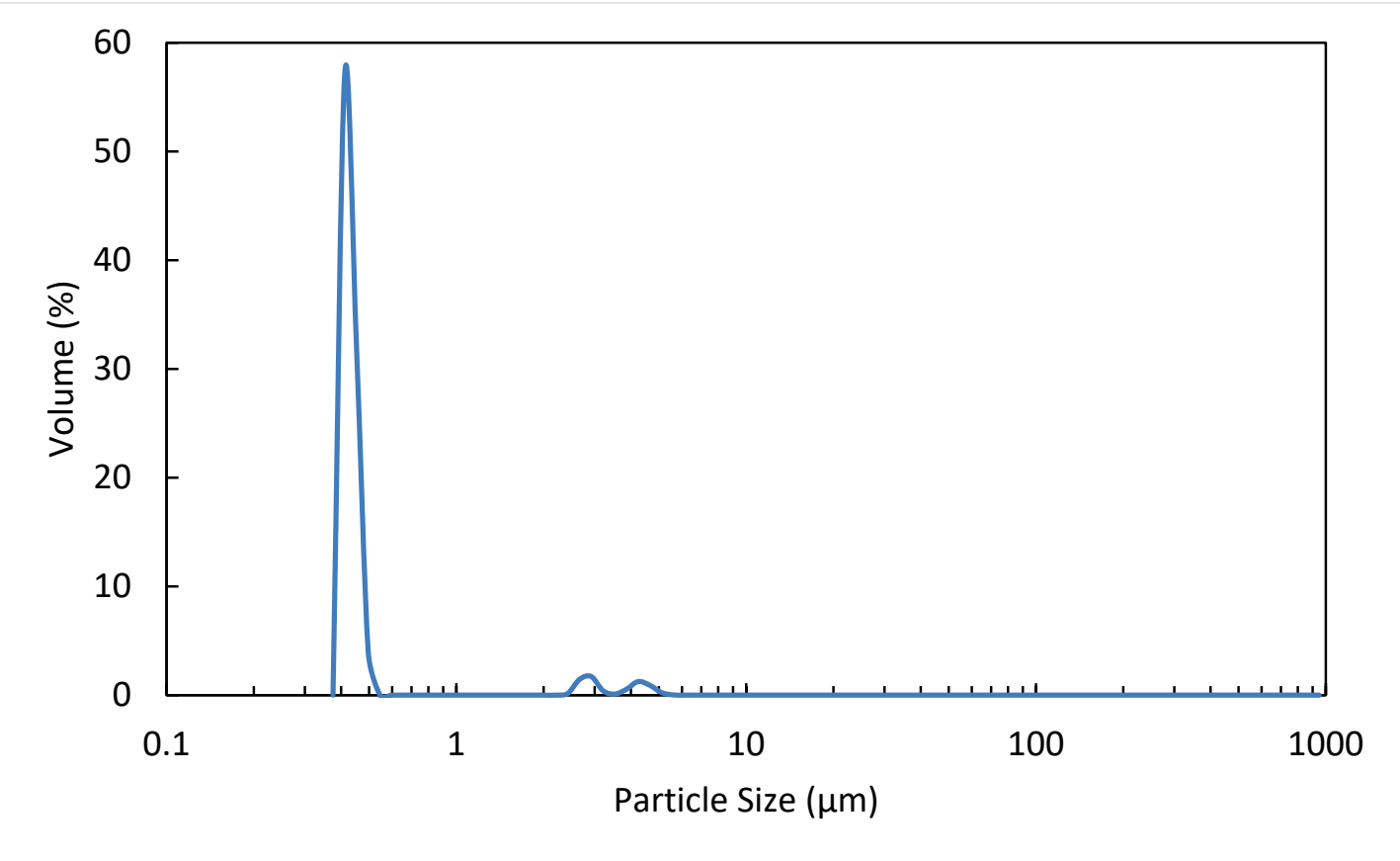


Figure A19. PSD Results of Silica Fume (150048).

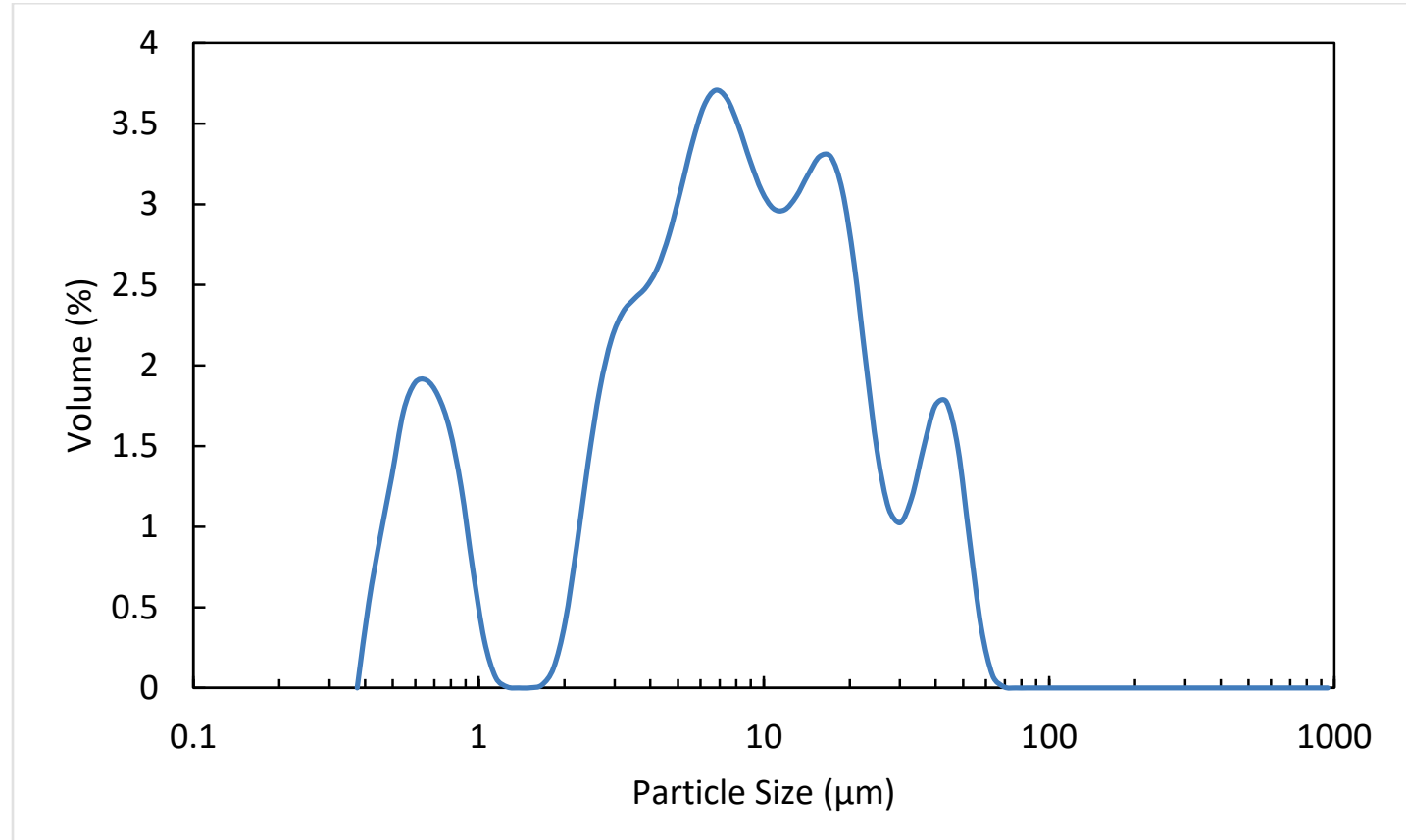

Figure A20. PSD Results of Silica Fume (150049).

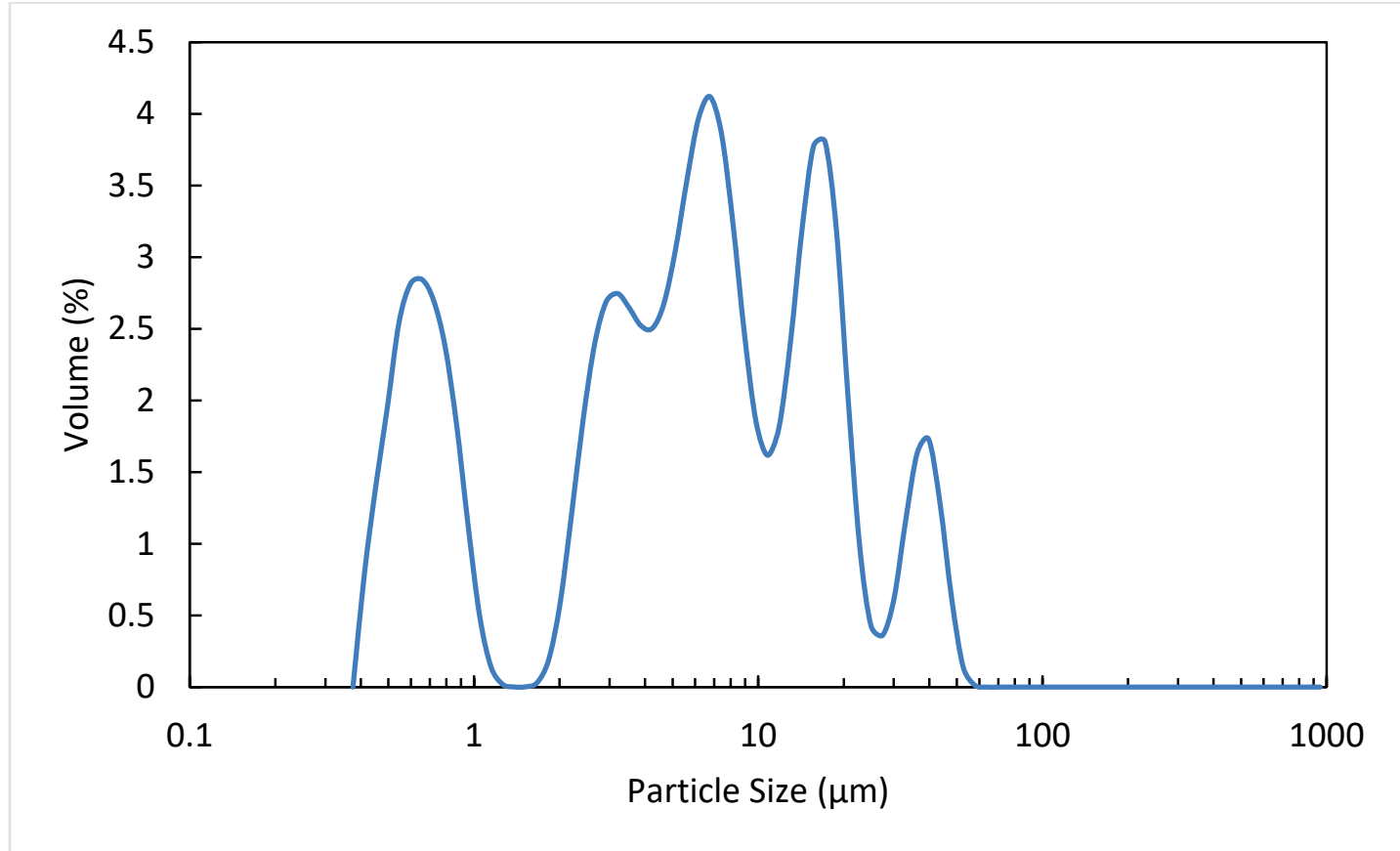


Figure A21. PSD Results of Silica Fume (150050).

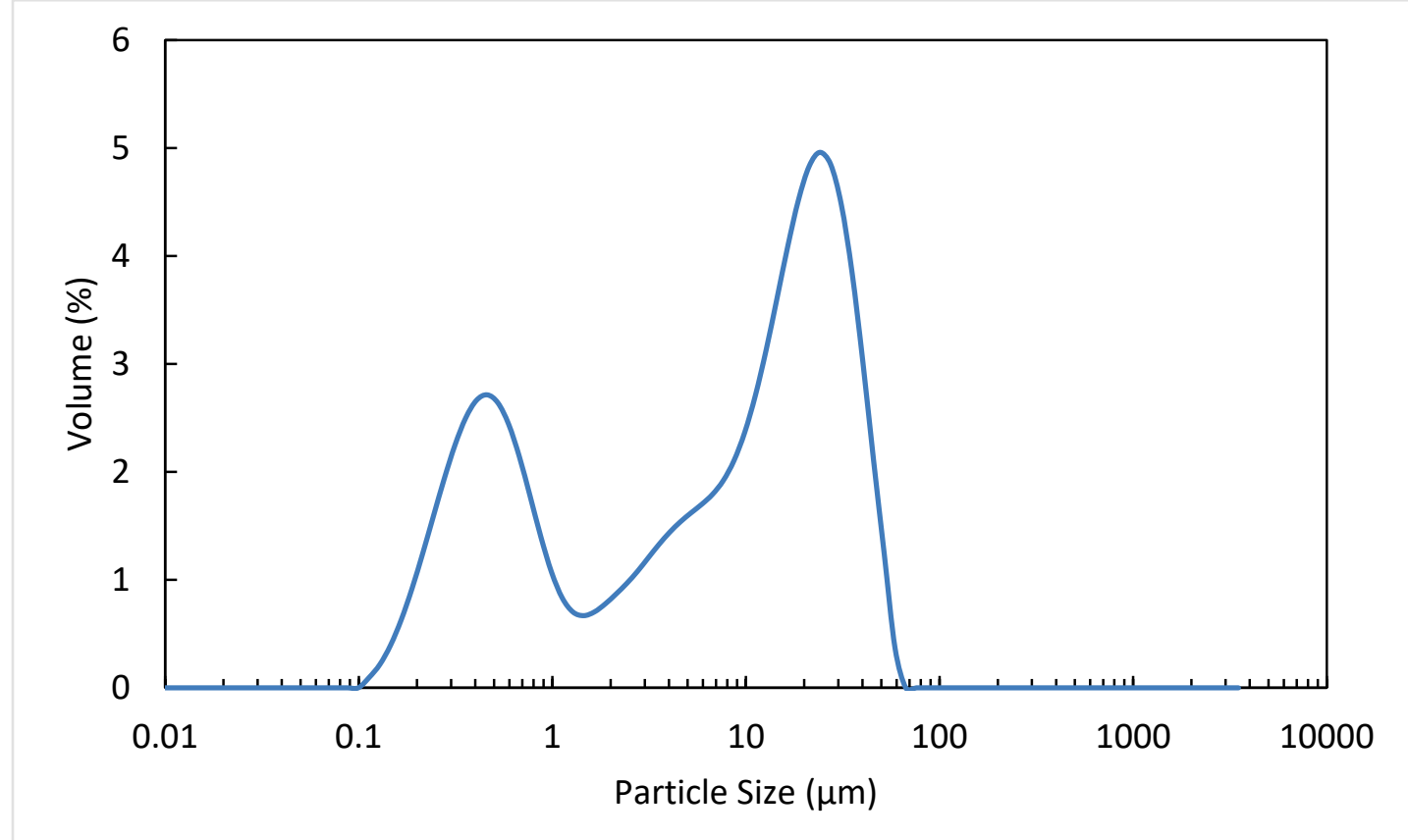

Figure A22. PSD Results of Silica Fume (150051).

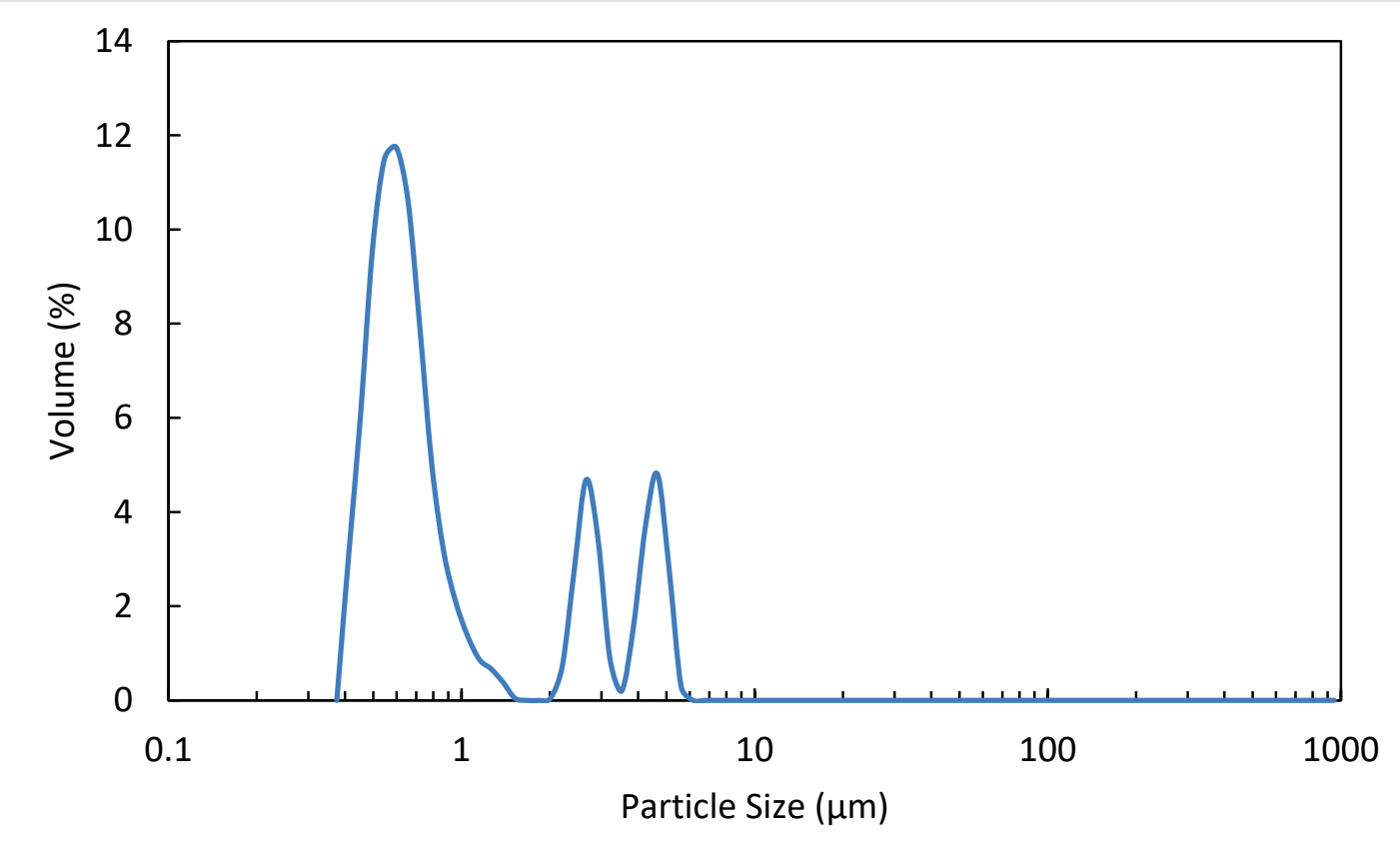


Figure A23. PSD Results of Silica Fume (150052).

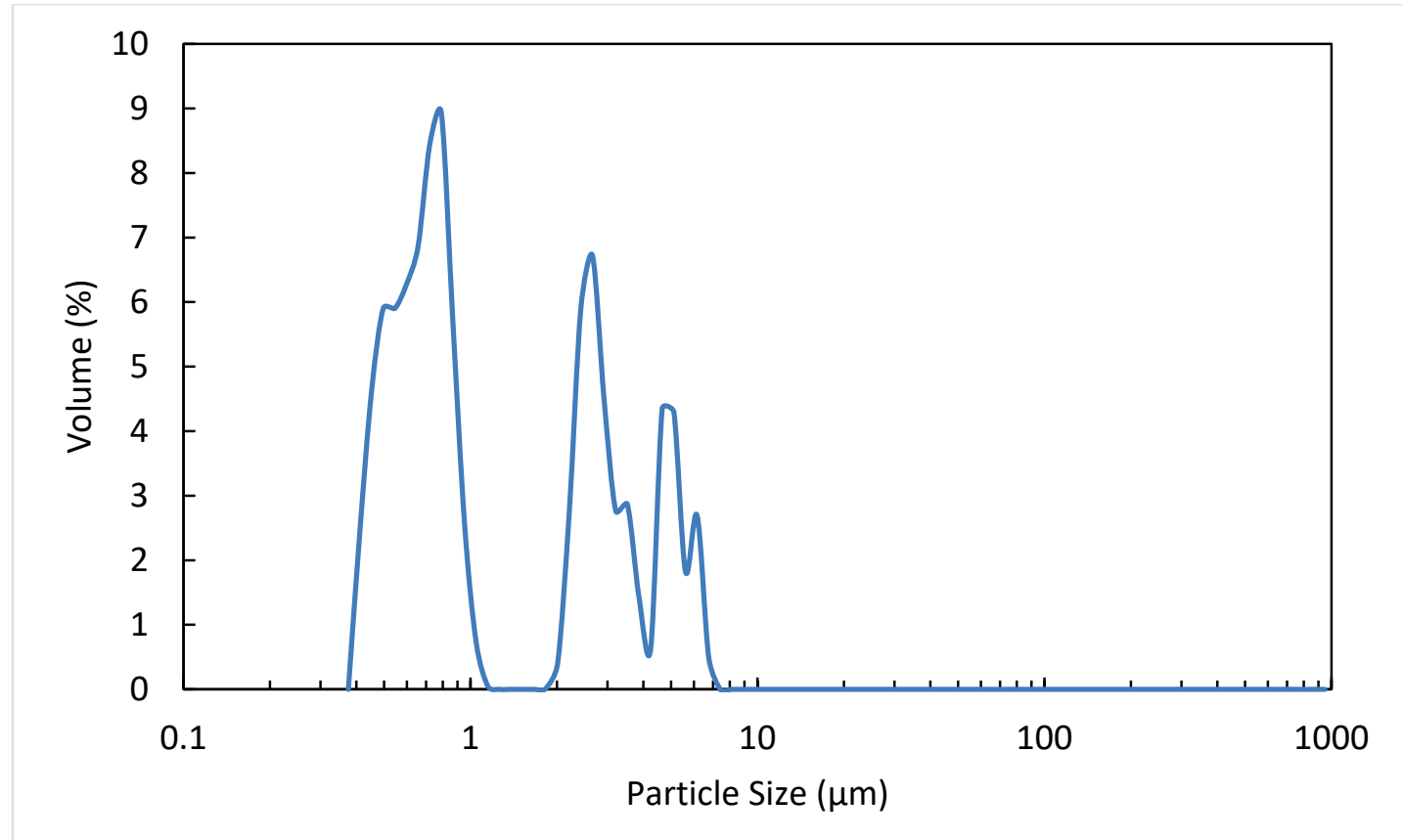

Figure A24. PSD Results of Silica Fume (170003).

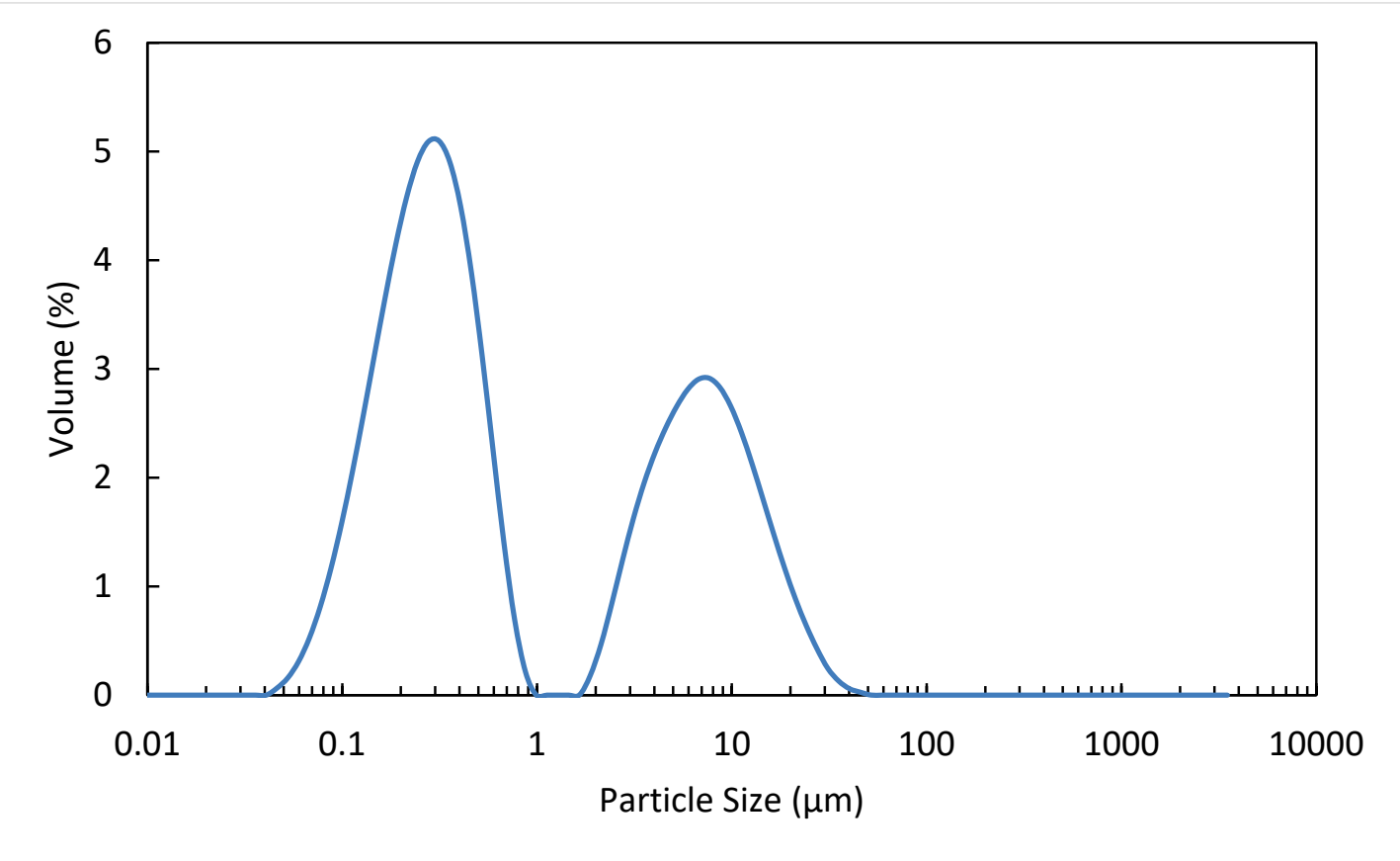


Figure A25. PSD Results of Silica Fume (Guam F10).

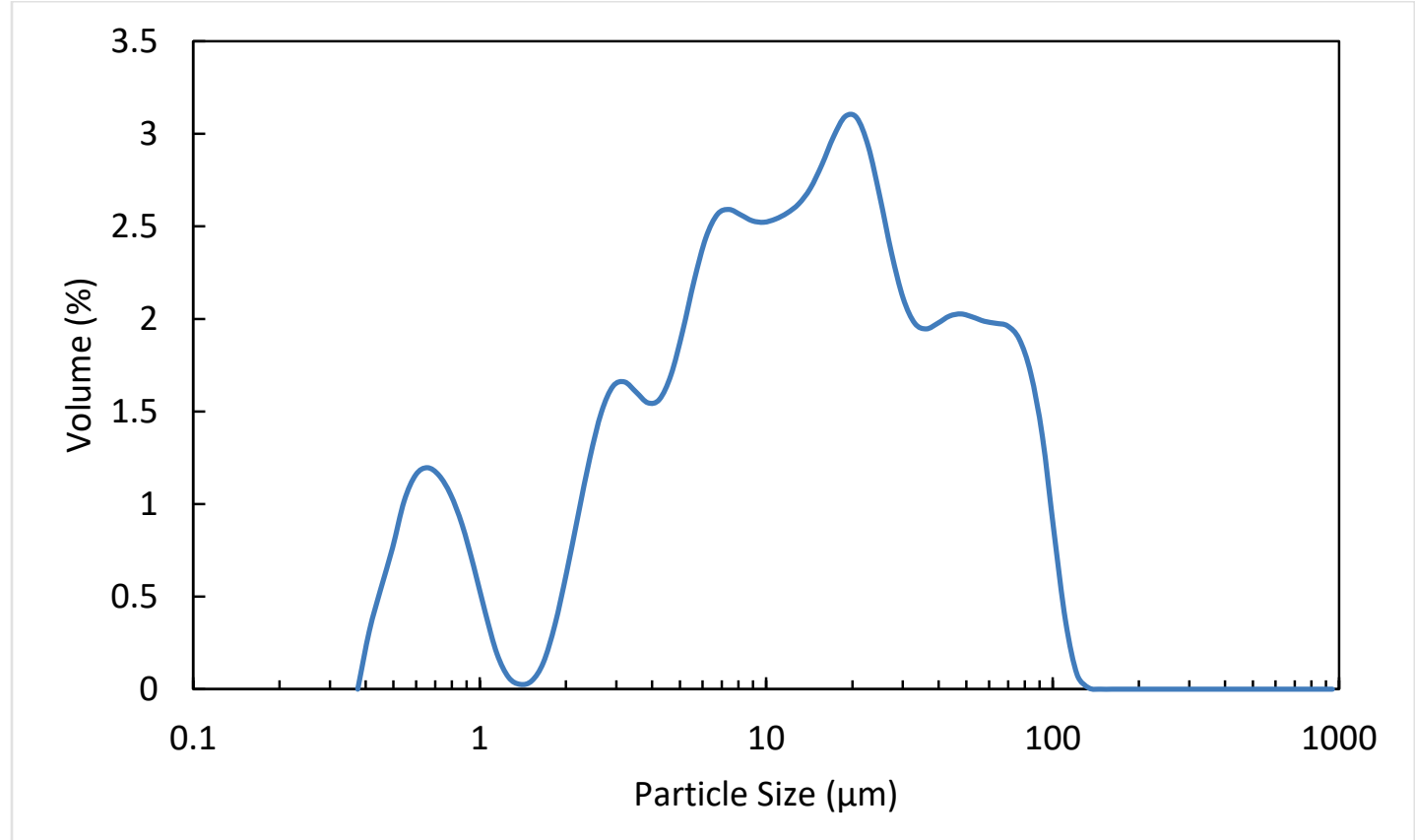

Figure A26. PSD Results of Silica Fume (Ecotech85).

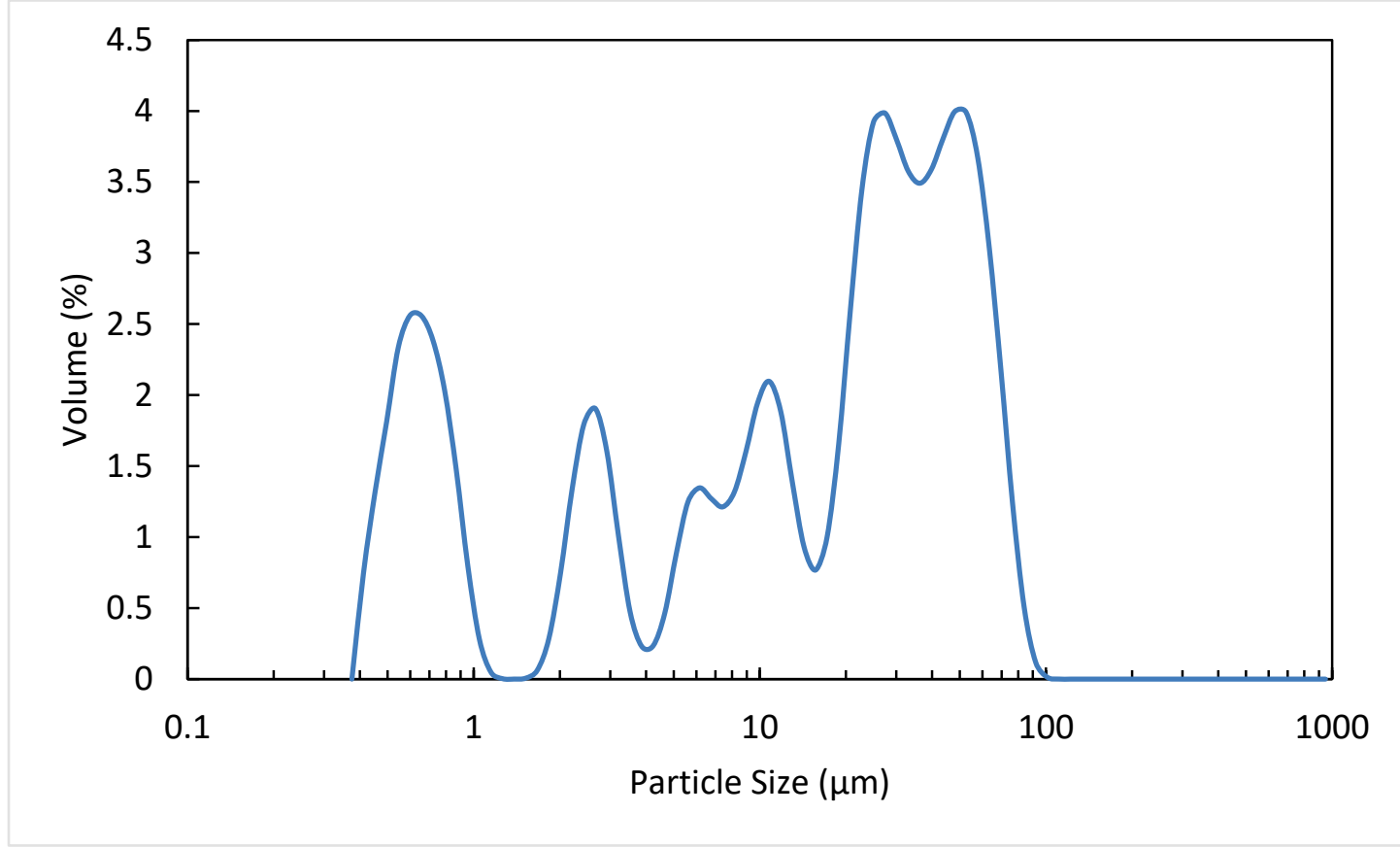


Figure A27. PSD Results of Silica Flour (Sil-co-sil).

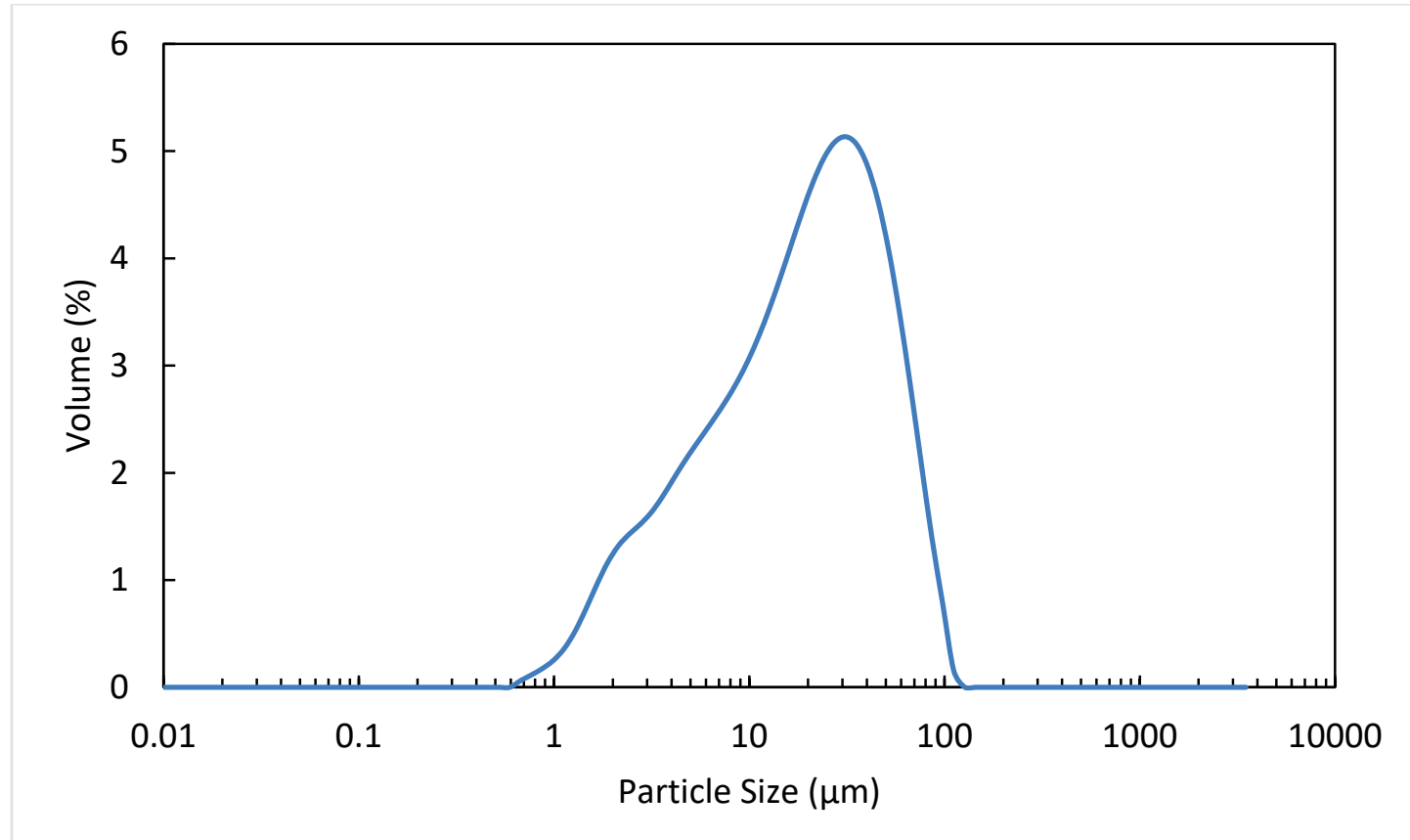

Figure A28. PSD Results of Silica Sand (F50).

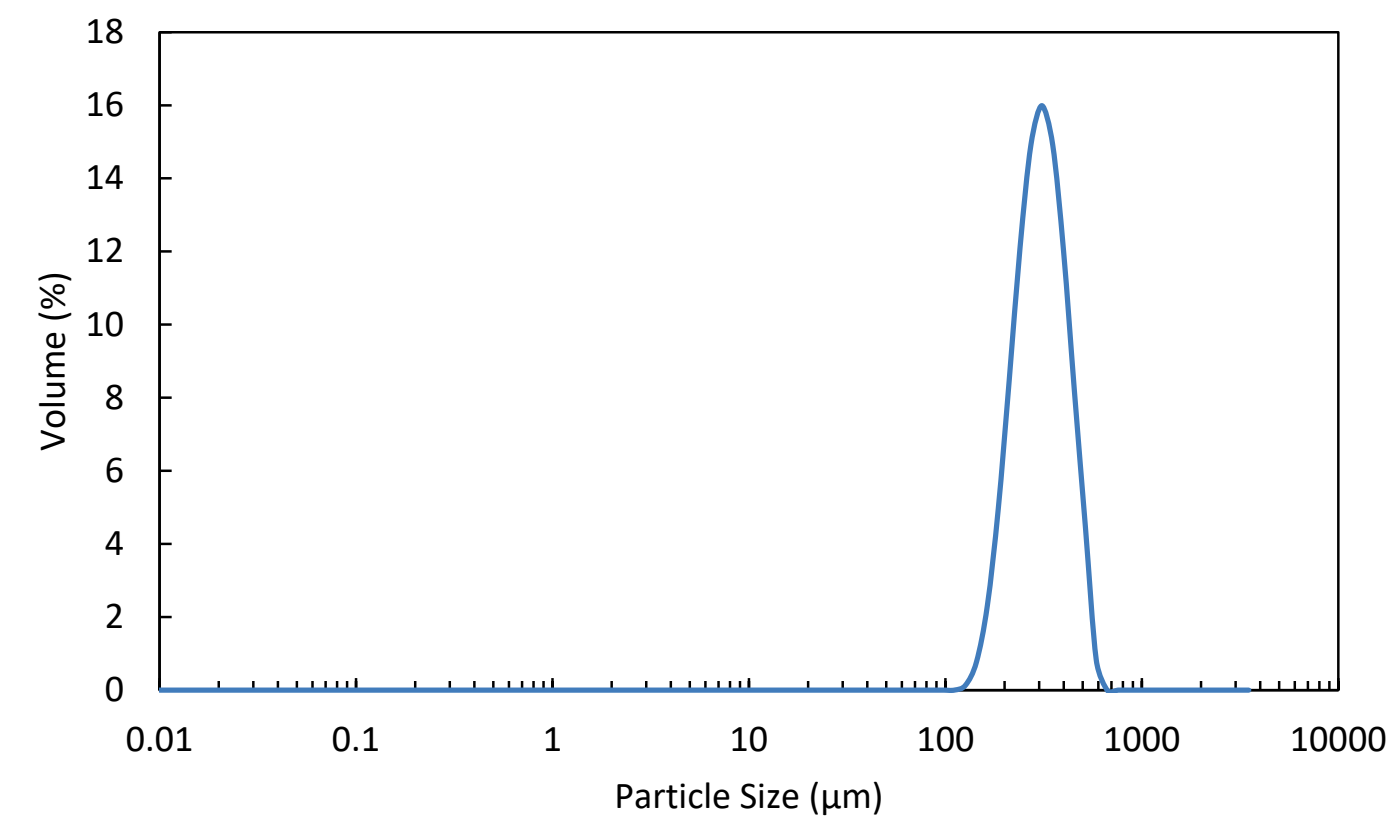


Figure A29. PSD Results of Slag (170080).

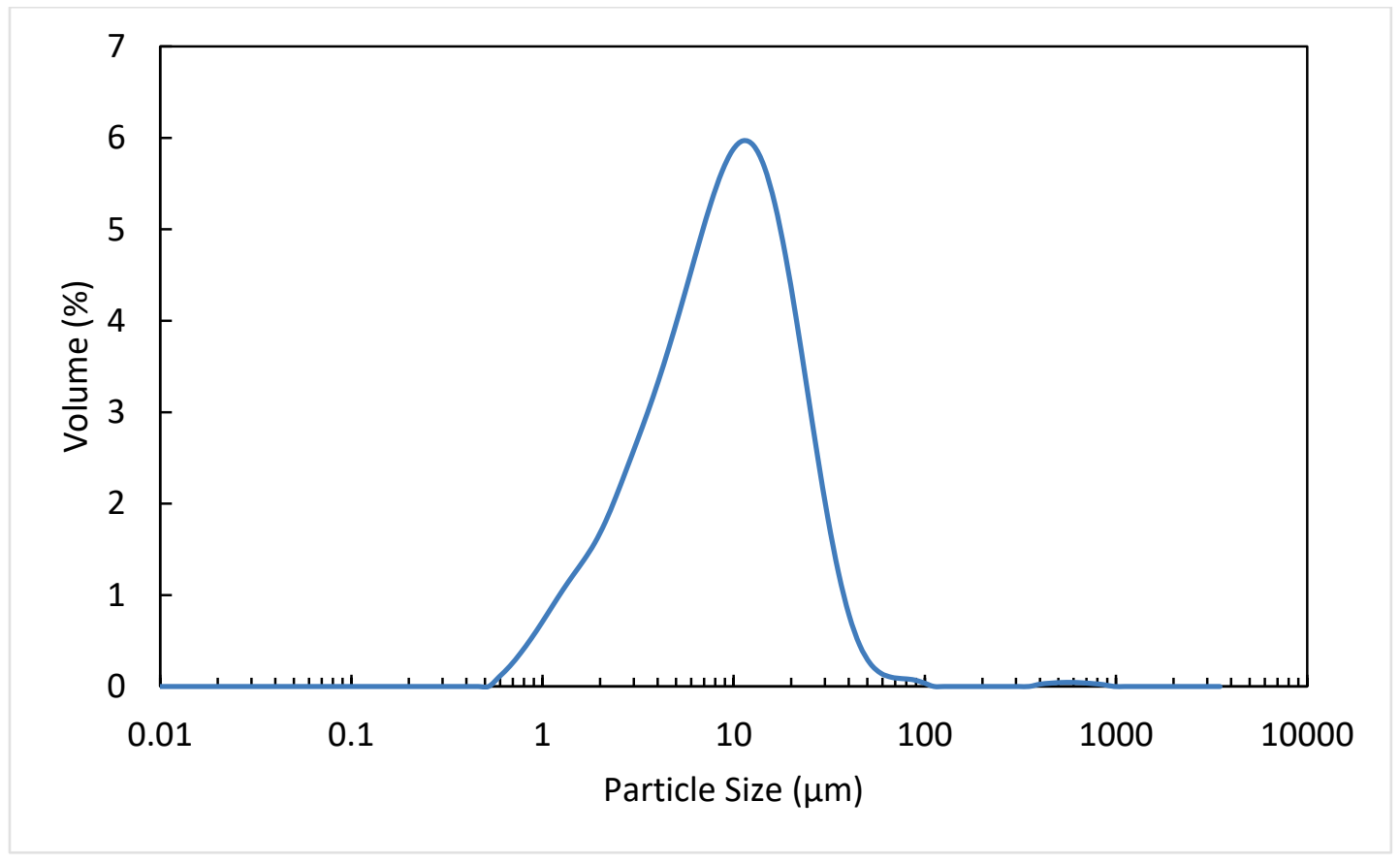




\section{Appendix B: X-Ray Fluorescence Results}

Figure B1. XRF Results of Cement (170052).

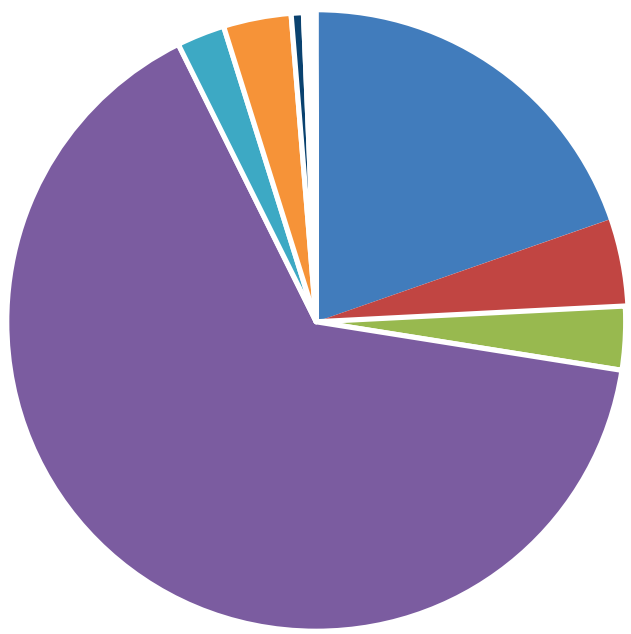
- SiO2
- Al2O3 - Fe2O3 - $\mathrm{CaO}$
- $\mathrm{MgO}$
- SO3
- $\mathrm{K} 2 \mathrm{O}$
- $\mathrm{Na} 2 \mathrm{O}$
- P2O5
- TiO2
- $\mathrm{Mn} 2 \mathrm{O} 3$ - SrO
$\square \mathrm{ZnO} \quad \mathrm{Cr} 2 \mathrm{O} 3$

Figure B2. XRF Results of Cement (170065).

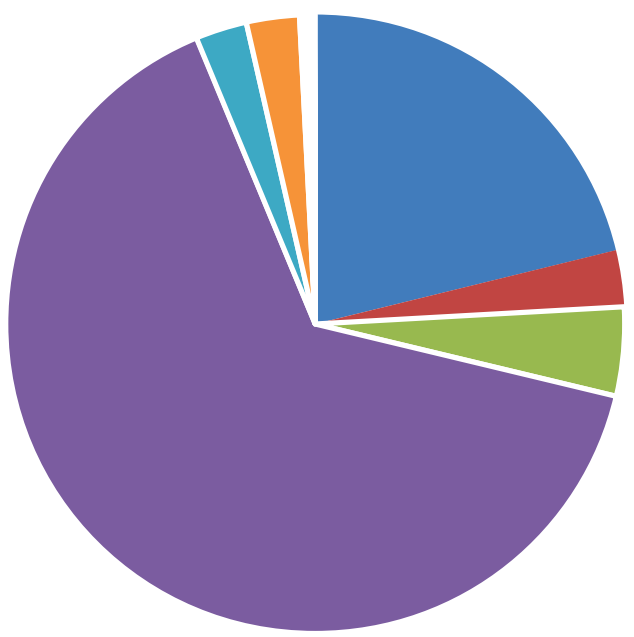
- SiO2
- Al2O3
- $\mathrm{CaO}$
- $\mathrm{MgO}$
- SO3
- $\mathrm{K} 2 \mathrm{O}$
- Na2O
- P2O5
- TiO2
- Mn2O3 - SrO
- $\mathrm{ZnO}$
- $\mathrm{Cr} 2 \mathrm{O} 3$ 
Figure B3. XRF Results of Fly Ash (080159).

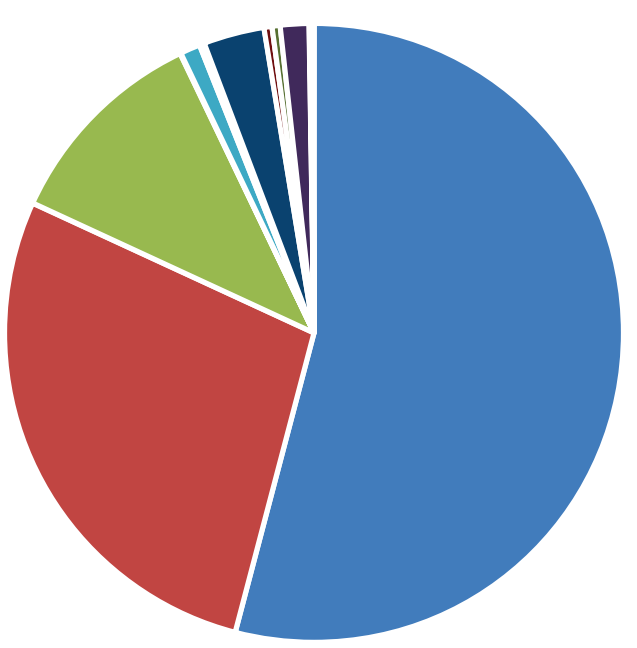

$$
\begin{aligned}
& -\mathrm{SiO} 2 \backsim \mathrm{Al} 2 \mathrm{O} 3 \backsim \mathrm{Fe} 2 \mathrm{O}=\mathrm{CaO} \backsim \mathrm{MgO} \backsim \mathrm{SO} 3 \backsim \mathrm{K} 2 \mathrm{O} \\
& -\mathrm{Na} 2 \mathrm{O}-\mathrm{P} 2 \mathrm{O} 5=\mathrm{TiO} 2 \backsim \mathrm{Mn} 2 \mathrm{O} 3=\mathrm{SrO}\|\mathrm{ZnO}\| \mathrm{Cr} 2 \mathrm{O} 3
\end{aligned}
$$

Figure B4. XRF Results of Fly Ash (100015).

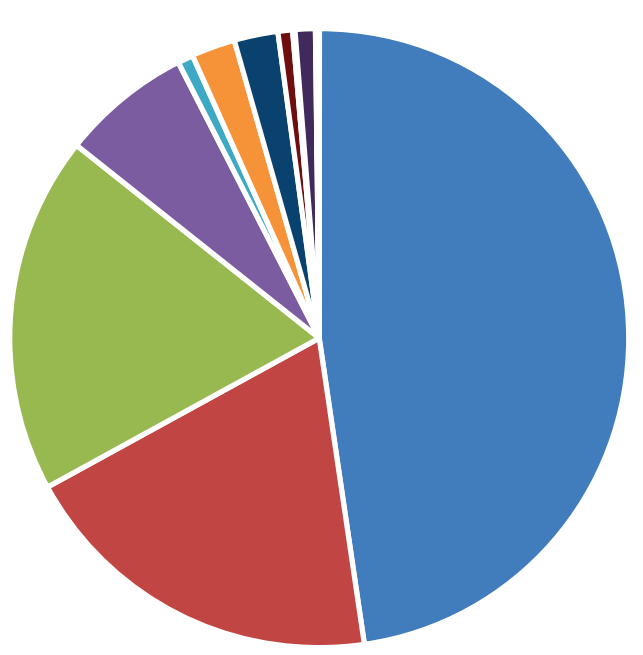

$$
\begin{aligned}
& -\mathrm{SiO} 2-\mathrm{Al} 2 \mathrm{O} 3-\mathrm{Fe} 2 \mathrm{O}=\mathrm{CaO} \backsim \mathrm{MgO} \backsim \mathrm{SO} 3 \backsim \mathrm{K} 2 \mathrm{O} \\
& -\mathrm{Na} 2 \mathrm{O}-\mathrm{P} 2 \mathrm{O} 5-\mathrm{TiO} 2-\mathrm{Mn} 2 \mathrm{O} 3-\mathrm{SrO} \quad \mathrm{ZnO} \| \mathrm{Cr} 2 \mathrm{O} 3
\end{aligned}
$$


Figure B5. XRF Results of Fly Ash (100069).

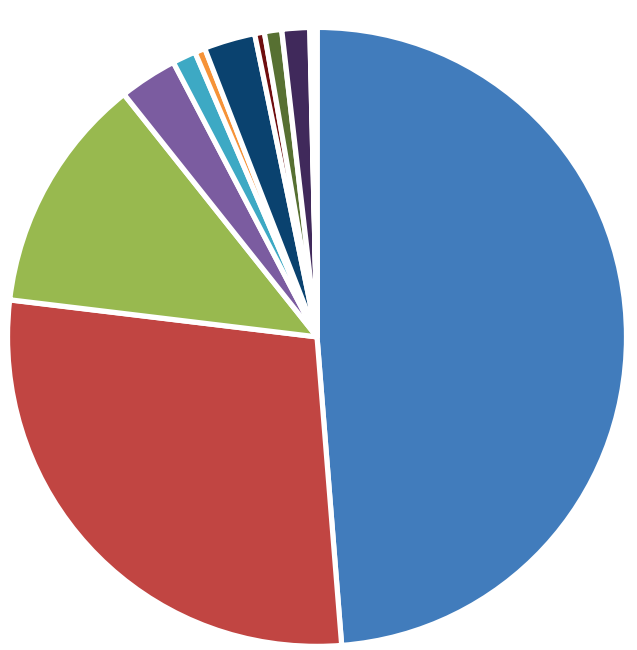

$$
\begin{aligned}
& -\mathrm{SiO} 2 \backsim \mathrm{Al} 2 \mathrm{O} 3 \backsim \mathrm{Fe} 2 \mathrm{O}=\mathrm{CaO} \backsim \mathrm{MgO} \backsim \mathrm{SO} 3 \backsim \mathrm{K} 2 \mathrm{O}
\end{aligned}
$$

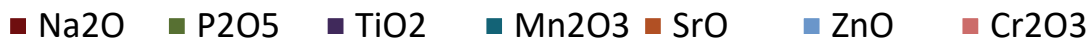

Figure B6. XRF Results of Fly Ash (120013).

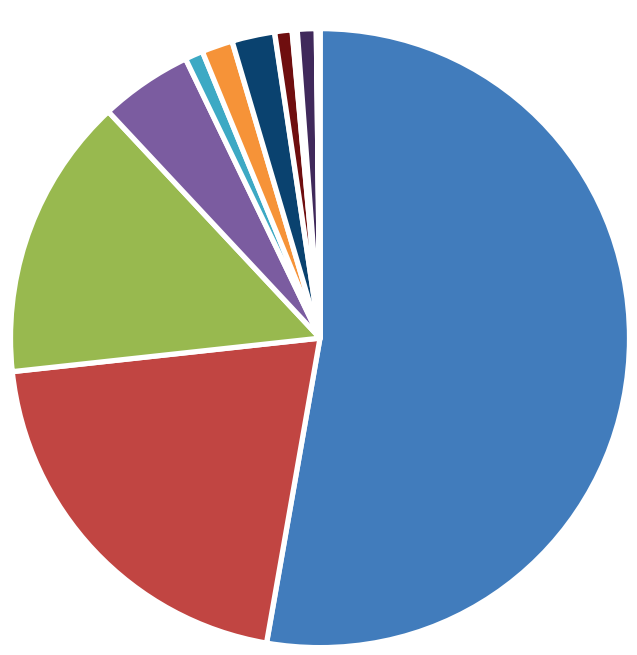

$$
\begin{aligned}
& -\mathrm{SiO} 2-\mathrm{Al} 2 \mathrm{O}=\mathrm{Fe} 2 \mathrm{O} 3-\mathrm{CaO}=\mathrm{MgO}=\mathrm{SO} 3 \approx \mathrm{K} 2 \mathrm{O} \\
& -\mathrm{Na} 2 \mathrm{O}-\mathrm{P} 2 \mathrm{O} 5-\mathrm{TiO} 2-\mathrm{Mn} 2 \mathrm{O} 3-\mathrm{SrO} \backsim \mathrm{ZnO} \| \mathrm{Cr} 2 \mathrm{O}
\end{aligned}
$$


Figure B7. XRF Results of Fly Ash (120083).

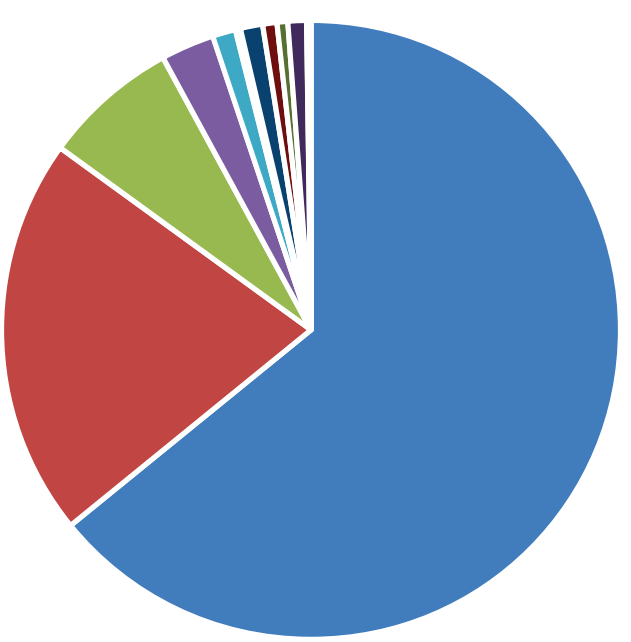

$$
\begin{aligned}
& -\mathrm{SiO} 2-\mathrm{Al} 2 \mathrm{O} 3-\mathrm{Fe} 2 \mathrm{O}=\mathrm{CaO}=\mathrm{MgO} \backsim \mathrm{SO} 3 \backsim \mathrm{K} 2 \mathrm{O} \\
& -\mathrm{Na} 2 \mathrm{O}-\mathrm{P} 2 \mathrm{O} 5=\mathrm{TiO} 2 \backsim \mathrm{Mn} 2 \mathrm{O} 3=\mathrm{SrO}\|\mathrm{ZnO}\| \mathrm{Cr} 2 \mathrm{O} 3
\end{aligned}
$$

Figure B8. XRF Results of Fly Ash (120104).

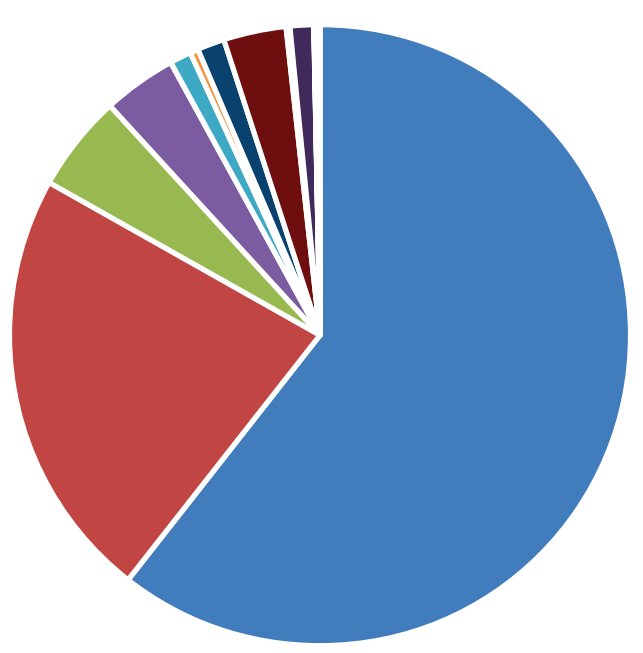

$$
\begin{aligned}
& -\mathrm{SiO} 2=\mathrm{Al} 2 \mathrm{O}=\mathrm{Fe} 2 \mathrm{O} 3 \approx \mathrm{CaO} \backsim \mathrm{MgO} \approx \mathrm{SO} 3 \approx \mathrm{K} 2 \mathrm{O} \\
& -\mathrm{Na} 2 \mathrm{O}-\mathrm{P} 2 \mathrm{O} 5=\mathrm{TiO} 2-\mathrm{Mn} 2 \mathrm{O} 3=\mathrm{SrO}\|\mathrm{ZnO}\| \mathrm{Cr} 2 \mathrm{O} 3
\end{aligned}
$$


Figure B9. XRF Results of Fly Ash (120222).

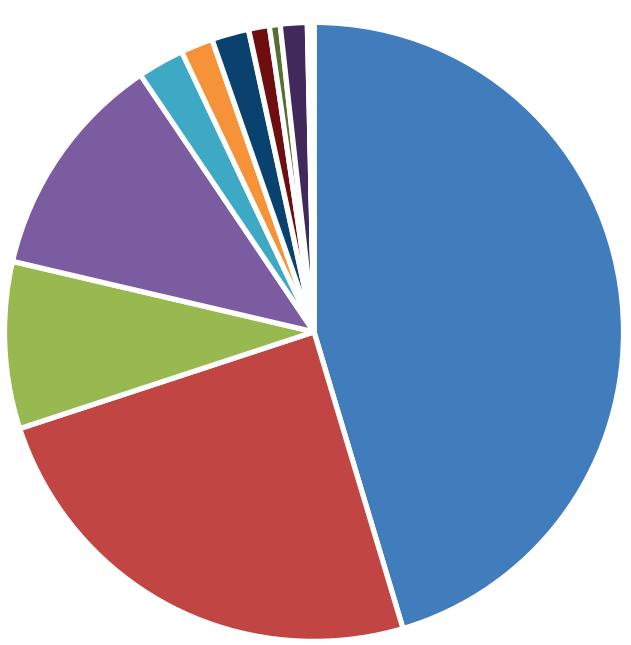

$$
\begin{aligned}
& -\mathrm{SiO} 2-\mathrm{Al} 2 \mathrm{O} 3-\mathrm{Fe} 2 \mathrm{O}=\mathrm{CaO}=\mathrm{MgO} \backsim \mathrm{SO} 3 \backsim \mathrm{K} 2 \mathrm{O} \\
& -\mathrm{Na} 2 \mathrm{O}-\mathrm{P} 2 \mathrm{O} 5=\mathrm{TiO} 2=\mathrm{Mn} 2 \mathrm{O} 3-\mathrm{SrO} \| \mathrm{ZnO} \backsim \mathrm{Cr} 2 \mathrm{O} 3
\end{aligned}
$$

Figure B10. XRF Results of Fly Ash (130032).

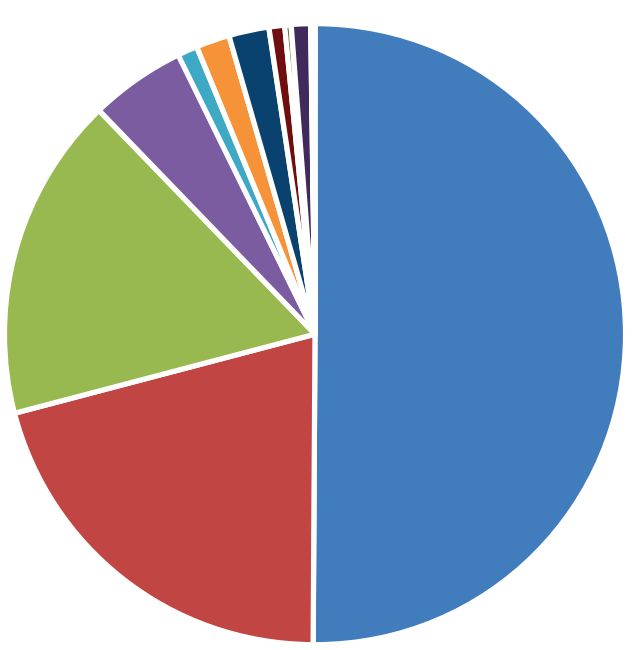

$$
\begin{aligned}
& -\mathrm{SiO} 2=\mathrm{Al} 2 \mathrm{O}=\mathrm{Fe} 2 \mathrm{O} 3 \approx \mathrm{CaO} \backsim \mathrm{MgO} \approx \mathrm{SO} 3 \approx \mathrm{K} 2 \mathrm{O} \\
& -\mathrm{Na} 2 \mathrm{O}-\mathrm{P} 2 \mathrm{O} 5-\mathrm{TiO} 2 \quad \mathrm{Mn} 2 \mathrm{O}=\mathrm{SrO}\|\mathrm{ZnO}\| \mathrm{Cr} 2 \mathrm{O} 3
\end{aligned}
$$


Figure B11. XRF Results of Fly Ash (140022).

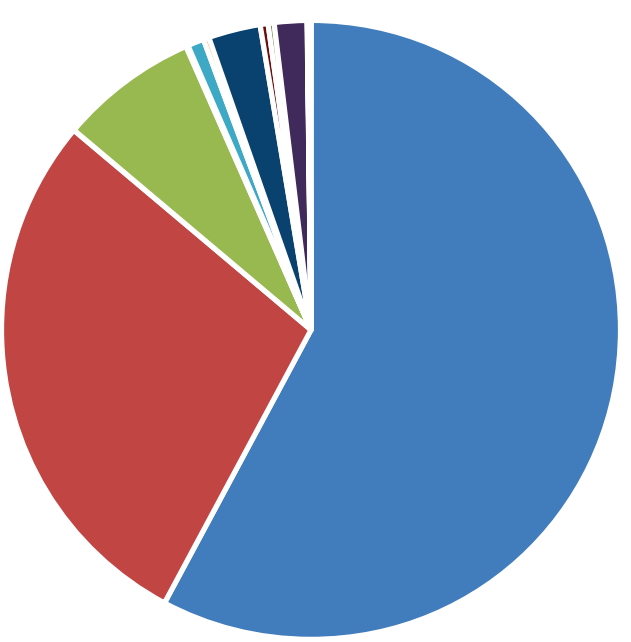

$$
\begin{aligned}
& -\mathrm{SiO} 2-\mathrm{Al} 2 \mathrm{O} 3-\mathrm{Fe} 2 \mathrm{O}=\mathrm{CaO}=\mathrm{MgO} \backsim \mathrm{SO} 3 \backsim \mathrm{K} 2 \mathrm{O} \\
& -\mathrm{Na} 2 \mathrm{O}-\mathrm{P} 2 \mathrm{O} 5=\mathrm{TiO} 2 \backsim \mathrm{Mn} 2 \mathrm{O} 3=\mathrm{SrO}\|\mathrm{ZnO}\| \mathrm{Cr} 2 \mathrm{O} 3
\end{aligned}
$$

Figure B12. XRF Results of Fly Ash (140054).

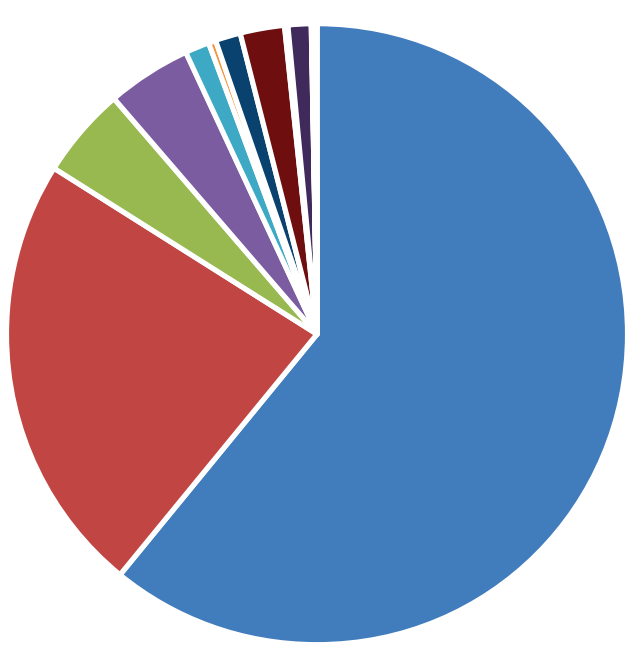

$$
\begin{aligned}
& -\mathrm{SiO} 2=\mathrm{Al} 2 \mathrm{O}=\mathrm{Fe} 2 \mathrm{O} 3 \approx \mathrm{CaO} \backsim \mathrm{MgO} \approx \mathrm{SO} 3 \approx \mathrm{K} 2 \mathrm{O} \\
& -\mathrm{Na} 2 \mathrm{O}-\mathrm{P} 2 \mathrm{O} 5-\mathrm{TiO} 2 \quad \mathrm{Mn} 2 \mathrm{O}=\mathrm{SrO}\|\mathrm{ZnO}\| \mathrm{Cr} 2 \mathrm{O} 3
\end{aligned}
$$


Figure B13. XRF Results of Fly Ash (150108).

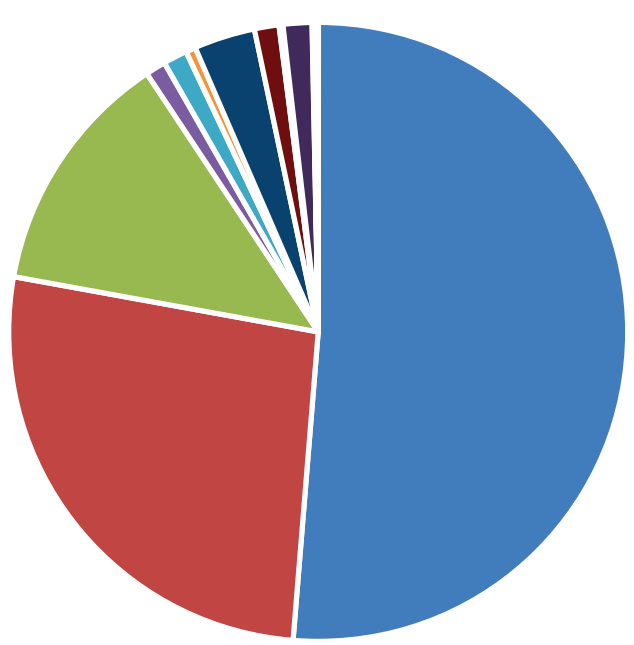

$$
\begin{aligned}
& -\mathrm{SiO} 2-\mathrm{Al} 2 \mathrm{O} 3-\mathrm{Fe} 2 \mathrm{O} 3-\mathrm{CaO} \backsim \mathrm{MgO} \backsim \mathrm{SO} 3 \backsim \mathrm{K} 2 \mathrm{O} \\
& -\mathrm{Na} 2 \mathrm{O}-\mathrm{P} 2 \mathrm{O} 5=\mathrm{TiO} 2-\mathrm{Mn} 2 \mathrm{O} 3=\mathrm{SrO} \| \mathrm{ZnO} \backsim \mathrm{Cr} 2 \mathrm{O} 3
\end{aligned}
$$

Figure B14. XRF Results of Fly Ash (150109).

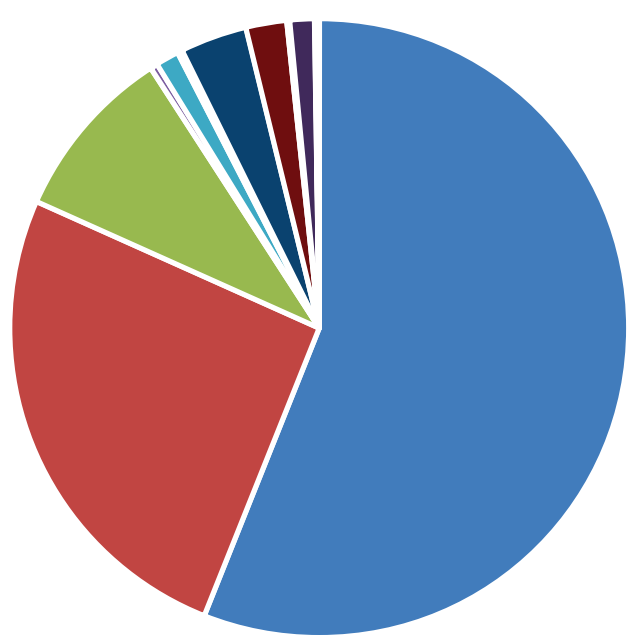

$$
\begin{aligned}
& \square \mathrm{SiO} 2 \| \mathrm{Al} 2 \mathrm{O}=\mathrm{Fe} 2 \mathrm{O}=\mathrm{CaO} \backsim \mathrm{MgO} \backsim \mathrm{SO}=\mathrm{K} 2 \mathrm{O} \\
& -\mathrm{Na} 2 \mathrm{O}-\mathrm{P} 2 \mathrm{O} 5=\mathrm{TiO} 2 \backsim \mathrm{Mn} 2 \mathrm{O} 3=\mathrm{SrO} \| \mathrm{ZnO} \backsim \mathrm{Cr} 2 \mathrm{O} 3
\end{aligned}
$$


Figure B15. XRF Results of Silica Fume (Guam F10).

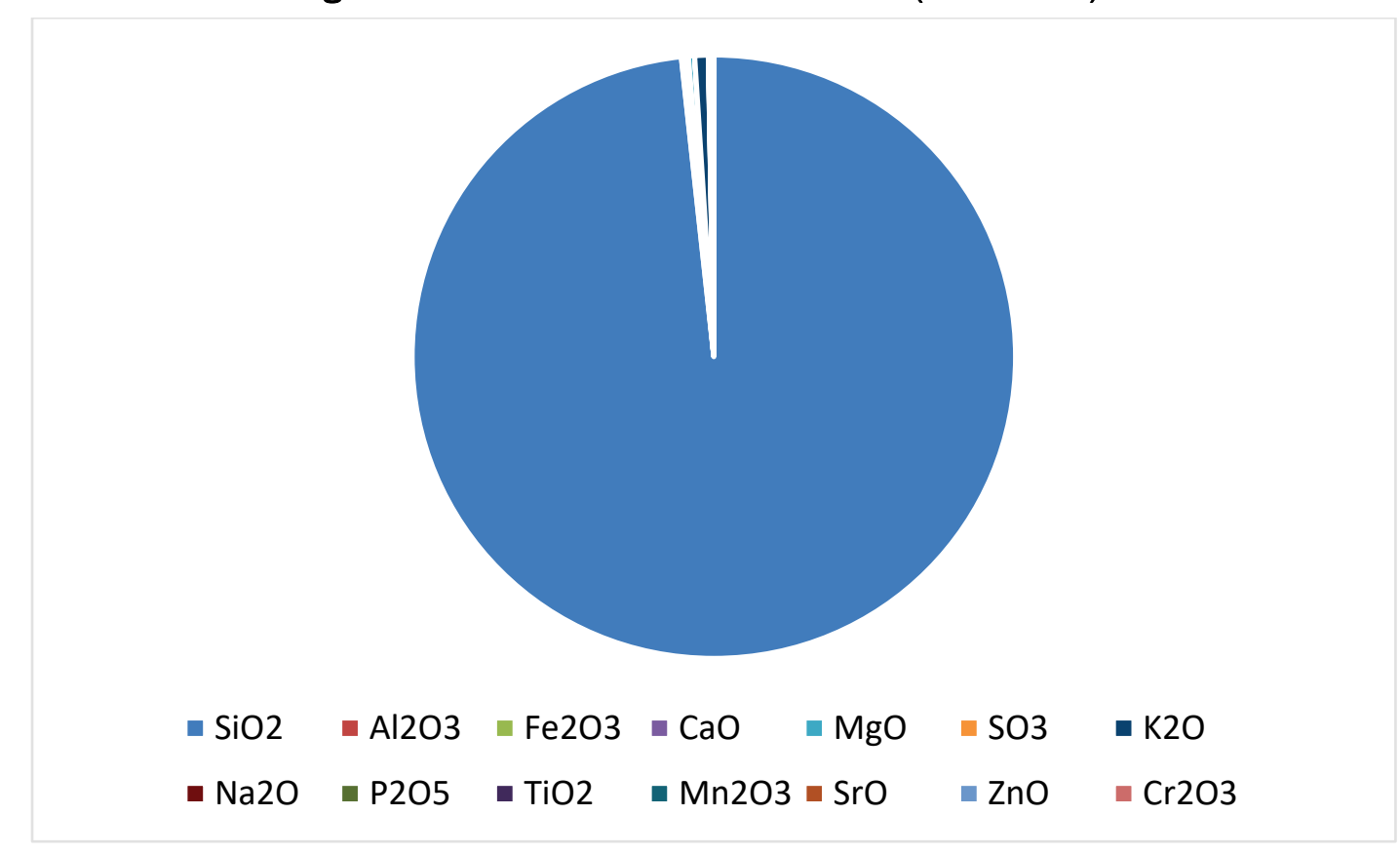

Figure B16. XRF Results of Silica Fume (130008).

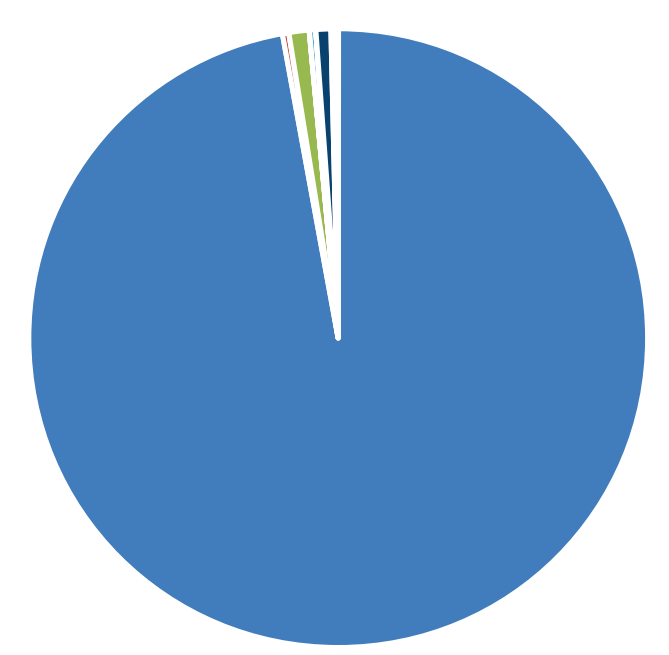

$$
\begin{aligned}
& -\mathrm{SiO} 2-\mathrm{Al} 2 \mathrm{O} 3-\mathrm{Fe} 2 \mathrm{O} 3-\mathrm{CaO}=\mathrm{MgO} \backsim \mathrm{SO}=\mathrm{K} 2 \mathrm{O}
\end{aligned}
$$

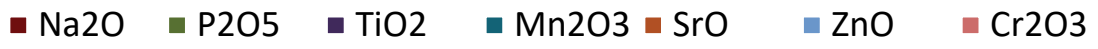


Figure B17. XRF Results of Silica Fume (130050).

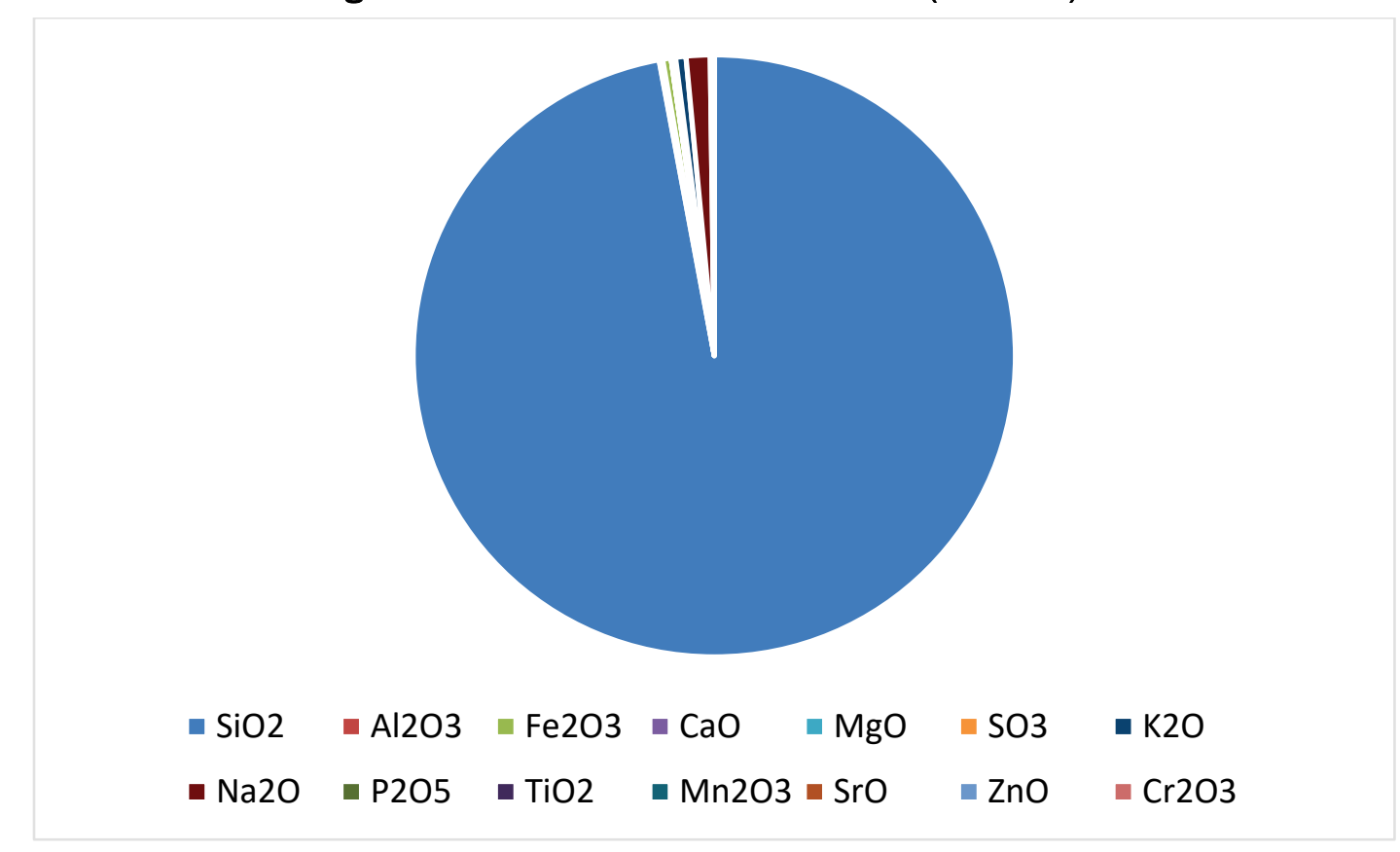

Figure B18. XRF Results of Silica Fume (140092).

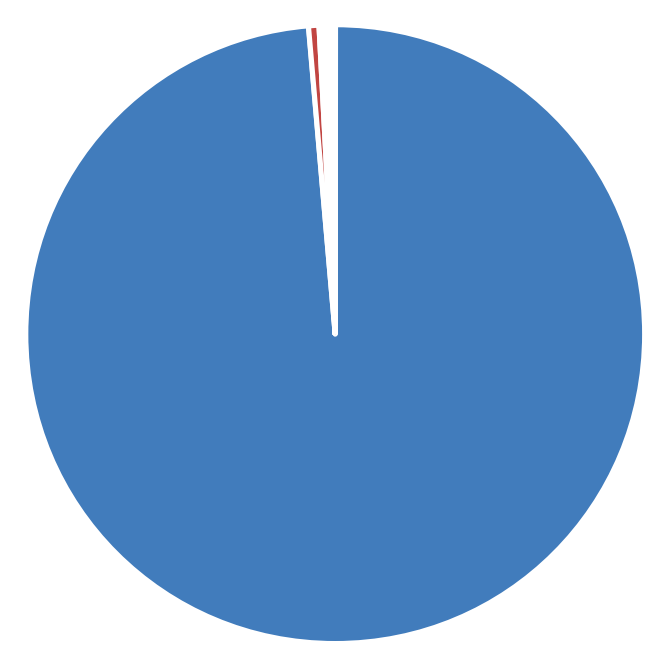

$$
\begin{aligned}
& -\mathrm{SiO} 2-\mathrm{Al} 2 \mathrm{O} 3-\mathrm{Fe} 2 \mathrm{O} 3-\mathrm{CaO}=\mathrm{MgO} \backsim \mathrm{SO}=\mathrm{K} 2 \mathrm{O}
\end{aligned}
$$

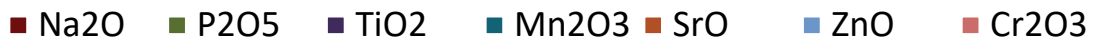


Figure B19. XRF Results of Silica Fume (140093).

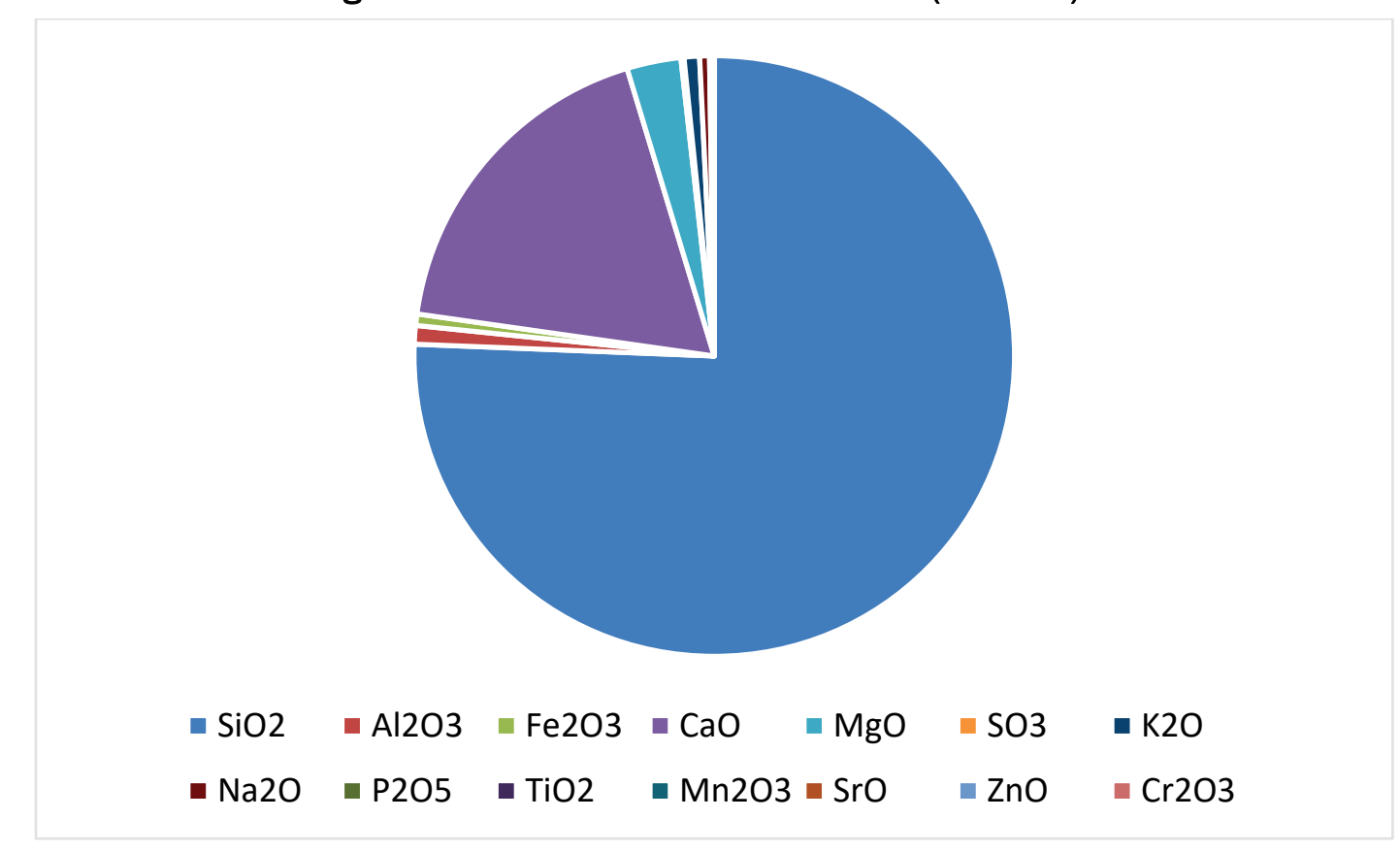

Figure B20. XRF Results of Silica Fume (140094).

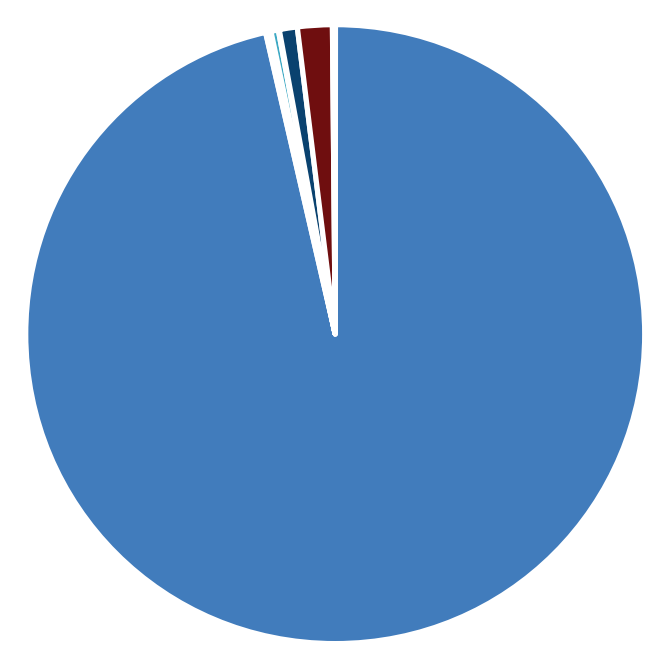

$$
\begin{aligned}
& -\mathrm{SiO} 2-\mathrm{Al} 2 \mathrm{O} 3-\mathrm{Fe} 2 \mathrm{O} 3-\mathrm{CaO}=\mathrm{MgO} \backsim \mathrm{SO}=\mathrm{K} 2 \mathrm{O}
\end{aligned}
$$

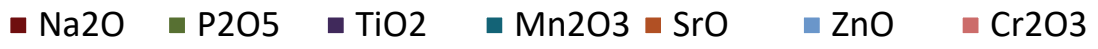


Figure B21. XRF Results of Silica Fume (150148).

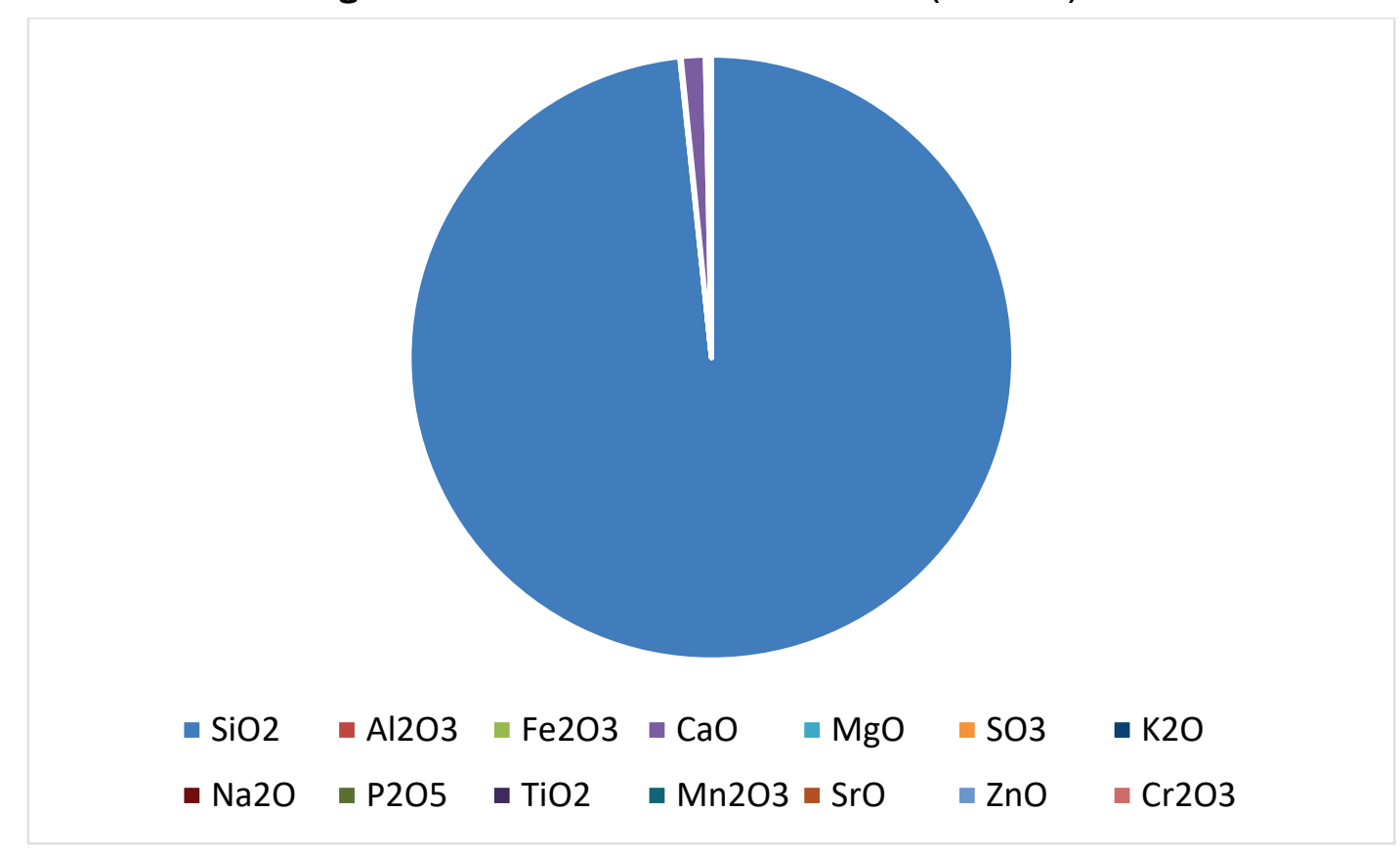

Figure B22. XRF Results of Silica Fume (150049).

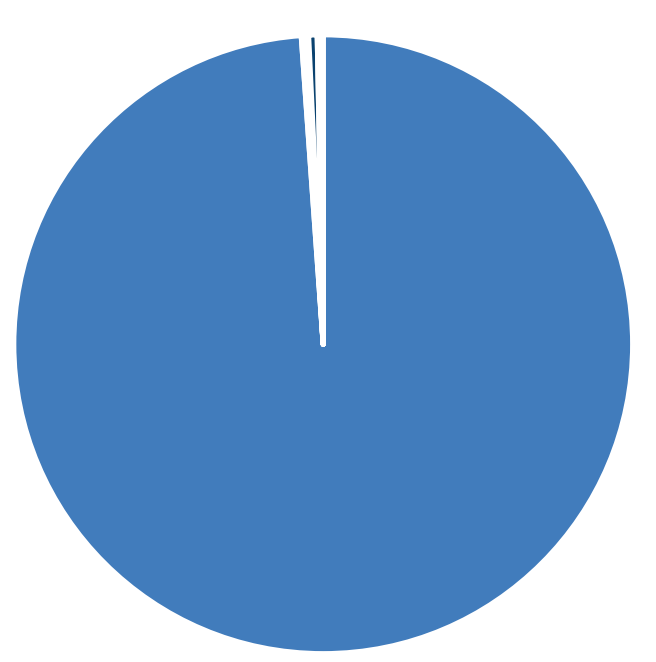

$$
\begin{aligned}
& \because \mathrm{SiO} 2-\mathrm{Al} 2 \mathrm{O} 3-\mathrm{Fe} 2 \mathrm{O} 3-\mathrm{CaO}=\mathrm{MgO} \backsim \mathrm{SO} 3=\mathrm{K} 2 \mathrm{O} \\
& \text { - } \mathrm{Na} 2 \mathrm{O}-\mathrm{P} 2 \mathrm{O} 5=\mathrm{TiO} 2 \square \mathrm{Mn} 2 \mathrm{O} 3=\mathrm{SrO}\|\mathrm{ZnO}\| \mathrm{Cr} 2 \mathrm{O} 3
\end{aligned}
$$


Figure B23. XRF Results of Silica Fume (150050).

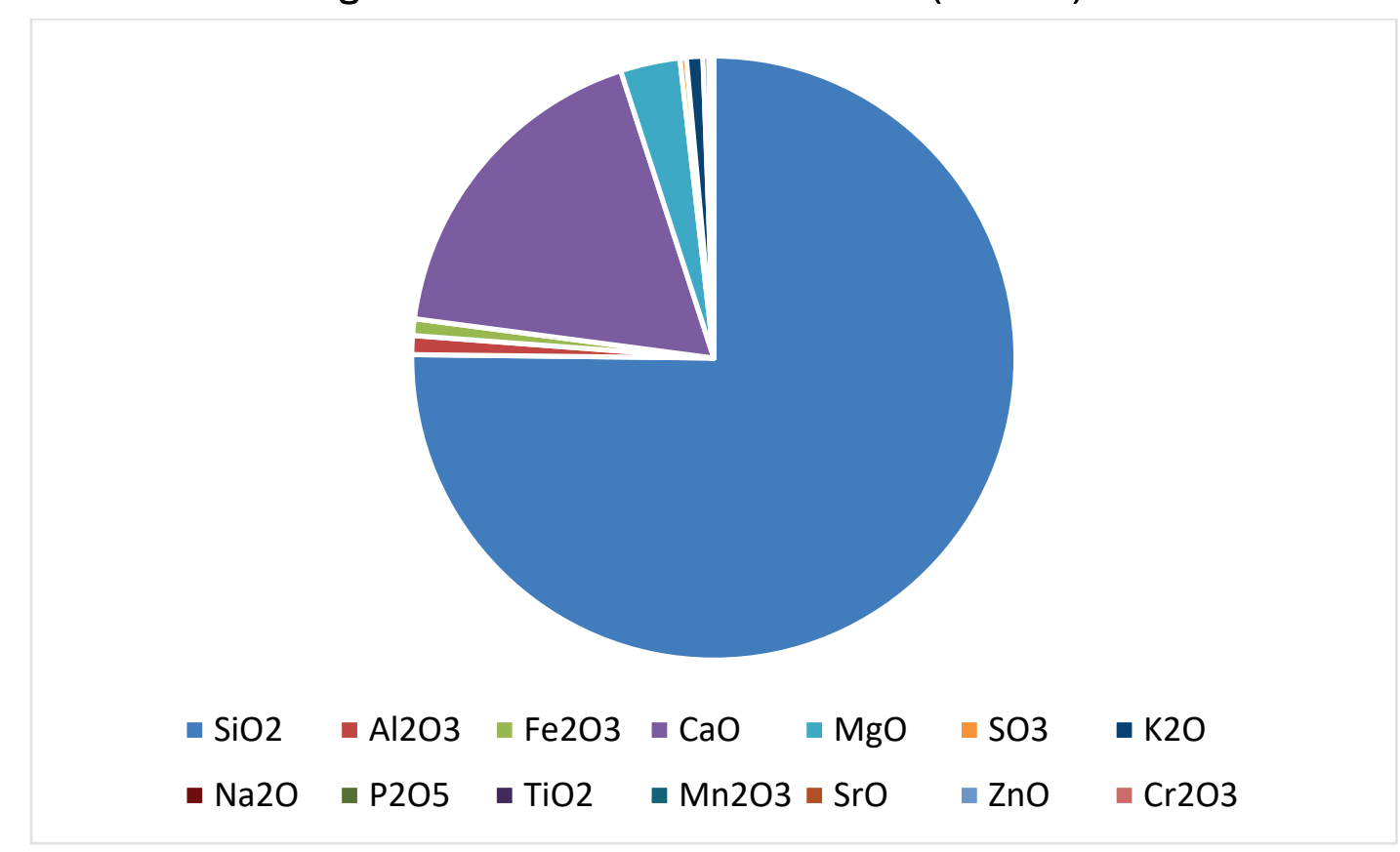

Figure B24. XRF Results of Silica Fume (150051).

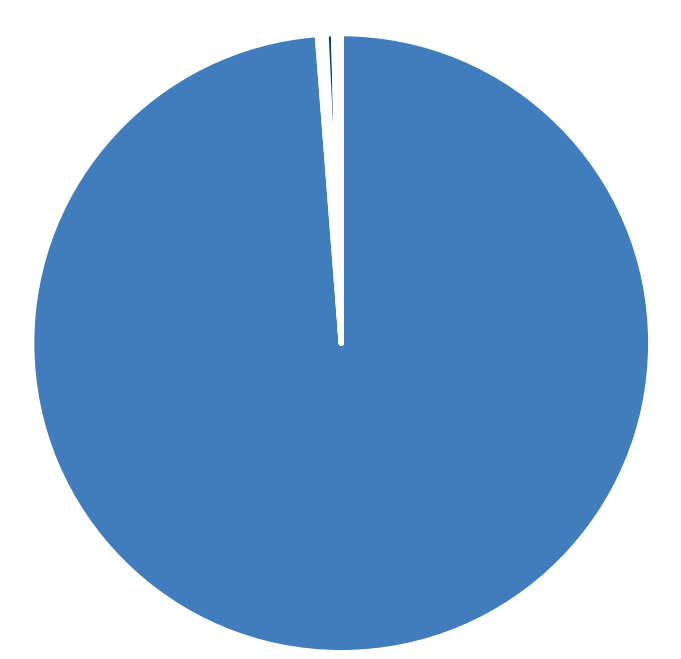
- $\mathrm{SiO} 2$
- Al2O3
- $\mathrm{Fe} 2 \mathrm{O} 3-\mathrm{CaO}$
- $\mathrm{MgO}$
- SO3
- $\mathrm{K} 2 \mathrm{O}$
- $\mathrm{Na} 2 \mathrm{O}$
- P2O5 - TiO2
- Mn2O3 - SrO
- $\mathrm{ZnO} \quad \mathrm{Cr} 2 \mathrm{O} 3$ 
Figure B25. XRF Results of Silica Fume (Ecotech85).

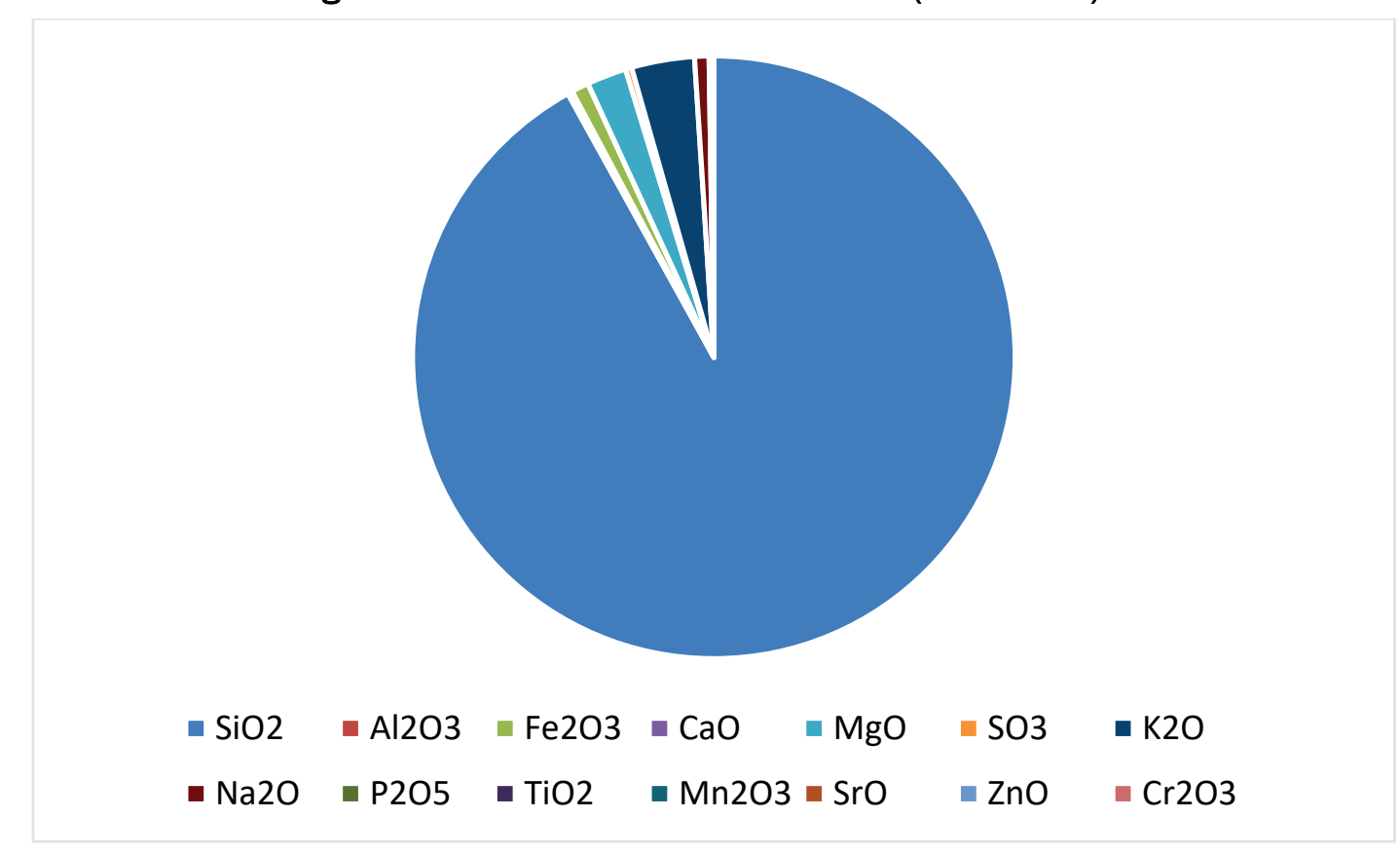

Figure B26. XRF Results of Silica Flour (Sil-co-sil).

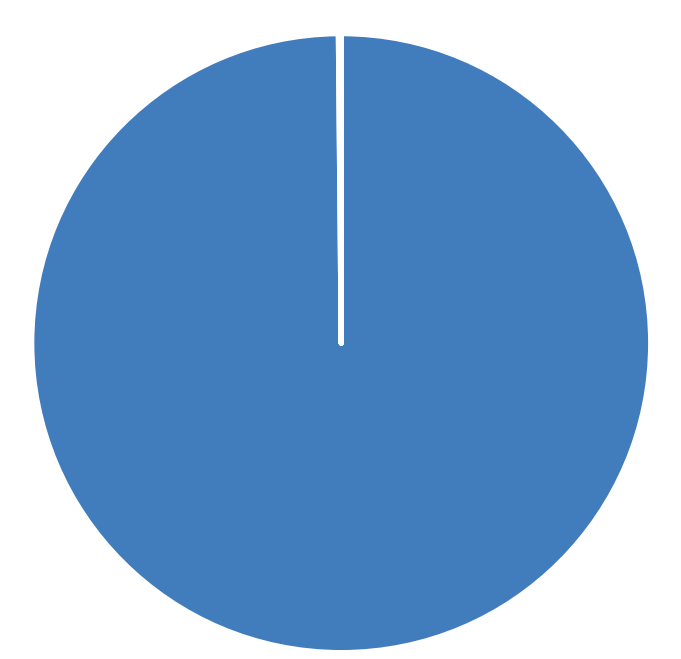
- $\mathrm{SiO} 2$
- Al2O3
- $\mathrm{Fe} 2 \mathrm{O}=\mathrm{CaO}$
- $\mathrm{MgO}$
- SO3
- $\mathrm{K} 2 \mathrm{O}$
- Na2O
- P2O5 - TiO2
- Mn2O3 - SrO
- $\mathrm{ZnO} \quad \mathrm{Cr} 2 \mathrm{O} 3$ 
Figure B27. XRF Results of Silica Sand (F50).

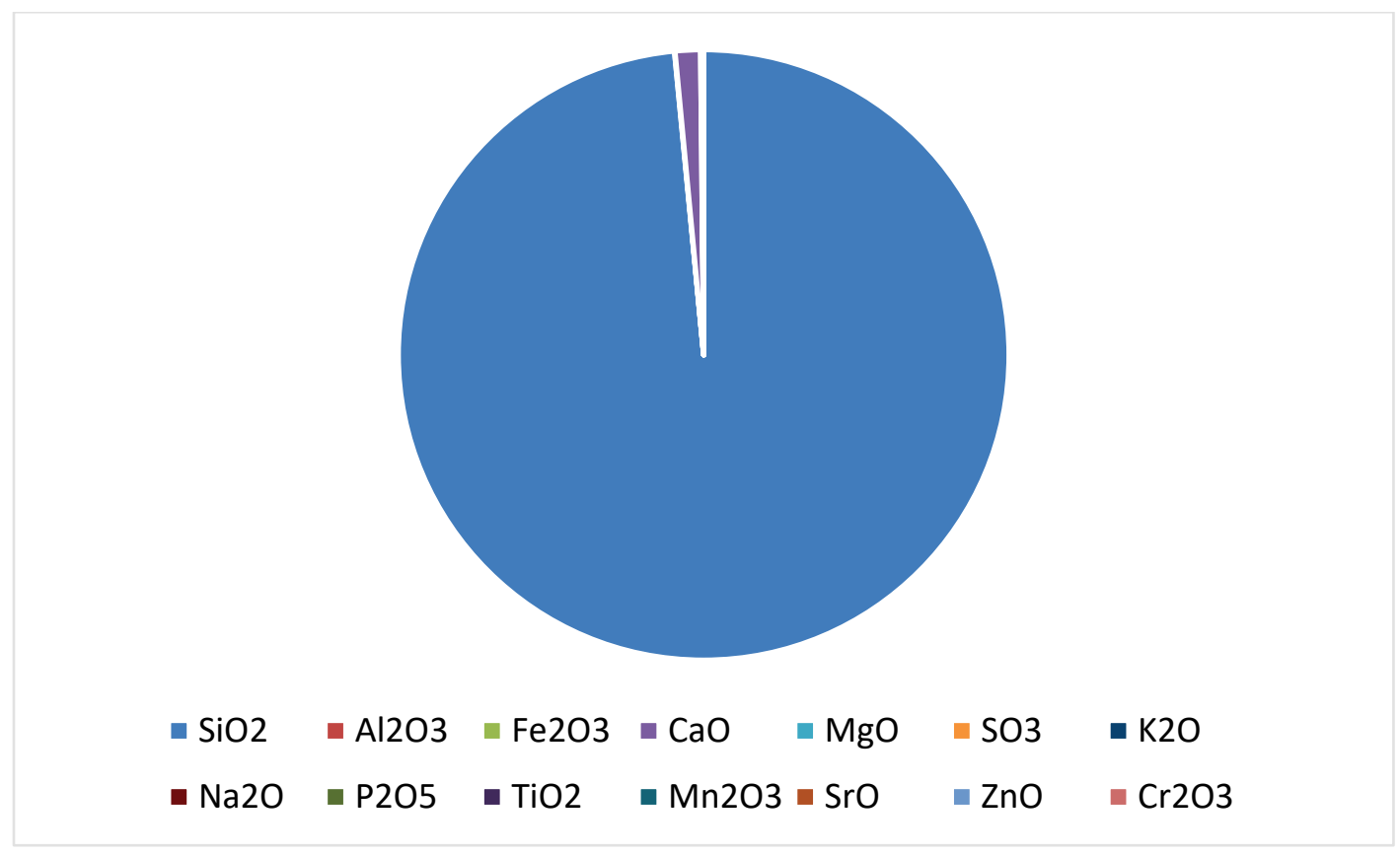




\section{Appendix C: X-Ray Diffraction Results}

Figure C1. XRD Results of Fly Ash (080159).

\begin{tabular}{|c|c|c|c|c|c|c|}
\hline Phase ID (3) & Chemical Formula & NA & NR & NP & $\mathrm{Wt} \%$ (esd) & RIR \\
\hline Mullite. syn & $\mathrm{Al}_{4.59} \mathrm{Si}_{1.41} \mathrm{O}_{9.7}$ & - & 29 & 10 & $11.2(4.8)$ & 0.83 \\
\hline Quartz low & $\mathrm{SiO}_{2}$ & - & 12 & 9 & $7.2(3.1)$ & 3.02 \\
\hline Hematite & $\mathrm{Fe}_{2} \mathrm{O}_{3}$ & 2 & 11 & 9 & $2.5(1.1)$ & 3.16 \\
\hline Amorphous + Others & $\mathrm{SiO}_{2}$ & & & & $79.0(54.2)$ & 2.50 \\
\hline
\end{tabular}

Refinement Converged (R/E=1.31), Round=3, Iter=4, $P=33, R=3.97 \%(E=3.03 \%, E P S=0.5)$
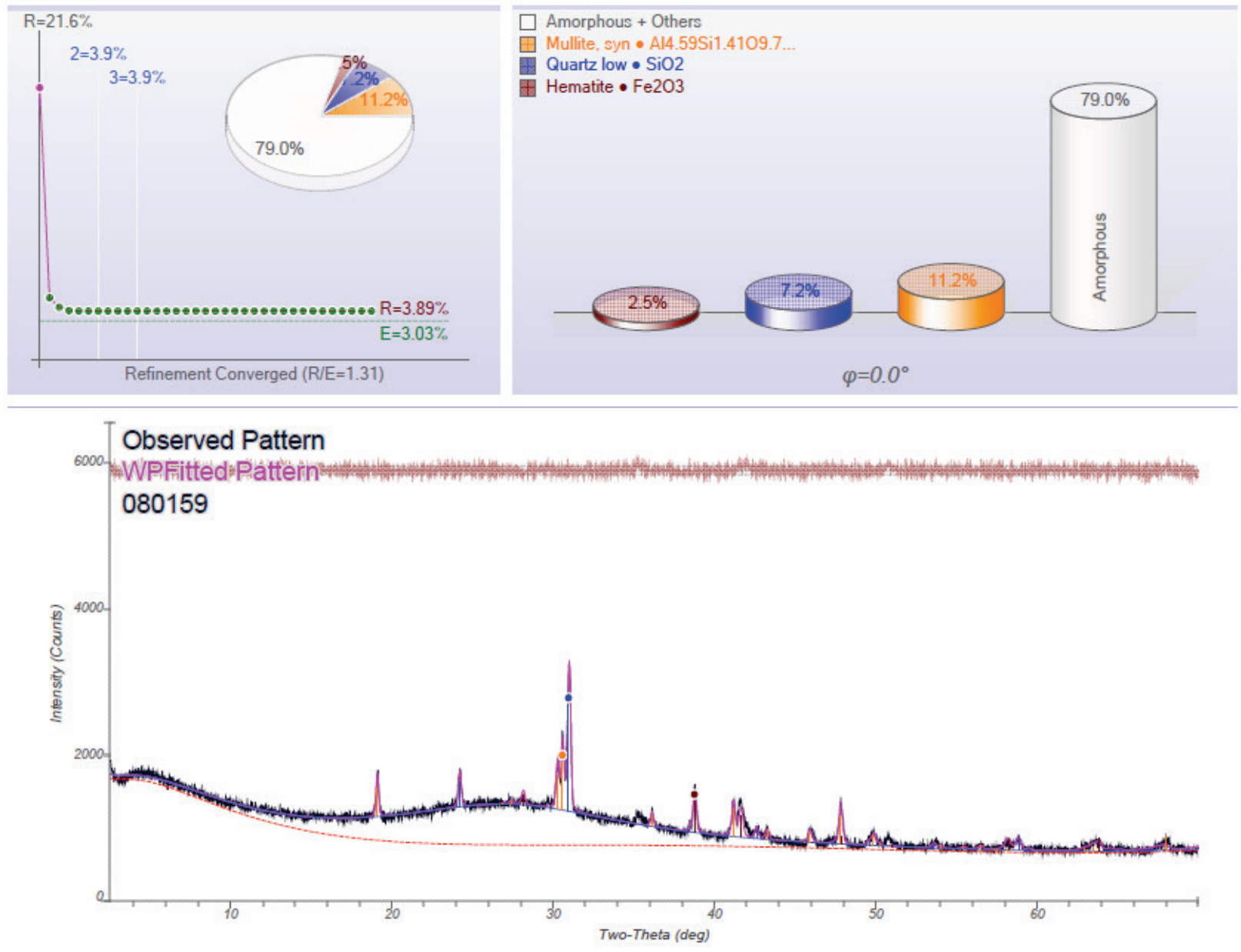
Figure C2. XRD Results of Fly Ash (100015).

\begin{tabular}{l|l|r|r|r|r|r|}
\hline Phase ID (4) & Chemical Formula & NA & NR & NP & Wt\% (esd) & RIR \\
\hline Quartz low & $\mathrm{SiO}_{2}$ & -- & 12 & 9 & $7.3(7.4)$ & 3.02 \\
Mullite, syn & $\mathrm{Al}_{4.59} \mathrm{Si}_{1.41} \mathrm{O}_{9.7}$ & -- & 29 & 10 & $11.6(11.7)$ & 0.83 \\
Hematite & $\mathrm{Fe}_{2} \mathrm{O}_{3}$ & 2 & 11 & 9 & $5.2(5.3)$ & 3.16 \\
Magnetite & $\mathrm{Fe}_{3} \mathrm{O}_{4}$ & -- & 8 & 8 & $6.1(6.2)$ & 5.13 \\
Amorphous + Others & $\mathrm{SiO}_{2}$ & & & & $69.9(123.5)$ & 2.50
\end{tabular}

XRF(Wt\%): $\mathrm{Fe} 2 \mathrm{O} 3=11.5 \%, \mathrm{SiO} 2=80.2 \%, \mathrm{Al} 2 \mathrm{O} 3=8.5 \%$

Refinement Halted (R/E=1.33), Round=3, Iter=6, $P=37, R=3.76 \%(E=2.82 \%, E P S=0.5)$
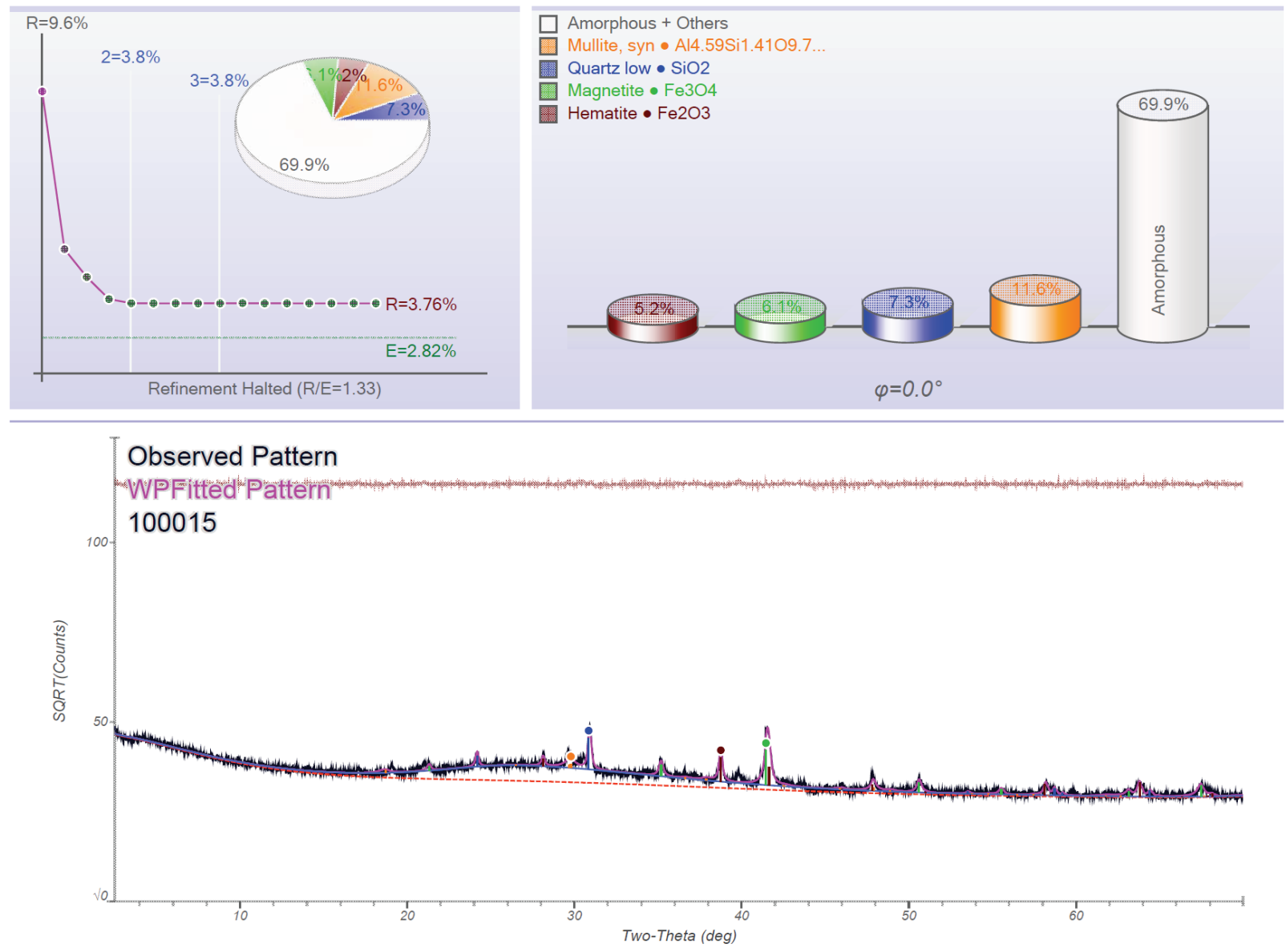
Figure C3. XRD Results of Fly Ash (100069).

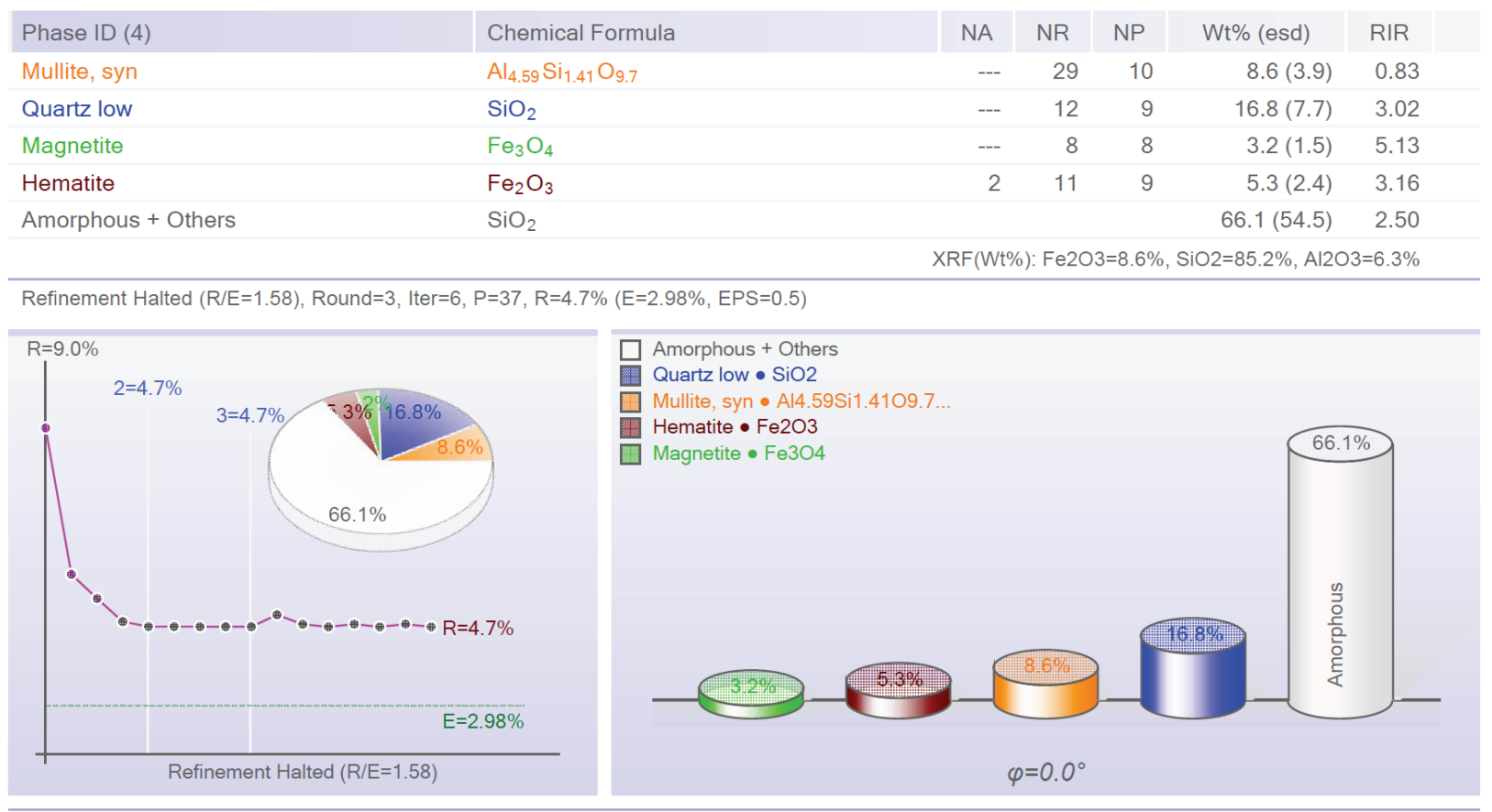

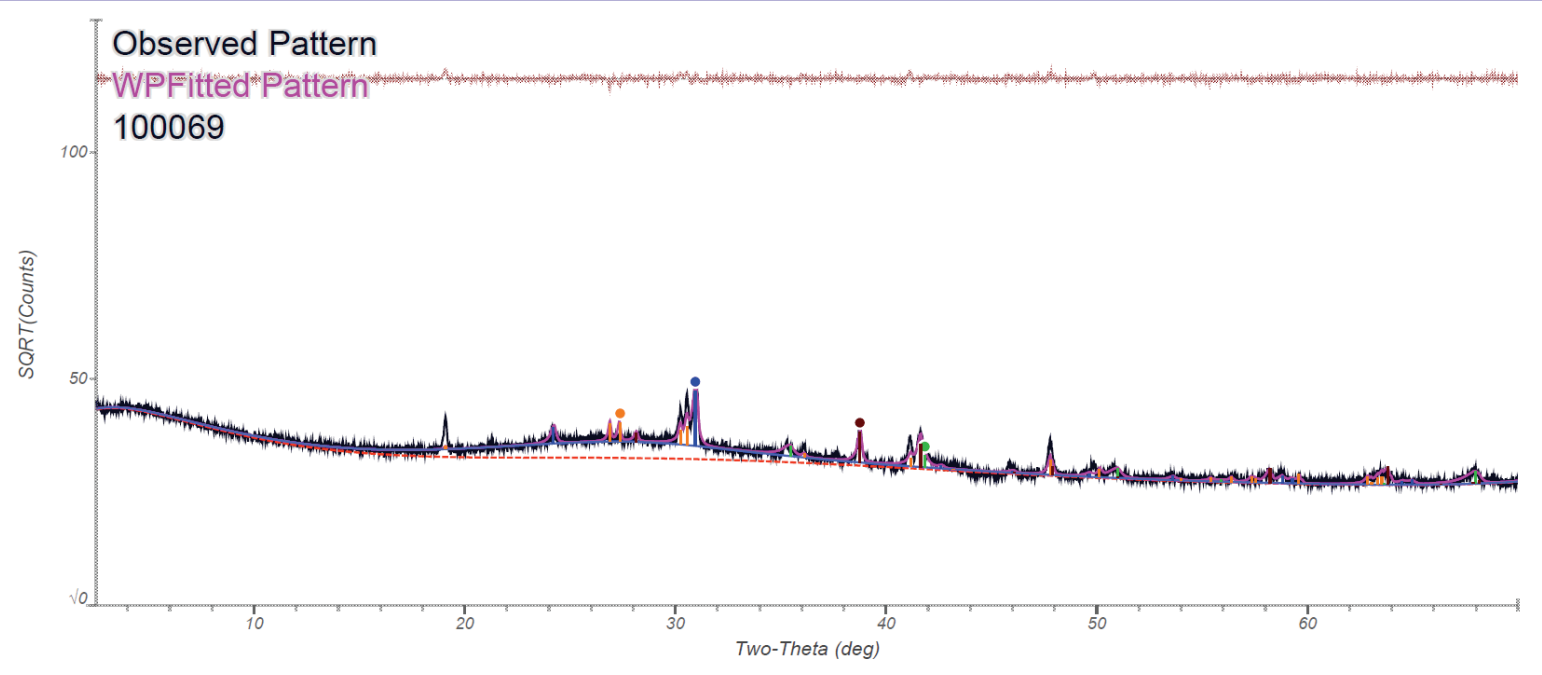


Figure C4. XRD Results of Fly Ash (120013).

\begin{tabular}{|c|c|c|c|c|c|c|}
\hline Phase ID (4) & Chemical Formula & NA & NR & NP & $\mathrm{Wt} \%$ (esd) & RIR \\
\hline Quartz low & $\mathrm{SiO}_{2}$ & --- & 12 & 9 & $9.7(3.6)$ & 3.02 \\
\hline Mullite, syn & $\mathrm{Al}_{4.59} \mathrm{Si}_{1.41} \mathrm{O}_{9.7}$ & --- & 29 & 10 & $8.9(3.5)$ & 0.83 \\
\hline Hematite & $\mathrm{Fe}_{2} \mathrm{O}_{3}$ & 2 & 11 & 9 & $3.6(1.3)$ & 3.16 \\
\hline Magnetite & $\mathrm{Fe}_{3} \mathrm{O}_{4}$ & -- & 8 & 8 & $3.7(1.4)$ & 5.13 \\
\hline Amorphous + Others & $\mathrm{SiO}_{2}$ & & & & $74.0(45.6)$ & 2.50 \\
\hline
\end{tabular}
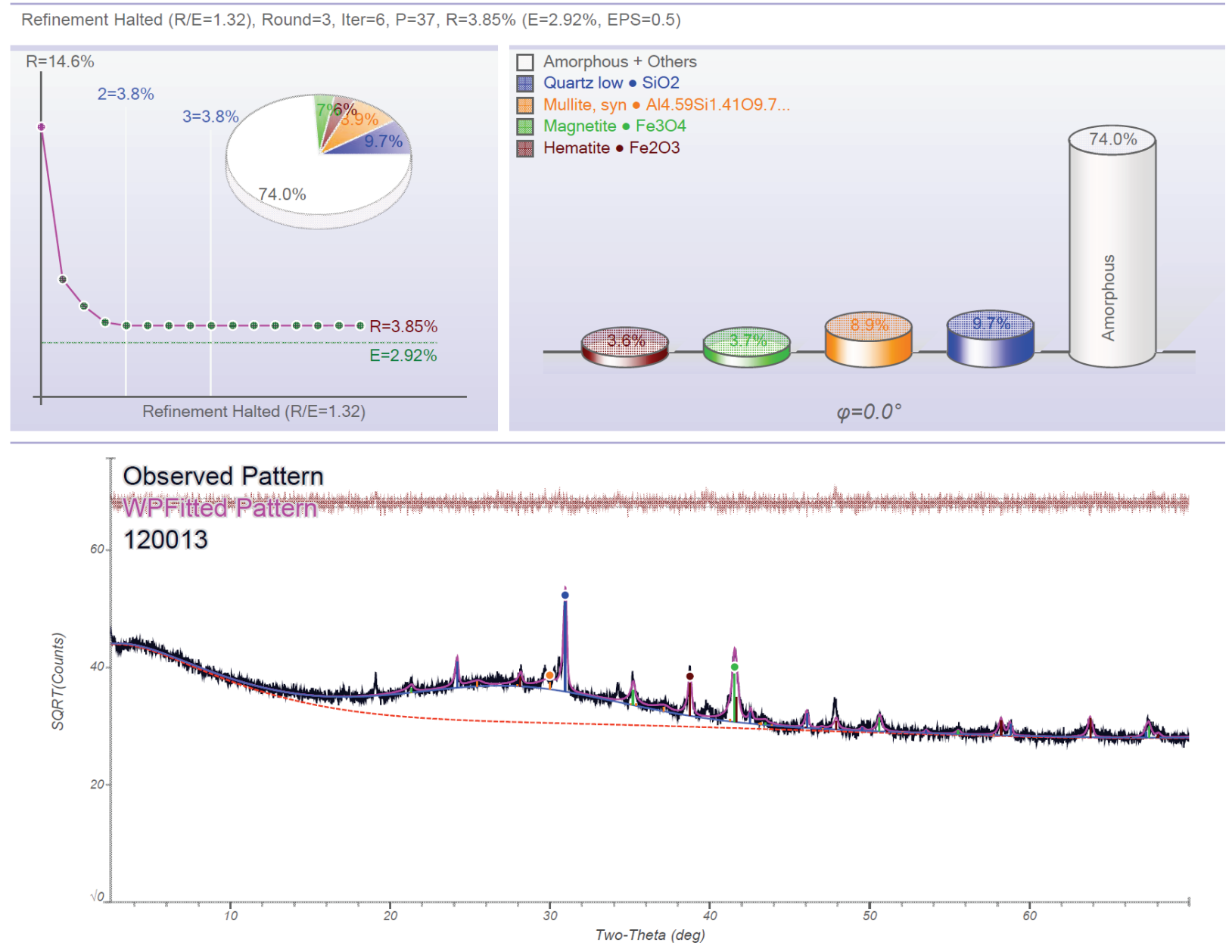
Figure C5. XRD Results of Fly Ash (120083).

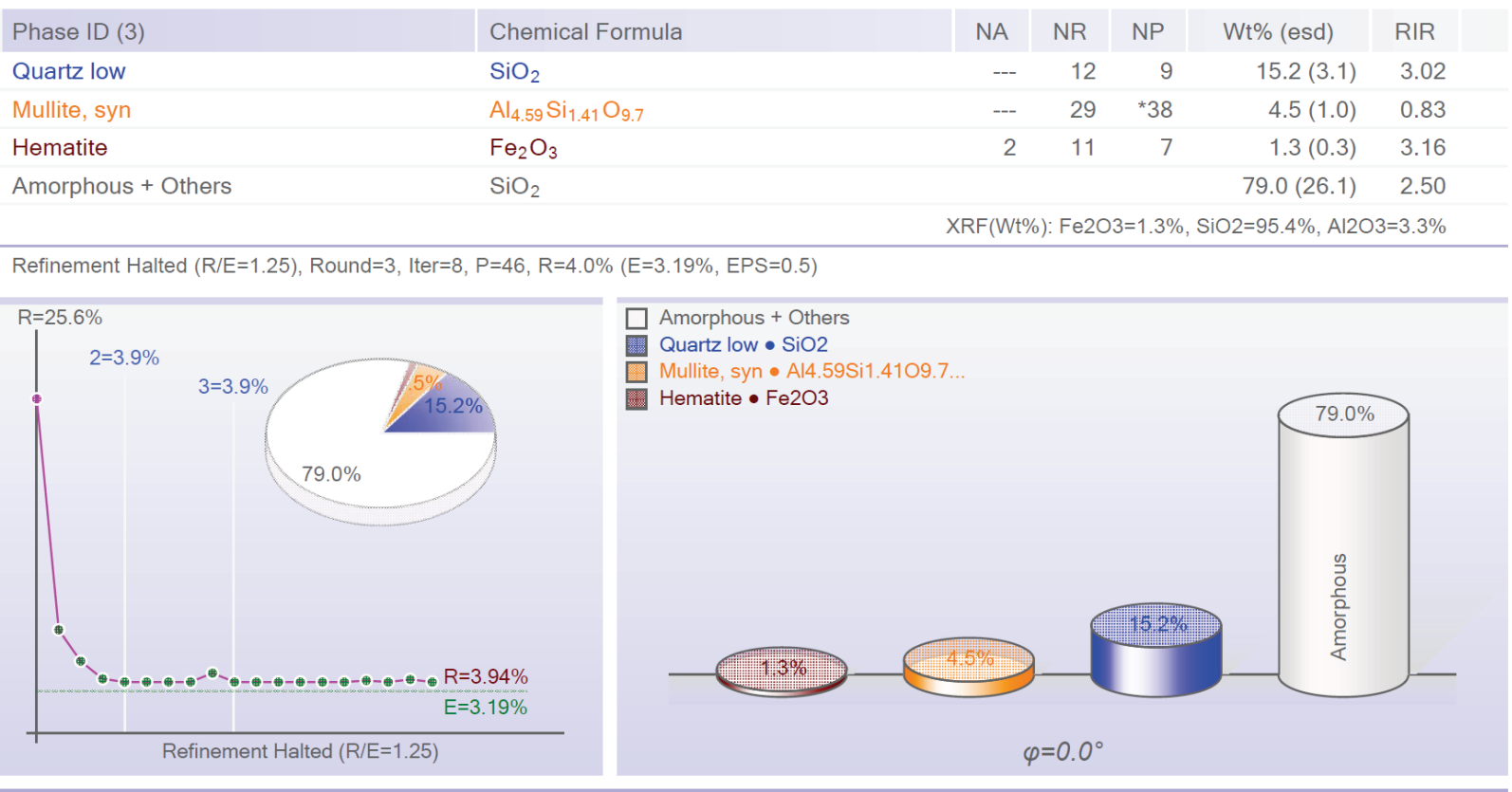

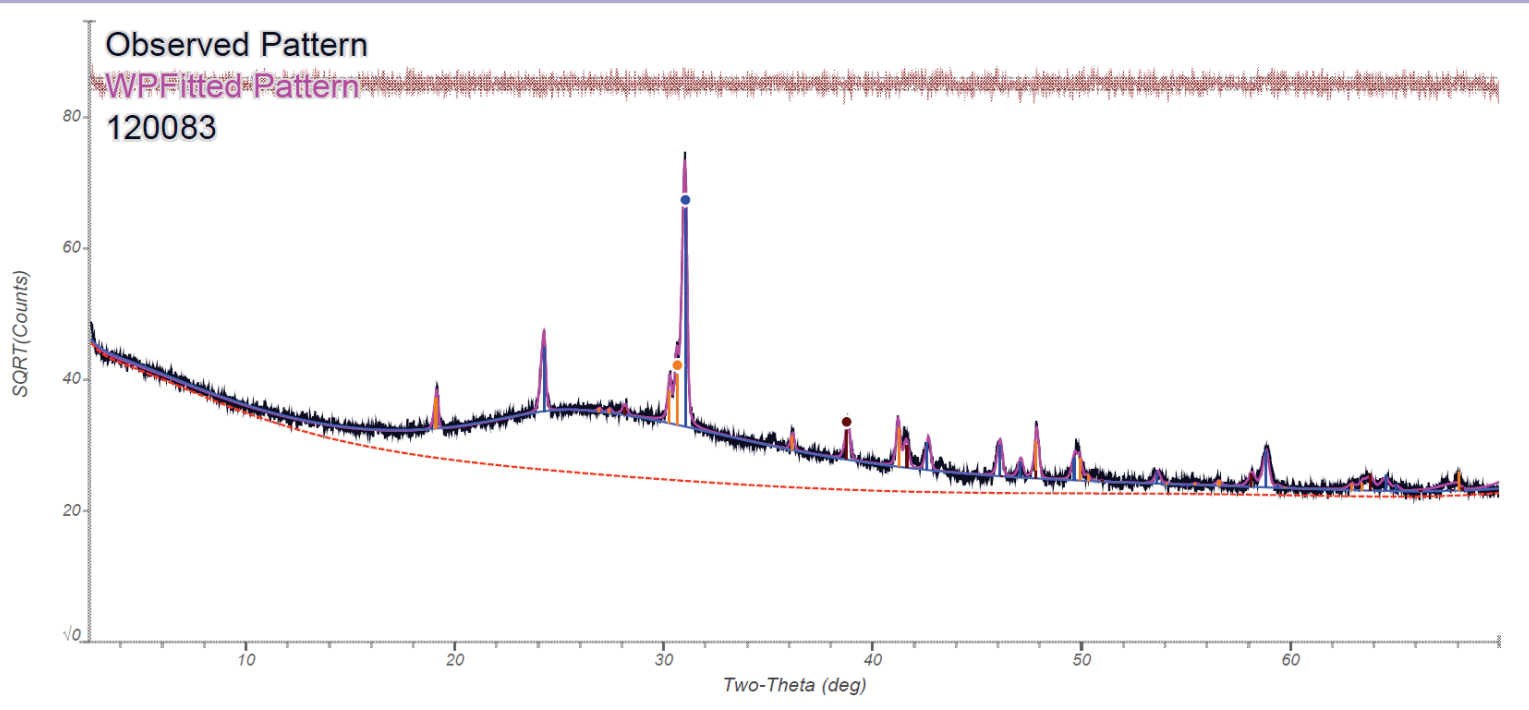


Figure C6. XRD Results of Fly Ash (120104).

\begin{tabular}{l|l|r|r|r|r|r|}
\hline Phase ID (3) & Chemical Formula & NA & NR & NP & Wt\% (esd) & RIR \\
\hline Quartz low & $\mathrm{SiO}_{2}$ & -- & 12 & 9 & $22.1(2.6)$ & 3.02 \\
Hematite & $\mathrm{Fe}_{2} \mathrm{O}_{3}$ & 2 & 11 & 7 & $1.0(0.2)$ & 3.16 \\
Mullite & $\mathrm{Al}_{\left(\mathrm{Al}_{1.272} \mathrm{Si}_{0.728} \mathrm{O}_{4.864}\right)}$ & -- & 30 & 10 & $8.9(1.3)$ & 0.85 \\
Amorphous + Others & $\mathrm{SiO}_{2}$ & & & & $67.9(13.3)$ & 2.50 \\
\hline
\end{tabular}

XRF(Wt\%): $\mathrm{Fe} 2 \mathrm{O} 3=1.0 \%, \mathrm{SiO} 2=92.5 \%, \mathrm{Al} 2 \mathrm{O} 3=6.5 \%$

Refinement Converged ( $R / E=1.17)$, Round $=3$, Iter=3, $P=34, R=3.97 \%(E=3.38 \%, E P S=0.5)$
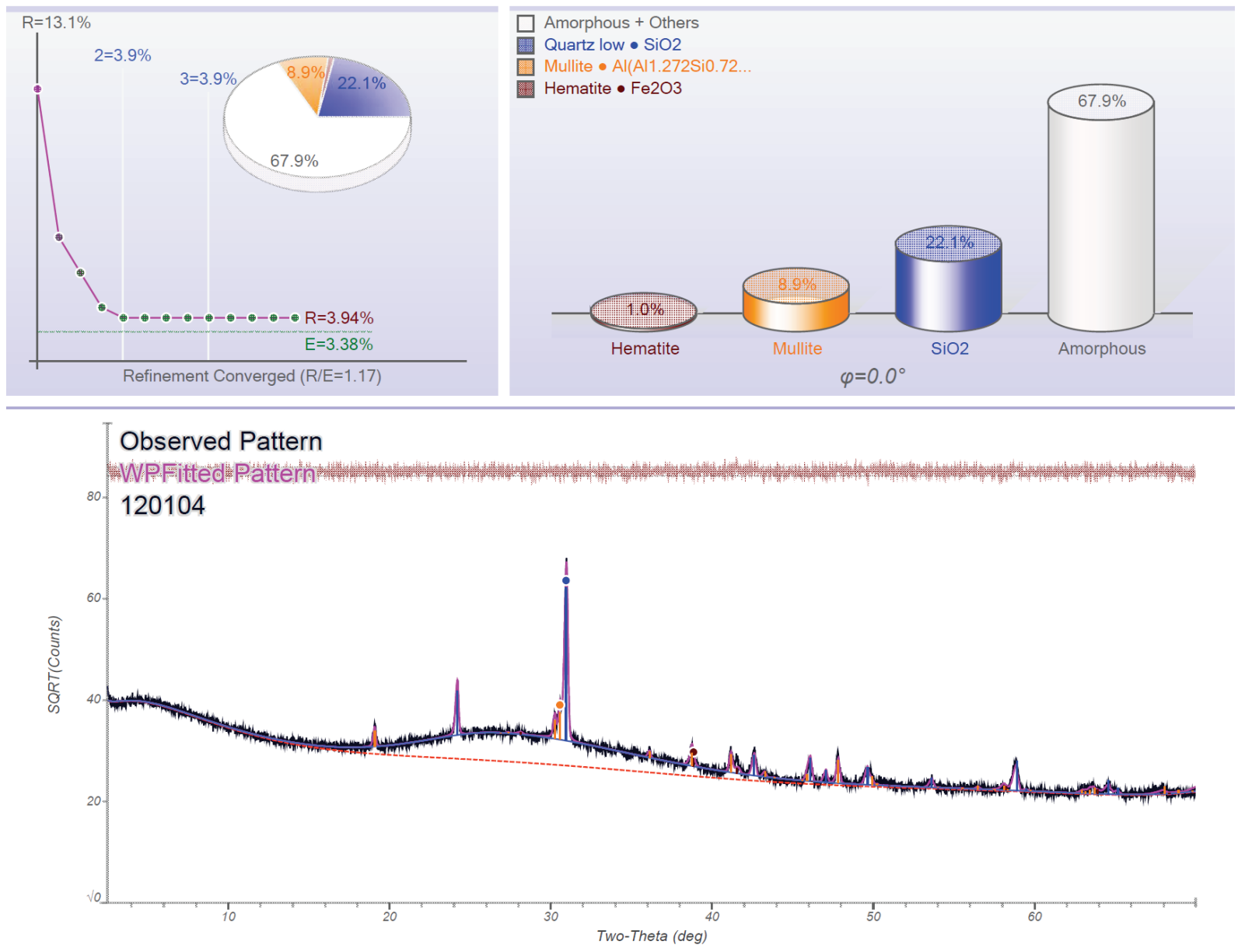
Figure C7. XRD Results of Fly Ash (120222).

\begin{tabular}{|c|c|c|c|c|c|c|}
\hline Phase ID (3) & Chemical Formula & NA & NR & NP & $\mathrm{Wt} \%$ (esd) & RIR \\
\hline Quartz low & $\mathrm{SiO}_{2}$ & --- & 12 & 9 & $13.4(2.6)$ & 3.02 \\
\hline Mullite & $\operatorname{Al}\left(\mathrm{Al}_{1.272} \mathrm{Si}_{0.728} \mathrm{O}_{4.864}\right)$ & --- & 30 & 10 & $11.2(3.5)$ & 0.85 \\
\hline Hematite & $\mathrm{Fe}_{2} \mathrm{O}_{3}$ & 2 & 11 & 9 & $3.6(0.8)$ & 3.16 \\
\hline Amorphous + Others & $\mathrm{SiO}_{2}$ & & & & $71.8(17.3)$ & 2.50 \\
\hline
\end{tabular}

XRF(Wt $\%):$ Fe2O3=3.6\%, SiO2=88.3\%, Al2O3=8.1\%

Refinement Converged (R/E=1.27), Round=3, Iter=4, $P=34, R=4.31 \%(E=3.39 \%$, EPS=0.5)
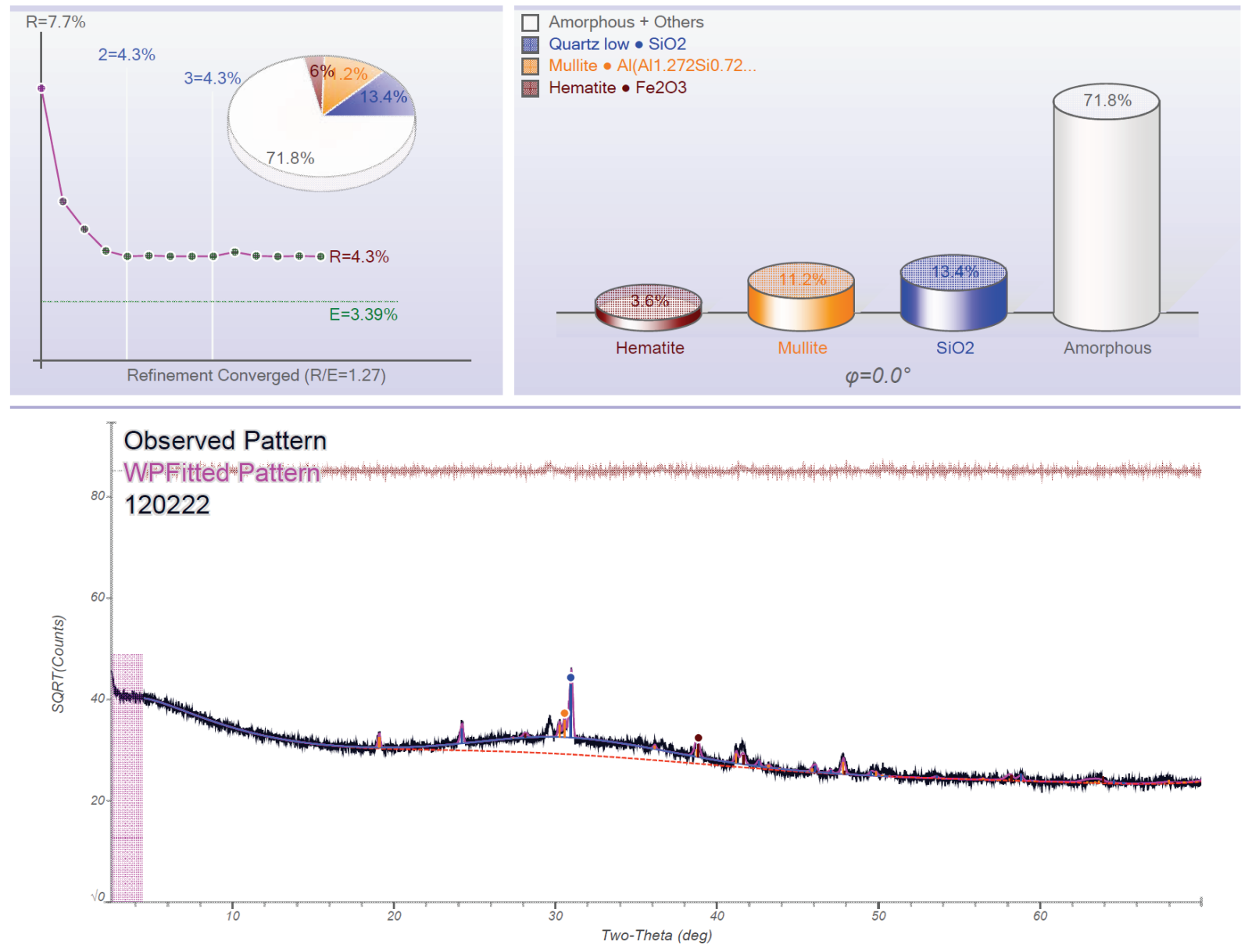
Figure C8. XRD Results of Fly Ash (130032).

\begin{tabular}{|c|c|c|c|c|c|c|}
\hline Phase ID (3) & Chemical Formula & NA & NR & $\mathrm{NP}$ & $\mathrm{Wt} \%$ (esd) & RIR \\
\hline Quartz low & $\mathrm{SiO}_{2}$ & --- & 12 & 9 & $7.9(5.6)$ & 3.02 \\
\hline Hematite & $\mathrm{Fe}_{2} \mathrm{O}_{3}$ & 2 & 11 & 9 & $3.6(2.5)$ & 3.16 \\
\hline Mullite & $\mathrm{Al}\left(\mathrm{Al}_{1.272} \mathrm{Si}_{0.728} \mathrm{O}_{4.864}\right)$ & --- & 30 & 10 & $11.7(8.2)$ & 0.85 \\
\hline Amorphous + Others & $\mathrm{SiO}_{2}$ & & & & $76.8(88.6)$ & 2.50 \\
\hline
\end{tabular}

Refinement Converged (R/E=1.53), Round=3, Iter=6, $P=34, R=4.39 \%(E=2.87 \%, E P S=0.5)$
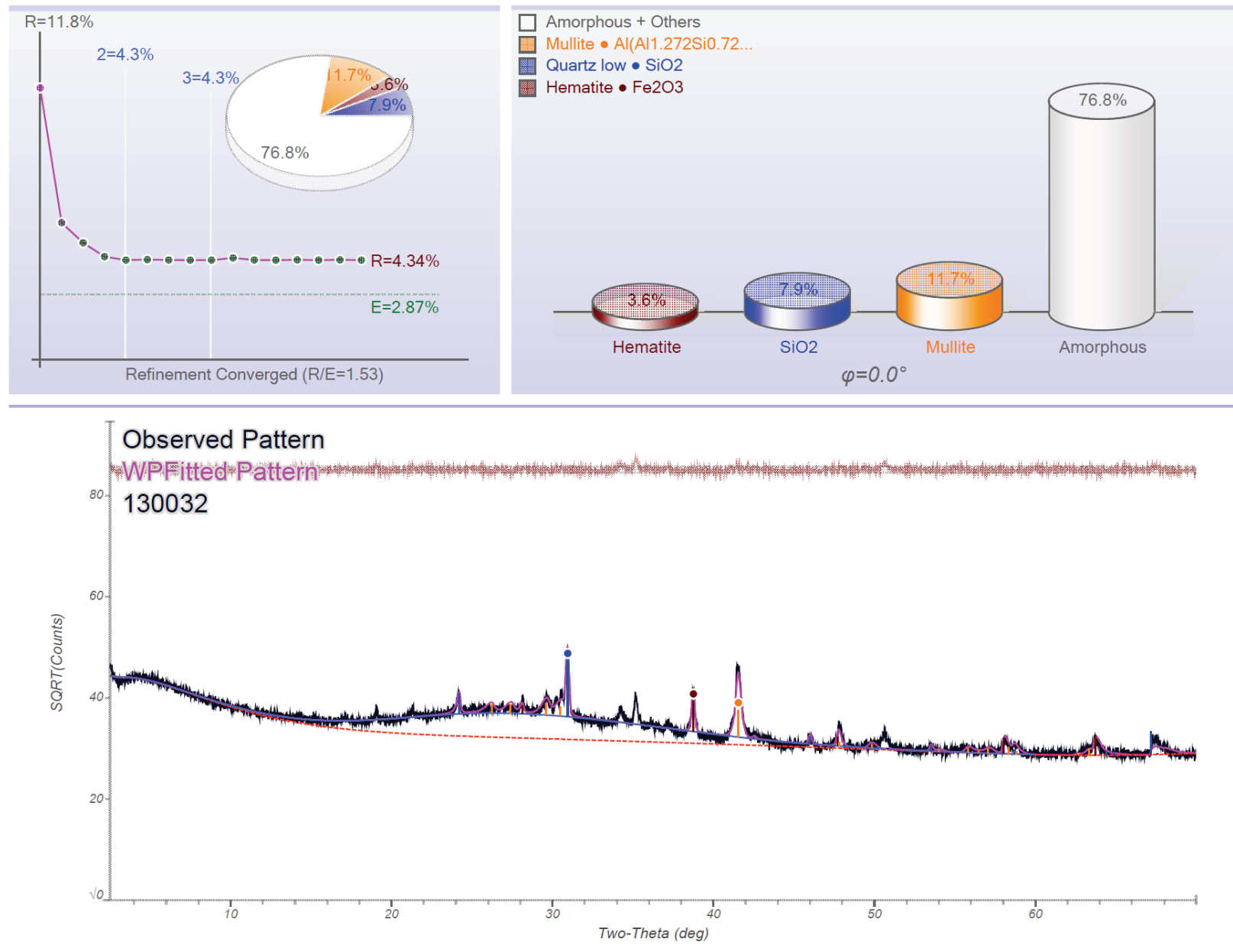
Figure C9. XRD Results of Fly Ash (140022).

\begin{tabular}{|c|c|c|c|c|c|c|}
\hline Phase ID (4) & Chemical Formula & NA & NR & $\mathrm{NP}$ & $\mathrm{Wt} \%$ (esd) & RIR \\
\hline Mullite, syn & $\mathrm{Al}_{4.59} \mathrm{Si}_{1.41} \mathrm{O}_{9.7}$ & --- & 29 & 10 & $20.9(2.2)$ & 0.83 \\
\hline Hematite & $\mathrm{Fe}_{2} \mathrm{O}_{3}$ & 2 & 11 & 9 & $2.0(0.3)$ & 3.16 \\
\hline Quartz & $\mathrm{SiO}_{2}$ & -- & 12 & 9 & $17.0(1.6)$ & 3.07 \\
\hline Maghemite & $\mathrm{Fe}_{1.966} \mathrm{O}_{2.963}$ & --- & 80 & 9 & $2.7(0.4)$ & 2.79 \\
\hline Amorphous + Others & $\mathrm{SiO}_{2}$ & & & & $57.5(10.6)$ & 2.50 \\
\hline
\end{tabular}

$\mathrm{XRF}(\mathrm{W}+\%): \mathrm{Fe} 2 \mathrm{O} 3=4.6 \%, \mathrm{SiO} 2=80.1 \%, \mathrm{Al} 2 \mathrm{O} 3=15.3 \%$

Refinement Converged (R/E=1.29), Round=3, Iter=3, $P=36, R=4.31 \%(E=3.35 \%$, EPS $=0.5)$
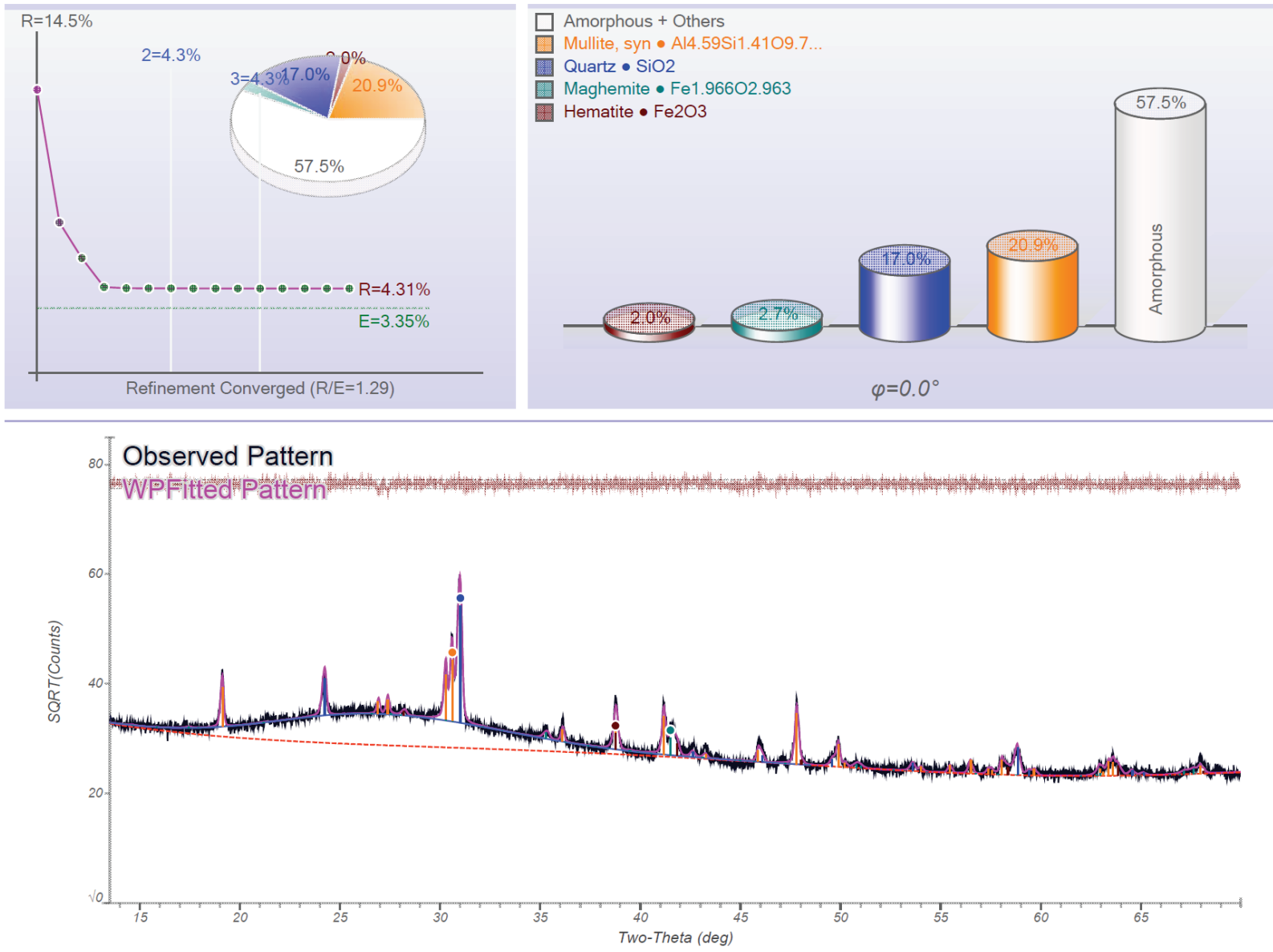
Figure C10. XRD Results of Fly Ash (140054).

\begin{tabular}{l|l|r|r|r|r|r|}
\hline Phase ID (4) & Chemical Formula & NA & NR & NP & Wt\% (esd) & RIR \\
\hline Magnetite & $\mathrm{Fe}_{3} \mathrm{O}_{4}$ & -- & 8 & 5 & $0.0(0.0)$ & 5.13 \\
Quartz low & $\mathrm{SiO}_{2}$ & -- & 12 & 9 & $26.4(4.5)$ & 3.02 \\
Mullite, syn & $\mathrm{Al}_{4.59} \mathrm{Si}_{1.41} \mathrm{O}_{9.7}$ & -- & 29 & 10 & $6.3(1.2)$ & 0.83 \\
Hematite & $\mathrm{Fe}_{2} \mathrm{O}_{3}$ & 2 & 11 & 7 & $1.4(0.3)$ & 3.16 \\
Amorphous + Others & $\mathrm{SiO}_{2}$ & & & & $65.9(20.4)$ & 2.50
\end{tabular}

$\mathrm{XRF}(\mathrm{Wt} \%): \mathrm{Fe} 2 \mathrm{O} 3=1.4 \%, \mathrm{SiO} 2=93.9 \%, \mathrm{Al} 2 \mathrm{O} 3=4.6 \%$

Refinement Converged (R/E=1.38), Round=3, Iter=6, $P=34, R=4.68 \%(E=3.40 \%$, EPS $=0.5)$
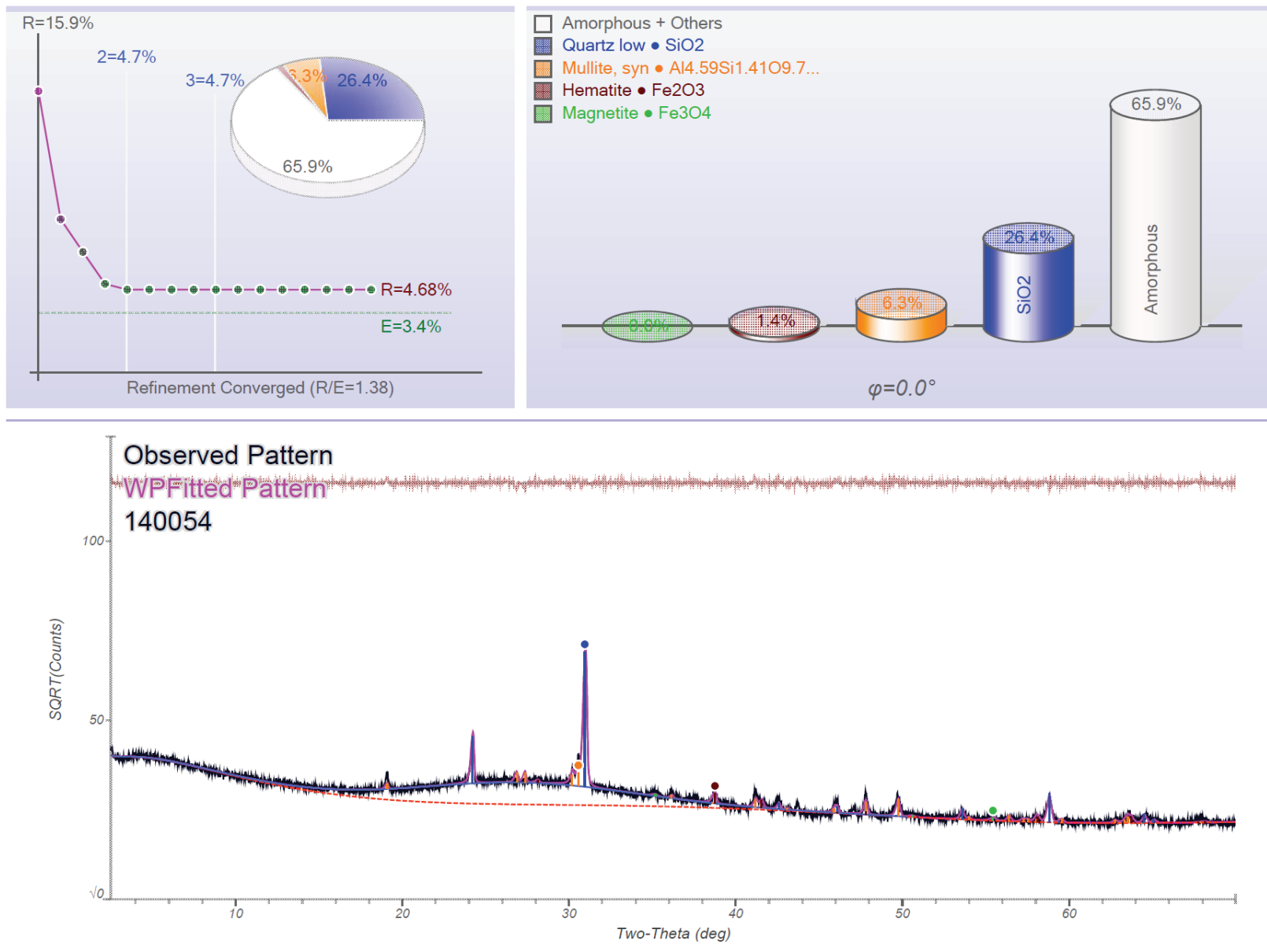
Figure C11. XRD Results of Fly Ash (150108).

\begin{tabular}{|c|c|c|c|c|c|c|}
\hline Phase ID (4) & Chemical Formula & NA & NR & NP & $W t \%$ (esd) & RIR \\
\hline Quartz & $\mathrm{SiO}_{2}$ & 2 & 34 & 9 & $5.9(1.0)$ & 4.04 \\
\hline Magnetite, syn & $\mathrm{Fe}^{+2} \mathrm{Fe}_{2}+3 \mathrm{O}_{4}$ & -- & 7 & 8 & $3.1(0.5)$ & 4.90 \\
\hline Mullite & $A I_{2.28} \mathrm{Si}_{.72} \mathrm{O}_{4.86}$ & 8 & 31 & 10 & $10.0(1.7)$ & 0.85 \\
\hline Hematite & $\mathrm{Fe}_{2} \mathrm{O}_{3}$ & 2 & 11 & 9 & $1.0(0.2)$ & 3.15 \\
\hline \multirow[t]{2}{*}{ Amorphous + Others } & $\mathrm{SiO}_{2}$ & & & & $80.0(21.4)$ & 2.50 \\
\hline & & \multicolumn{5}{|c|}{$X \mathrm{XF}(\mathrm{W} t \%): \mathrm{Fe} 2 \mathrm{O} 3=4.2 \%, \mathrm{SiO} 2=88.6 \%, \mathrm{Al} 2 \mathrm{O} 3=7.3 \%$} \\
\hline
\end{tabular}

Refinement Halted $(R / E=1.2), \quad$ Round $=3$, Iter=6, $P=37, R=4.23 \%(E=3.54 \%, E P S=0.5)$
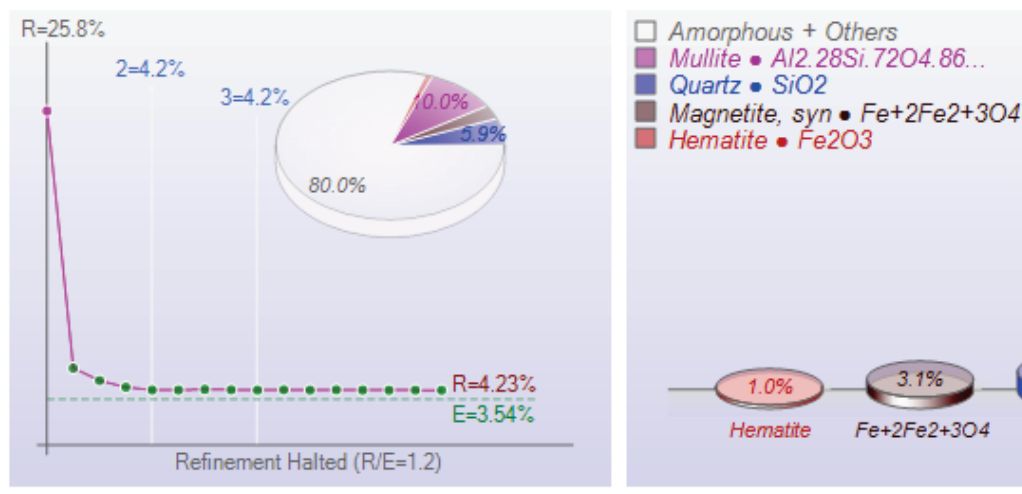

Magnetite, syn • $\mathrm{Fe}+2 \mathrm{Fe} 2+3 \mathrm{O} 4$

Hematite - $\mathrm{Fe} 2 \mathrm{O} 3$
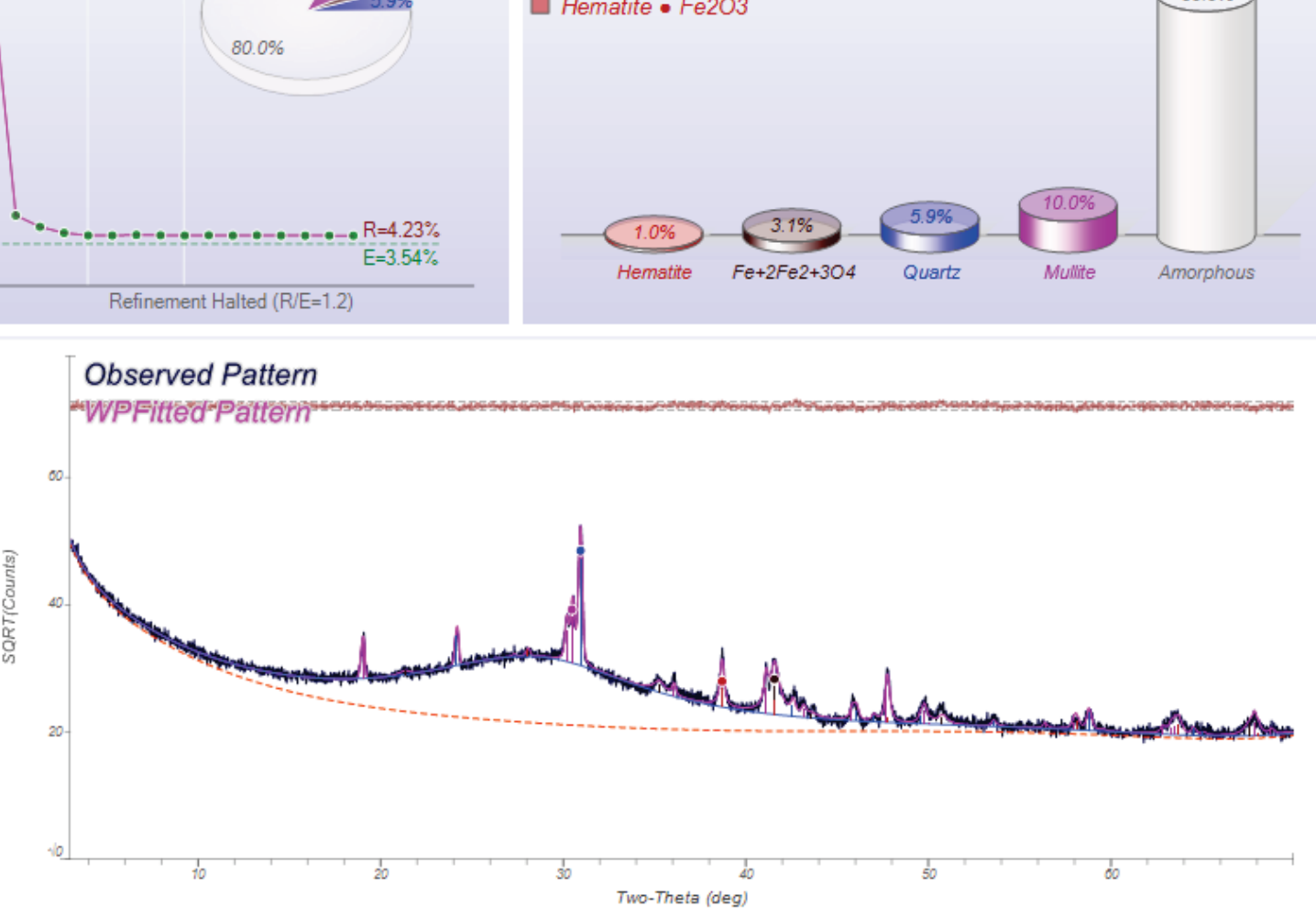
Figure C12. XRD Results of Fly Ash (150109).

\begin{tabular}{l|l|r|r|r|r|r}
\hline Phase ID (3) & Chemical Formula & NA & NR & NP & Wt\% (esd) & RIR \\
\hline Mullite & $\mathrm{Al}_{2.28} \mathrm{Si}_{.72} \mathrm{O}_{4.86}$ & 8 & 31 & 10 & $10.8(2.9)$ & 0.86 \\
Quartz & $\mathrm{SiO}_{2}$ & 2 & 34 & 9 & $12.1(3.2)$ & 4.04 \\
Hematite & $\mathrm{Fe}_{2} \mathrm{O}_{3}$ & 2 & 11 & 9 & $1.3(0.4)$ & 3.18 \\
Amorphous + Others & $\mathrm{SiO}_{2}$ & & & & $75.8(32.8)$ & 2.50
\end{tabular}

XRF(Wt $\%): F e 2 O 3=1.3 \%, \mathrm{SiO} 2=90.8 \%, \mathrm{Al} 2 \mathrm{O} 3=7.9 \%$

Refinement Converged ( $R / E=1.26)$, Round $=3$, Iter $=3, P=34, R=4.74 \%(E=3.77 \%, E P S=0.5)$
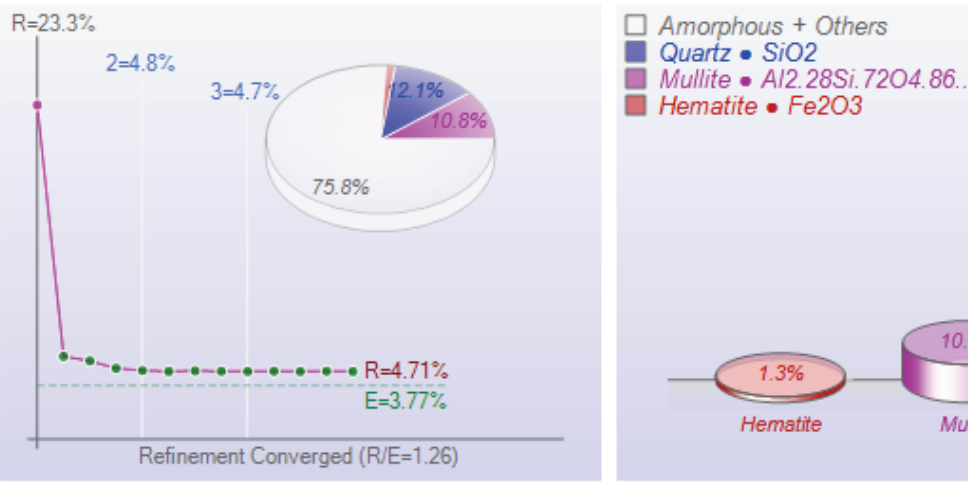

Quartz • SiO2

matite - Fe2O3
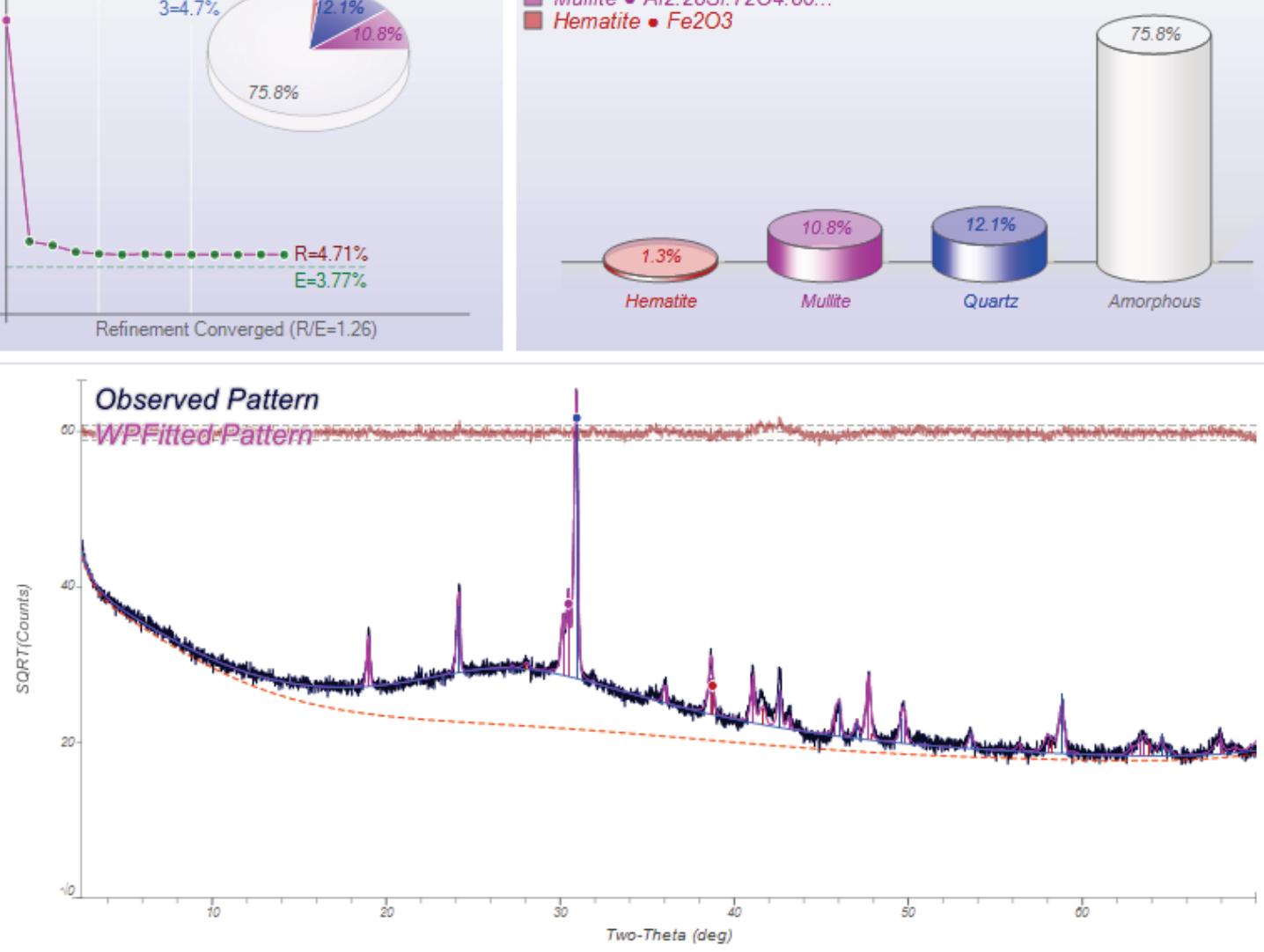
Figure C13. XRD Results of Fly Ash (150110).

\begin{tabular}{|c|c|c|c|c|c|c|}
\hline Phase ID (7) & Chemical Formula & NA & NR & NP & Wt\% (esd) & RIR \\
\hline Quartz & $\mathrm{SiO}_{2}$ & 2 & 34 & 9 & $18.8(2.4)$ & 4.04 \\
\hline Mullite & $\mathrm{Al}_{2.28} \mathrm{Si}_{.72} \mathrm{O}_{4.86}$ & 8 & 31 & 10 & $4.5(0.7)$ & 0.86 \\
\hline Hematite & $\mathrm{Fe}_{2} \mathrm{O}_{3}$ & 2 & 11 & 9 & $1.2(0.3)$ & 3.18 \\
\hline Magnetite, syn & $\mathrm{Fe}^{+2} \mathrm{Fe}_{2}+3 \mathrm{O}_{4}$ & -- & 7 & 4 & $0.0(0.0)$ & 4.90 \\
\hline Anatase & $\mathrm{TiO}_{2}$ & 2 & 14 & 7 & $0.3(0.2)$ & 4.74 \\
\hline Albite (heat-treated) & 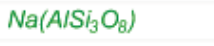 & -- & 114 & 11 & $0.1(0.0)$ & 0.64 \\
\hline Iron & $\mathrm{Fe}$ & 1 & 2 & 5 & $0.4(0.1)$ & 8.16 \\
\hline Amorphous + Others & $\mathrm{SiO}_{2}$ & & & & $74.7(15.7)$ & 2.50 \\
\hline
\end{tabular}

Refinement Halted $(R / E=1.21)$, Round $=3$, Iter=6, $P=51, R=5.11 \%(E=4.23 \%$. $E P S=0.5)$
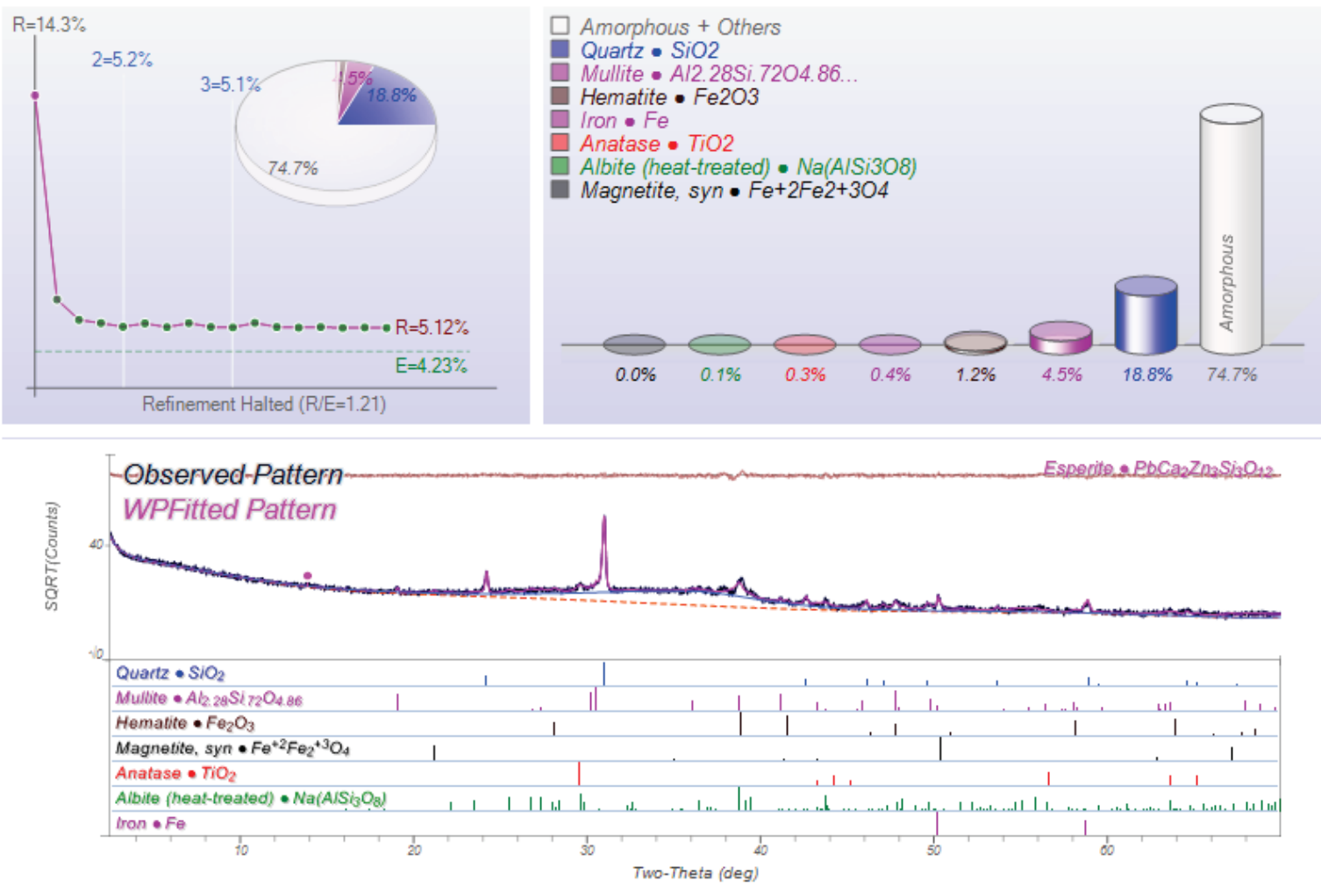
Figure C14. XRD Results of Fly Ash (150111).

\begin{tabular}{|c|c|c|c|c|c|c|}
\hline Phase ID (10) & Chemical Formula & NA & NR & NP & $\mathrm{Wt} \%$ (esd) & RIR \\
\hline Iron & $\mathrm{Fe}$ & 1 & 2 & 5 & $0.1(0.1)$ & 8.16 \\
\hline Quartz & $\mathrm{SiO}_{2}$ & 2 & 34 & 9 & $18.5(2.8)$ & 4.04 \\
\hline Mullite & $\mathrm{Al}_{2.28} \mathrm{Si}_{72} \mathrm{O}_{4.86}$ & 8 & 31 & 10 & $3.6(0.9)$ & 0.86 \\
\hline Anatase & $\mathrm{TiO}_{2}$ & 2 & 14 & 7 & $0.6(0.2)$ & 4.80 \\
\hline Perovskite & $\mathrm{CaTiO}_{3}$ & 4 & 31 & 10 & $9.4(1.4)$ & 2.68 \\
\hline Periclase & $\mathrm{MgO}$ & --- & 2 & 5 & $3.0(0.8)$ & 3.04 \\
\hline IImenite & $\mathrm{FeTiO}_{3}$ & --- & 16 & *24 & $4.8(0.9)$ & 3.01 \\
\hline Hematite & $\mathrm{Fe}_{2} \mathrm{O}_{3}$ & --- & 11 & 9 & $0.8(0.2)$ & 3.04 \\
\hline Marcasite & $\mathrm{FeS}_{2}$ &.-- & 14 & 10 & $1.3(0.3)$ & 2.50 \\
\hline Lime & $\mathrm{CaO}$ & 2 & 3 & 6 & $1.1(0.2)$ & 5.33 \\
\hline Amorphous + Others & $\mathrm{SiO}_{2}$ & & & & $56.9(16.9)$ & 2.50 \\
\hline
\end{tabular}

XRF(Wt $\%): \mathrm{Fe} 2 \mathrm{O} 3=4.2 \%, \mathrm{TiO} 2=8.6 \%, \mathrm{CaO}=5.0 \%, \mathrm{SO}=1.7 \%, \mathrm{SiO} 2=76.4 \%, \mathrm{Al} 2 \mathrm{O}=2.6 \%, \mathrm{MgO}=3.0 \%$

Refinement Halted $(R / E=1.26)$, Round $=3$, Iter $=6, P=64, R=5.43 \%(E=4.31 \%$, $E P S=0.5)$
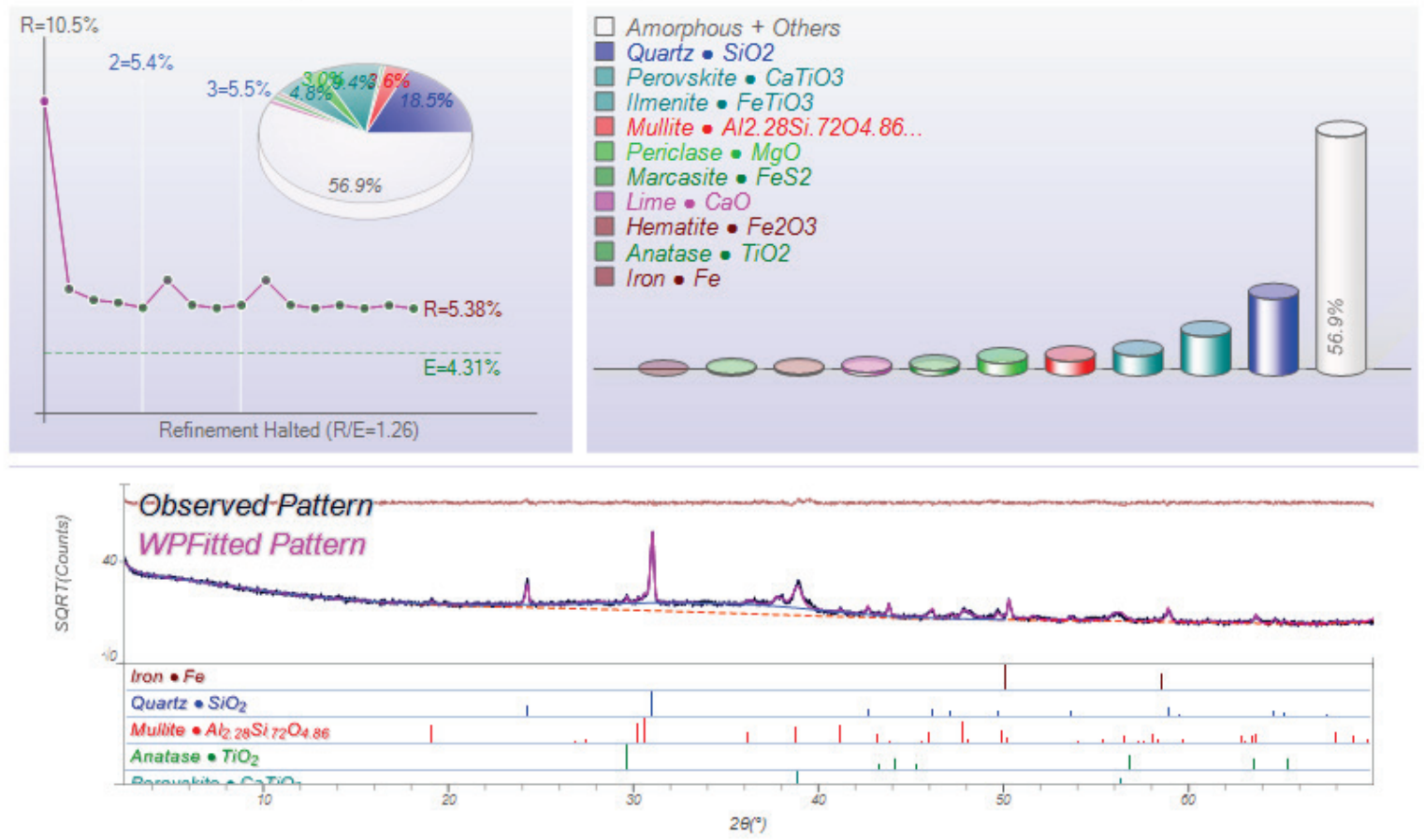
Figure C15. XRD Results of Fly Ash (150112).

\begin{tabular}{|c|c|c|c|c|c|c|}
\hline Phase ID (8) & Chemical Formula & NA & NR & NP & Wt\% (esd) & RIR \\
\hline Portlandite, syn & $\mathrm{Ca}(\mathrm{OH})_{2}$ & -- & 8 & 9 & $17.7(2.0)$ & 2.90 \\
\hline Brucite & $\mathrm{Mg}(\mathrm{OH})_{2}$ & -- & 6 & 9 & $13.8(1.6)$ & 2.12 \\
\hline Anatase, syn & $\mathrm{TiO}_{2}$ & -- & 8 & 9 & $1.3(0.2)$ & 4.96 \\
\hline Hematite & $\mathrm{Fe}_{2} \mathrm{O}_{3}$ & 2 & 11 & 9 & $1.1(0.2)$ & 3.16 \\
\hline Quartz & $\mathrm{SiO}_{2}$ & --- & 12 & 9 & $15.2(1.7)$ & 3.07 \\
\hline Periclase, syn & $\mathrm{MgO}$ & --- & 2 & 5 & $8.5(1.0)$ & 1.00 \\
\hline Hatrurite, syn & $\mathrm{Ca}_{3} \mathrm{SiO}_{5}$ & $--\cdot$ & 72 & 11 & $4.4(0.5)$ & 0.93 \\
\hline Zincite & $\mathrm{ZnO}$ & 2 & 10 & 9 & $0.0(0.0)$ & 6.00 \\
\hline Amorphous + Others & $\mathrm{SiO}_{2}$ & & & & $38.0(12.1)$ & 2.50 \\
\hline
\end{tabular}

Refinement Halted $(R / E=1.21)$ \& Round $=3$, Iter $=6, P=54, R=5.26 \%(E=4.34 \%, E P S=0.5)$
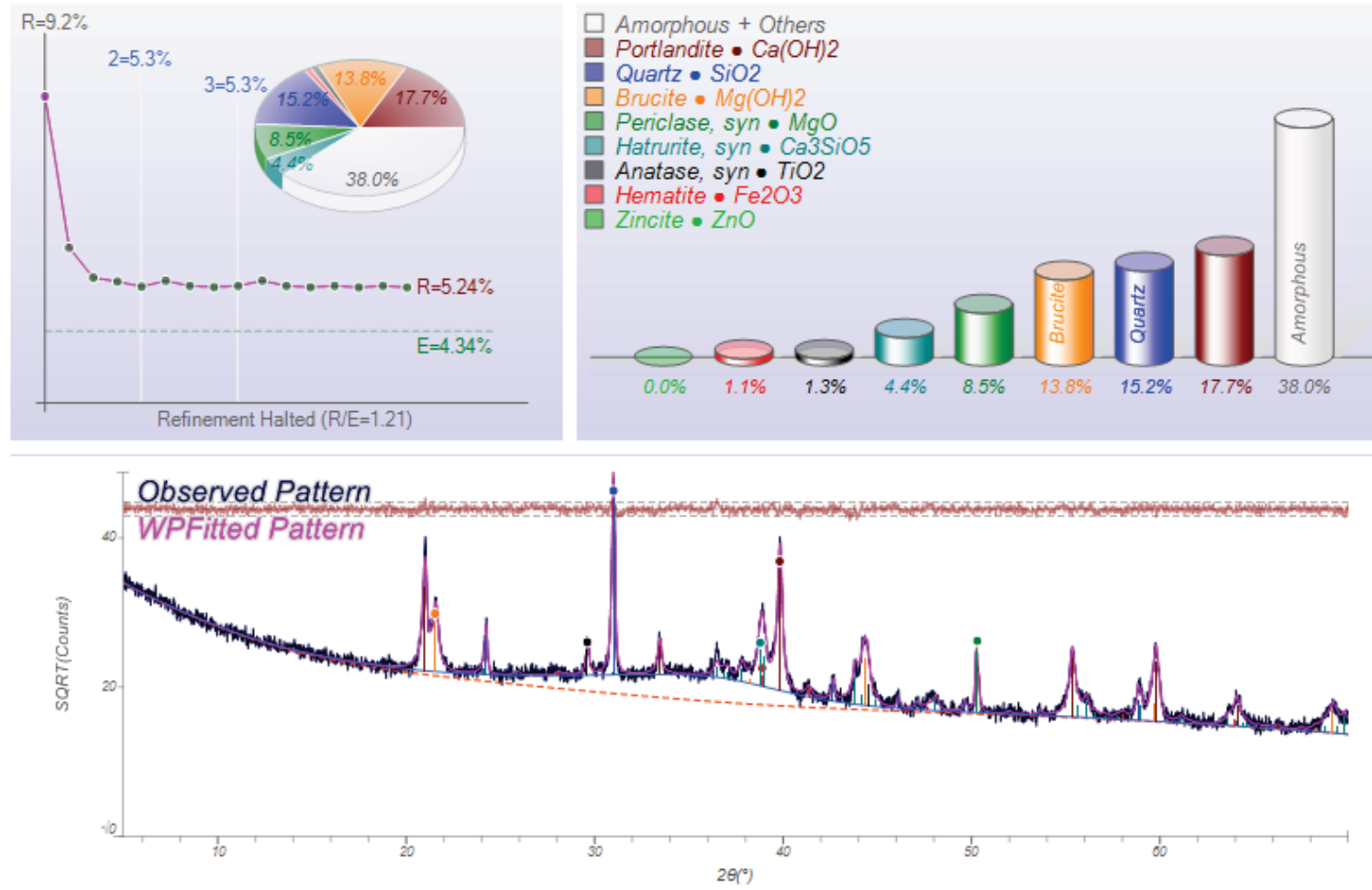
Figure C16. XRD Results of Fly Ash (150113).

\begin{tabular}{|c|c|c|c|c|c|c|}
\hline Phase ID (10) & Chemical Formula & NA & NR & NP & $W t \%$ (esd) & RIR \\
\hline Quartz & $\mathrm{SiO}_{2}$ & - & 12 & 9 & $8.3(0.8)$ & 3.0 \\
\hline Periclase & $\mathrm{MgO}$ & - & 2 & 5 & $2.7(0.3)$ & 3 \\
\hline Lime & $\mathrm{CaO}$ & - & 3 & 6 & $1.1(0.1)$ & 4. \\
\hline Anhydrite & $\mathrm{Ca}\left(\mathrm{SO}_{4}\right)$ & - & 24 & 10 & $15.2(1.5)$ & \\
\hline C3A - orthorhombic & $\mathrm{Ca}_{8.5} \mathrm{NaAl}_{6} \mathrm{O}_{18}$ & 18 & 208 & 10 & $14.1(1.4)$ & \\
\hline CA - CaAl2O4 & $\mathrm{CaAl}_{2} \mathrm{O}_{4}$ & 21 & 240 & 9 & $0.7(0.3)$ & \\
\hline Hatrurite & $\mathrm{Ca}_{27} \mathrm{Si}_{9} \mathrm{O}_{45}$ & 226 & 574 & 11 & $9.7(1.0)$ & \\
\hline Petalite $1 \mathrm{M}$ & $\mathrm{LiAISi}_{4} \mathrm{O}_{10}$ & - & 86 & 11 & $20.2(2.1)$ & \\
\hline Marcasite & $\mathrm{FeS}_{2}$ & - & 15 & 10 & $2.7(0.6)$ & \\
\hline Dolomite & $\mathrm{MgCa}\left(\mathrm{CO}_{3}\right)_{2}$ & 4 & 20 & 7 & $1.8(0.5)$ & \\
\hline Amorphous + Others & $\mathrm{SiO}_{2}$ & & & & $23.5(8.9)$ & \\
\hline
\end{tabular}

XRF(Wt $\%): F e 2 O 3=1.8 \%, \mathrm{CaO}=23.6 \%, \mathrm{SO}=12.5 \%, \mathrm{SiO} 2=50.1 \%, \mathrm{Al} 2 \mathrm{O}=9.1 \%, \mathrm{MgO}=3.1 \%, \mathrm{Na} 2 \mathrm{O}=0.5 \%, \mathrm{CO} 2=0.9 \%, \mathrm{Li} 2 \mathrm{O}=1.0 \%$

Refinement Halted $(R / E=1.32)$, Round $=3$, Iter=6, $P=66, R=5.54 \%(E=4.21 \%, E P S=0.5)$
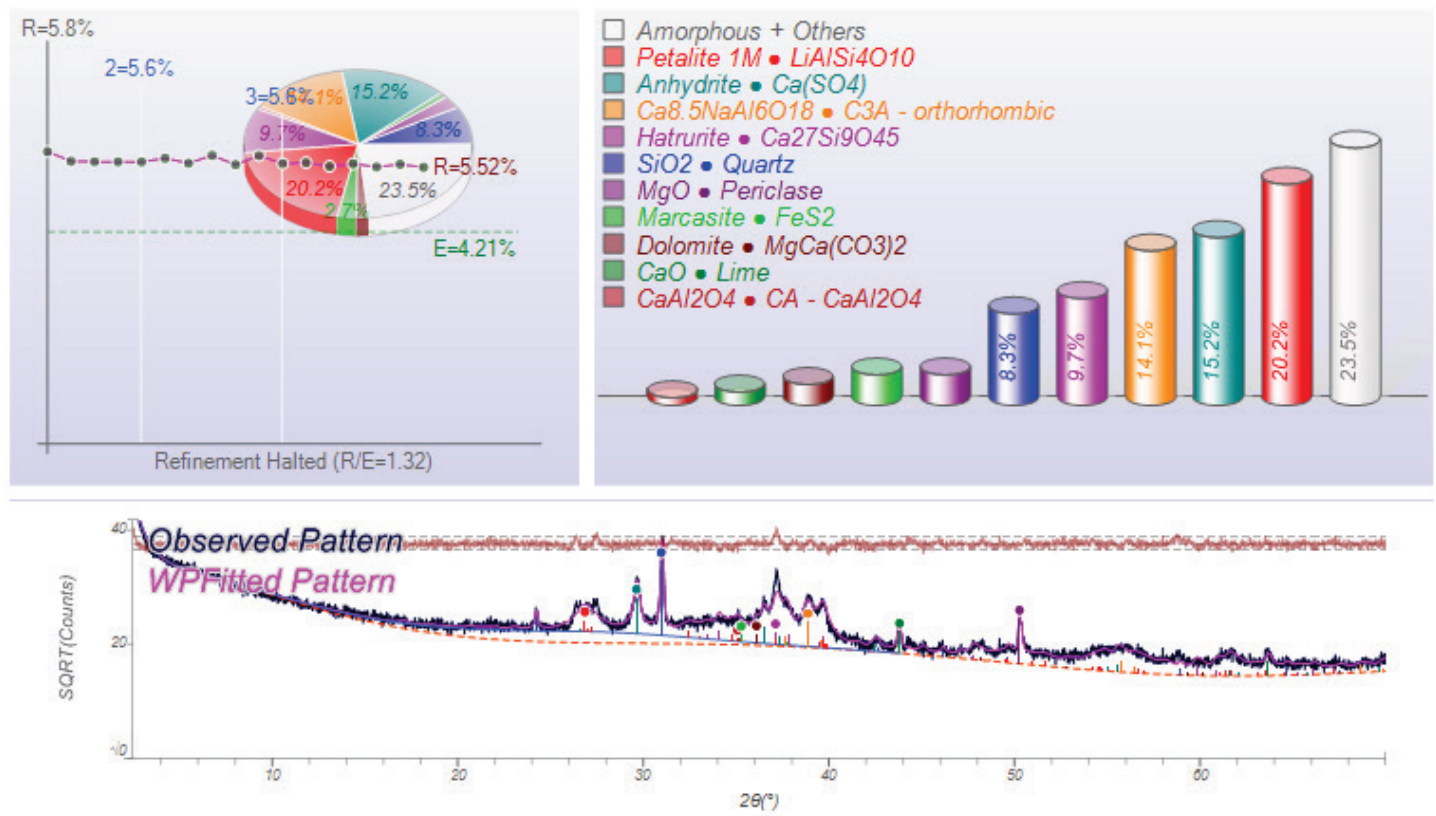


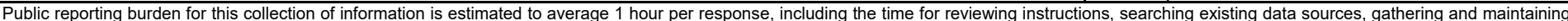

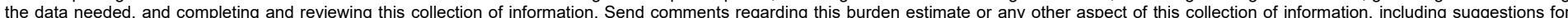

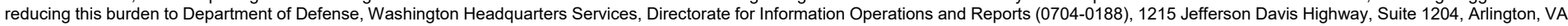

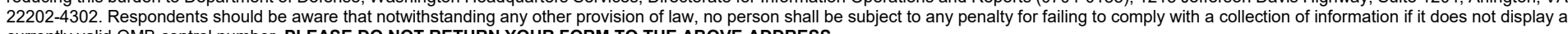
currently valid OMB control number. PLEASE DO NOT RETURN YOUR FORM TO THE ABOVE ADDRESS.

\begin{tabular}{|l|l|l} 
1. REPORT DATE (DD-MM-YYYY) & 2. REPORT TYPE & 3. DATES COVERED (FrOm - To)
\end{tabular} May 2019

\section{TITLE AND SUBTITLE} Final

Constituent Materials Characterization for Virtual Concrete Microstructure Generation

5a. CONTRACT NUMBER

5b. GRANT NUMBER

5c. PROGRAM ELEMENT NUMBER

\section{AUTHOR(S)}

5d. PROJECT NUMBER

Jameson D. Shannon, Cody M. Strack, and Robert D. Moser

5e. TASK NUMBER

5f. WORK UNIT NUMBER

2

\section{PERFORMING ORGANIZATION NAME(S) AND ADDRESS(ES)}

Geotechnical and Structures Laboratory

U.S. Army Engineer Research and Development Center

8. PERFORMING ORGANIZATION REPORT NUMBER

3909 Halls Ferry Road

Vicksburg, MS 39180-6199

\section{SPONSORING / MONITORING AGENCY NAME(S) AND ADDRESS(ES)}

U.S. Army Corps of Engineers

Washington, DC 20314-1000

ERDC/GSL TR-19-24

12. DISTRIBUTION / AVAILABILITY STATEMENT

Approved for public release; distribution is unlimited.

\section{SUPPLEMENTARY NOTES}

\section{ABSTRACT}

This effort was undertaken as a part of the Materials Modeling for Force Protection (MMFP) Military Engineering 6.2 applied research program. One of the main philosophies of MMFP is the creation of a materials-by-design process for predictive properties and material selection capabilities. This report details the capability improvements to facilitate materials-by-design technologies and the collection and characterization of material data to compile and calibrate an integrated materials-by-design model. The Virtual Cement and Concrete Testing Laboratory (VCCTL) was evaluated for suitability in hydration model generation, and various programs were evaluated for initial virtualization of physical elements. To provide model inputs for particle size analysis, X-ray diffraction (XRD), Xray fluorescence (XRF), scanning electron microscopy (SEM), and energy-dispersive spectroscopy (EDS) testing were conducted on a wide variety of constituent materials, and characterization data were processed included herein.

\section{SUBJECT TERMS}

Materials science

Materials - mechanical properties Computer simulation

\section{SECURITY CLASSIFICATION OF:}

\begin{tabular}{|l|l|}
\hline a. REPORT & b. ABSTRACT \\
Unclassified & Unclassified \\
\hline
\end{tabular}

Cement Hydration

Modeling

Virtual Microstructure

Computer programs

10. SPONSOR/MONITOR'S ACRONYM(S)

USACE

11. SPONSOR/MONITOR'S REPORT NUMBER(S) 